DÉCIO TOMASULO DE VICENTE

\title{
APLICAÇÃO DOS PADRÕES DA NORMA IEC 61850 \\ A SUBESTAÇÕES COMPARTILHADAS DE TRANSMISSÃO/DISTRIBUIÇÃO DE ENERGIA ELÉTRICA
}

Dissertação apresentada à Escola Politécnica da Universidade de São Paulo para obtenção do título de Mestre em Engenharia Elétrica 


\title{
DÉCIO TOMASULO DE VICENTE
}

\section{APLICAÇÃO DOS PADRÕES DA NORMA IEC 61850 \\ A SUBESTAÇÕES COMPARTILHADAS DE TRANSMISSÃO/DISTRIBUIÇÃO DE ENERGIA ELÉTRICA}

\author{
Dissertação apresentada à Escola Politécnica \\ da Universidade de São Paulo para obtenção \\ do título de Mestre em Engenharia Elétrica \\ Área de Concentração: Sistemas de Potência \\ Orientador: Prof. Dr. Eduardo César Senger
}

\section{São Paulo}


Este exemplar foi revisado e alterado em relação à versão original, sob responsabilidade única do autor e com a anuência de seu orientador.

São Paulo, 15 de dezembro de 2011.

Assinatura do autor

Assinatura do orientador

FICHA CATALOGRÁFICA

Vicente, Décio Tomasulo de

Aplicação dos padrões da norma IEC 61850 a subestações compartilhadas de transmissão/distribuição de energia elétrica / D.T. de Vicente. -- ed.rev.-- São Paulo, 2011.

p.

Dissertação (Mestrado) - Escola Politécnica da Universidade de São Paulo. Departamento de Engenharia de Energia e Automação Elétricas.

1.Cogeração de energia elétrica 2.Subestações elétricas I.Universidade de São Paulo. Escola Politécnica. Departamento de Engenharia de Energia e Automação Elétricas II.t. 


\section{AGRADECIMENTOS}

Aos meus pais e à minha família pelo apoio.

Ao professor Dr. Eduardo César Senger pela orientação e pelo apoio.

Aos professores Dr. Aderbal de Arruda Penteado Junior e Dr. Mário César Giacco Ramos pelo incentivo na realização do mestrado.

À Companhia de Transmissão de Energia Elétrica Paulista pela oportunidade e disponibilização de tempo e recursos necessários para o desenvolvimento deste trabalho. A todos que trabalham ou trabalharam comigo nesta companhia.

Ao professor Dr. Alberto Bianchi Junior, à pesquisadora do CPqD engenheira M.Sc. Patrícia Lopes Cavalcante e ao engenheiro M.Sc. Mário Roberto Bastos pelo incentivo e apoio na dissertação.

À Schweitzer Engineering Laboratories, à SPIN Engenharia e à ECIL Informática pelo apoio de seus profissionais e pelo fornecimento de recursos para o desenvolvimento prático deste trabalho.

Ao Guilherme Manna César pelas correções no abstract.

E a todos que direta ou indiretamente contribuíram para conclusão deste trabalho. 


\section{RESUMO}

Os objetivos deste trabalho são apresentar e avaliar o projeto de uma subestação focando o compartilhamento da instalação, dos equipamentos e particularmente das informações entre empresas de transmissão e distribuição de energia, o que gera implicações relativas à segurança de acesso aos dados, à segurança na manutenção e operação e à divisão das responsabilidades técnicas. A necessidade desse tipo de projeto vem se tornando frequente no estado de São Paulo à medida que cresce o acesso ao sistema de transmissão pelas usinas térmicas das empresas do setor sucroalcooleiro, em concordância com as resoluções normativas da Agência Nacional de Energia Elétrica.

O trabalho propõe a configuração de funções de supervisão e proteção utilizando a troca de informações entre os agentes através do serviço de mensagens prioritárias previsto na norma IEC 61850, em substituição aos relés auxiliares e ao painel de interface que utiliza cabos de cobre. Tendo a segurança como ponto principal de discussão quando se deseja conectar duas redes de comunicação de empresas diferentes, são avaliadas, através de simulações, as operações das lógicas de proteção, o acesso aos dados, e a troca de informações de supervisão. Algumas tecnologias apresentadas já são amplamente utilizadas na área de Tecnologia da Informação, como os requisitos de segurança digital e que, se utilizados em sistemas baseados na IEC 61850 sem impactar significantemente na performance e nos custos, apresentam enormes vantagens para os sistemas digitalizados das subestações. Por fim, são apresentadas as diferenças e os benefícios de se utilizar os recursos da norma para um projeto tão particular.

Palavras-chave: IEC 61850. Subestações. Cogeração de energia. 


\begin{abstract}
The aims of this study are to present and to evaluate the design of a substation, focusing on the sharing of the installation, equipments, and particularly on the information between transmission and distribution energy companies. This will highlight implications for data access security, along with the security concerning maintenance and operation of a substation and the division of technical responsibilities. The need for this type of project is becoming common in the state of São Paulo as the access to the transmission system by thermal power plants of sugar companies increases, in accordance with the normative resolutions of the Agência Nacional de Energia Elétrica.

The study proposes the configuration of supervision and protection functions using exchange of information between agents via priority messaging service provided by IEC 61850 instead of the auxiliary relays and panel interface that uses copper wires. When connecting two communication networks of different companies while considering safety as the main issue, simulations are conducted to evaluate protection logic operations, data access and supervision data exchange. Certain technologies presented here are already widely used in Information Technology, such as the cyber security requirements. When utilized in IEC 61850 based systems without significantly impacting performance and costs, these cyber security requeriments present great advantages for the substations' digitalized systems. Finally, differences and benefits are considered for the use of the resources of the norm for such a particular project.
\end{abstract}

Keywords: IEC 61850. Substations. Cogeneration 


\section{LISTA DE FIGURAS}

Figura 1 - Relé eletromecânico da General Electric de proteção de sobrecorrente temporizado

e instantâneo

Figura 2 - Relé estático da ASEA de proteção de distância .22

Figura 3 - Relé digital multifunção da Schweitzer Engineering Laboratories .24

Figura 4 - Estrutura de dados definida pela norma.....

Figura 5 - Característica de transmissão das mensagens GOOSE 32

Figura 6 - Mensagem GOOSE publicada em data sets .32

Figura 7 - Arquivos padronizados pela IEC 61850 34

Figura 8 - Diagrama unifilar de uma subestação padrão para seccionamento em $138 \mathrm{kV}$.......43

Figura 9 - Configuração final dos disjuntores na transferência de proteções 52

Figura 10 - Interface física de compartilhamento de informações

Figura 11 - Painel de interface com pontos de proteção, supervisão e circuitos de tensão e corrente

Figura 12 - Quantidade de cabos nas entradas e saídas dos IEDs 56

Figura 13 - Detalhe dos bornes seccionáveis no painel de interface lado da distribuidora .....56

Figura 14 - Detalhe dos bornes seccionáveis no painel de interface lado da transmissora .....57

Figura 15 - Quantidade de cabos no painel de interface para efetuar as interligações 57

Figura 16 - Quantidade de relés auxiliares nos painéis. 58

Figura 17 - Quantidade de relés auxiliares no painel de linha de transmissão 58

Figura 18 - Relés auxiliares no painel da proteção de barras 59

Figura 19 - Princípio da transmissão de luz no interior de uma fibra. 60

Figura 20 - Exemplo de segmentação de uma rede através de VLANs. 63

Figura 21 - Identificação do identificador de VLAN no pacote de dados. 63

Figura 22 - Arquitetura de testes. .66

Figura 23 - Arquitetura de testes montada em laboratório .67

Figura 24 - Portas, IPs e VLANs configuradas para a arquitetura de testes. 69 
Figura 25 - Característica da configuração de VLANs nas portas do switch 72

Figura 26 - Endereços MAC das portas e o envio de GOOSE pela porta 5D 74

Figura 27 - Porta 5C ativa e o envio de GOOSE permanece com o endereço MAC da 5D....75

Figura 28 - Teste de ping com apenas uma porta ativa no IED. .76

Figura 29 - Configuração do filtro por endereço MAC nas portas do switch. 77

Figura 30 - Acesso às propriedades da placa Intel PRO/100. 78

Figura 31 - Configuração da VLAN na placa de rede do computador da transmissora 78

Figura 32 - Teste da proteção de falha de disjuntor... 79

Figura 33 - Configurando o data set com o ponto CCOUT1 simulando o disparo da proteção de falha de disjuntor 80

Figura 34 - Configurações para publicação do GOOSE de falha de disjuntor ..... 80

Figura 35 - Janela de preferências da transmissão do GOOSE 82

Figura 36 - Assinatura do GOOSE pela transmissora com o ponto para disparo da proteção de falha de disjuntor 83

Figura 37 - Pacotes com o GOOSE de falha de disjuntor capturados pelo programa Ethereal

Figura 38 - Teste da transferida do disparo da proteção para o disjuntor paralelo.

Figura 39 - Configurando o data set com o ponto de trip do IED da transmissora. 85

Figura 40 - Configurações para publicação do GOOSE de disparo para a transferência de proteção

Figura 41 - Assinatura do GOOSE pela distribuidora com o ponto de disparo para a transferência de proteção 86

Figura 42 - Pacotes com o GOOSE da transferência de proteção capturados pelo programa

Ethereal

Figura 43 - Associação do Push Button 1 ao trip do IED da transmissora.

Figura 44 - Análise do comportamento do GOOSE com a atuação do trip no IED da transmissora

Figura 45 - Teste de troca de dados da distribuidora para a transmissora

Figura 46 - Canal de entrada de tensão fase A e neutro no IED SEL 451-4

Figura 47 - Configurando a relação de transformação no IED SEL 451-4 da distribuidora ...91 
Figura 48 - Visualizando a tensão em kV no display do IED da distribuidora 92

Figura 49 - Visualizando a tensão VA em kV do IED no programa Acselerator Quickset ....92 Figura 50 - Configurando o data set com o ponto de tensão da fase A do IED da distribuidora

Figura 51 - Configurações para publicação do GOOSE com o data set da tensão da fase A .93 Figura 52 - Assinatura do GOOSE com o data set da medida analógica tensão 94

Figura 53 - Mapeando a medida analógica RA001 no IED da transmissora..... 95

Figura 54 - Botões frontais configurados para mudar o estado dos equipamentos .95

Figura 55 - Visualização dos equipamentos no IED da distribuidora .96

Figura 56 - Configurando o data set com os estados dos equipamentos 97

Figura 57 - Configurações para publicação do GOOSE com o data set dos estados dos equipamentos

Figura 58 - Assinatura do GOOSE pelo IED da transmissora com os estados dos equipamentos

Figura 59 - Pontos auto publicados do IED da transmissora. 99

Figura 60 - Pacotes com o GOOSE da medida analógica capturados pelo programa Ethereal

Figura 61 - Pacotes capturados pelo programa Ethereal contendo o GOOSE dos equipamentos

Figura 62 -Mapeando a medida analógica de tensão

Figura 63 -Mapeando o estado desligado do disjuntor 24-1

Figura 64 -Mapeando o estado fechado do seccionador 28. 102

Figura 65 -Mapeando o estado fechado do seccionador 26

Figura 66 - Utilizando o endereço MAC da transmissora no computador da distribuidora .. 104

Figura 67 - Endereço MAC do computador configurado no switch da distribuidora. 104

Figura 68 - Endereço MAC do computador configurado no switch da transmissora. 105

Figura 69 - Arquitetura em anel com redundância 106 


\section{LISTA DE TABELAS}

Tabela 1 -Endereçamento multicast recomendado pela norma ..............................................33

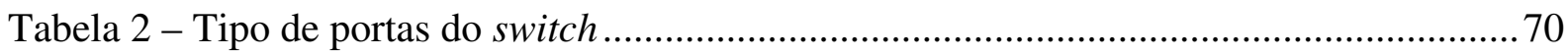

Tabela 3 - Regras de egresso das portas do switch .......................................................... 70

Tabela 4 - Regras de ingresso das portas do switch ........................................................... 71

Tabela 5 - Normas NERC CIP de segurança cibernética .................................................... 73

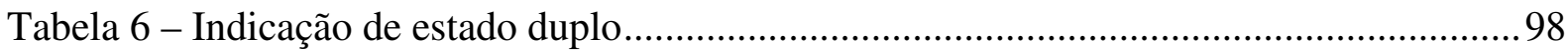




\section{LISTA DE ABREVIATURAS E SIGLAS}
ANEEL Agência Nacional de Energia Elétrica
CCD Contrato de Conexão à Distribuição
CCT Contrato de Conexão à Transmissão
CID Configured IED Description
CIM Common Information Model
CIP Critical Infrastructure Protection
CLP Controlador Lógico Programável
CUSD Contrato de Uso do Sistema de Distribuição
CUST Contrato de Uso do Sistema de Transmissão
DIT Demais Instalações da Transmissão
DNP Distributed Network Protocol

FACTS Flexible AC Transmissions Systems

FTP File Transfer Protocol

GOOSE Generic Oriented Object Substation Event

GPS Global Positioning System

GSSE Generic Substation Status Event

HTTP Hypertext Transfer Protocol

ICCP Inter-control Center Communication Protocol

ICD IED Capability Description

ICMP Internet Control Message Protocol

IEC International Electrotechnical Commission

IED Intelligent Electronic Device

IEEE Institute of Electrical and Electronics Engineers

IRIG Inter Range Instrumentation Group

ISO International Organization for Standardization

$\mathbf{k V} \quad$ quilo Volt

LAN Local Area Network

LED Light-Emmiting Diode

MAC Media Access Control

MMS Manufacturing Message Specification

NERC North American Electric Reliability Corporation 


$\begin{array}{cl}\text { ONS } & \text { Operador Nacional do Sistema Elétrico } \\ \text { OSI } & \text { Open Systems Interconnection } \\ \text { PCH } & \text { Pequenas Centrais Hidrelétricas } \\ \text { PING } & \text { Packet Internet Groper } \\ \text { PMU } & \text { Phasor Measurement Unit }\end{array}$

PROINFA Programa de Incentivos às Fontes Alternativas de Energia Elétrica

QoS Quality of Service

RAP Receita Annual Permitida

REA Resolução Autorizativa

REN Resolução Normativa

RSTP Rapid Spanning Tree Protocol

SAS Substation Automation System

SCADA Supervisory Control and Data Acquisition

SCD Substation Configuration Description

SCSM Specific Communication Service Mapping

SEL Schweitzer Engineering Laboratories

SEP Sistema Elétrico de Potência

SIN Sistema Interligado Nacional

SNMP Simple Network Management Protocol

SNTP Simple Network Time Protocol

SOE Sequence of Events

SOTF Switch Onto Fault

SSC Sistema de Supervisão e Controle

SSD System Specification Description

SSH Secure Shell

SSL Secure Socket Layer

ST $\quad$ Straight Tip

TASE Telecontrol Application Service Element

TC Transformador de Corrente

TI Tecnologia da Informação

TP Transformador de Potencial

UAC Unidade de Aquisição e Controle

UCA Utilities Communication Architecture 
UTE Usina Térmelétrica de Energia

UTP Unshielded Twisted Pair

UTR Unidade Terminal Remota

VID VLAN Identification

VLAN Virtual Local Area Network

WAN Wide Area Network

XML Extensible Mark-up Language 


\section{SUMÁRIO}

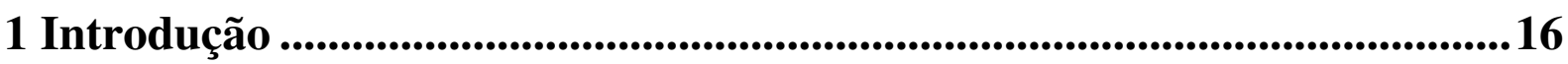

2 A modernização das subestações de energia .................................................18

2.1 Proteção dos sistemas elétricos de potência...........................................................................18

2.2 Sistemas de automação ................................................................................................25

2.3 Sistemas de supervisão e controle..............................................................................26

2.4 Os protocolos de comunicação ....................................................................................27

2.5 O papel da norma IEC 61850 na modernização das subestações..................................28

2.5.1 Requisitos gerais.........................................................................................................................30

2.5.2 A estrutura dos dados .............................................................................................30

2.5.3 Serviços de mensagens da norma IEC 61850 .............................................................31

2.5.4 Configuração da arquitetura de comunicação .........................................................34

3 Subestações compartilhadas .............................................................................35

3.1 O acesso ao SIN ............................................................................................................................35

3.2 Resoluções normativas da ANEEL ......................................................................................36

3.2.1 Resolução normativa $\mathrm{N}^{\circ} 68$ da ANEEL ......................................................................37

3.2.2 Resolução normativa $\mathrm{N}^{\circ} 312$ da ANEEL ................................................................37

3.3 Acesso às DITs..................................................................................................................................37

3.4 Resoluções autorizativas da ANEEL..................................................................................39

3.5 Cogeração ………......................................................................................................................39

3.5.1 Programa de Incentivo às Fontes Alternativas de Energia Elétrica ....................40

3.5.2 Usinas termelétricas de biomassa ...................................................................................41

3.6 Arranjo físico das subestações compartilhadas .............................................................42

3.7 Funções de proteção aplicadas na subestação compartilhada........................................44

3.7.1 Proteção de Distância..............................................................................................................45

3.7.2 Religamento automático das linhas .............................................................................45 
3.7.3 Proteção de sobrecorrente direcional ...............................................................45

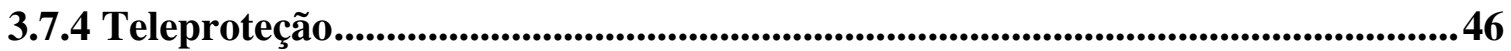

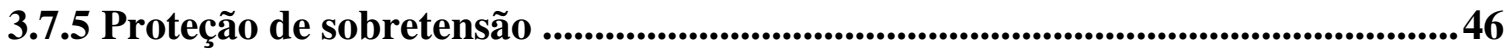

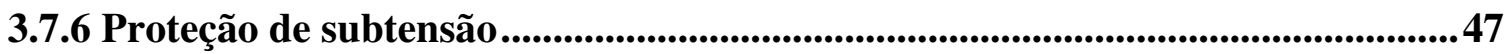

3.7.7 Proteção de fechamento sob falta ..............................................................................4

3.7.8 Proteção de barras ...............................................................................................................................47

3.7.9 Proteção de Falha de Disjuntor...................................................................................48

3.7.10 Proteção do transformador e dos geradores...................................................49

3.80 compartilhamento de informações entre os agentes ...........................................49

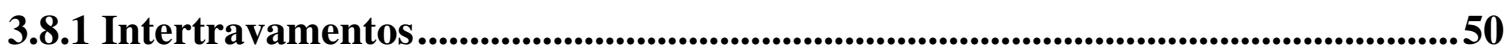

3.8.2 Esquema de falha de disjuntor.........................................................................50

3.8.3 Proteção diferencial de barras ......................................................................51

3.8.4 Transferência de proteção ........................................................................................................51

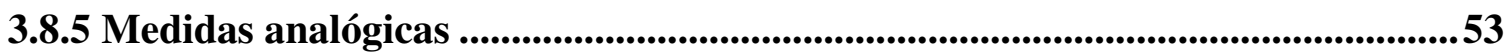

3.8.6 Estados dos disjuntores e seccionadores .....................................................54

3.8.7 A interface física para o compartilhamento de informações..............................54

3.8.8 A interface lógica para o compartilhamento de informações ...............................60

3.8.9 Considerações finais sobre as interfaces de compartilhamento...........................64

4 Avaliação da solução baseada na interface lógica para compartilhamento

de informações entre os agentes .......................................................................66

4.1 Implantação da arquitetura de testes..................................................................................68

4.1.1 Configuração dos switches ..................................................................................................69

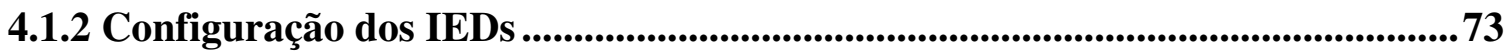

4.1.3 Configuração das interfaces de rede dos computadores ......................................77

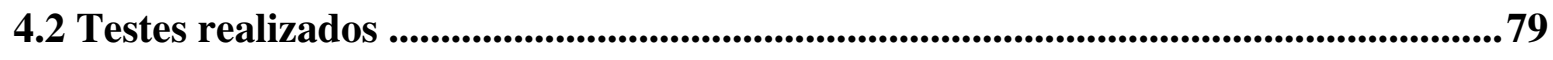

4.2.1 Simulação da proteção de falha de disjuntor ..........................................................79

4.2.2 Simulação da transferência de proteção ...........................................................85 
4.2.3 Simulação das informações para operação em tempo real ................................90

4.2.4 Visualizando os dados compartilhados ..............................................................................99

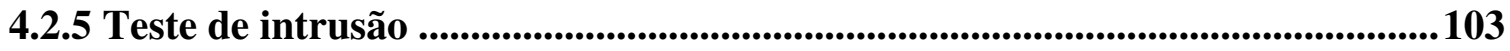

4.3 Recomendações de segurança ....................................................................................................105

4.4 Implementação em arquitetura de redundância...........................................................106

5 Conclusão..................................................................................................107 


\section{Introdução}

Nas últimas décadas, todas as áreas do conhecimento humano têm passado por profundas modificações fruto da evolução da informática, da eletrônica digital e da Tecnologia da Informação (TI). Na engenharia elétrica não foi diferente, e a norma da International Electrotechnical Commission (IEC), 61850 - Communication networks and systems in substations, surgiu para aplicar um novo conceito, mudando a forma como são elaborados os projetos de automação, bem como a operação e a manutenção das subestações de energia.

A implantação desta nova concepção em subestações que serão compartilhadas por empresas de transmissão e distribuição de energia, levanta questões sobre a segurança de acesso aos dados e a segurança na operação destas instalações no Sistema Interligado Nacional (SIN).

Os meios de compartilhamento empregados hoje ainda são conservadores e por isso os atuais pontos de discussão, envolvendo a substituição definitiva dos atuais sistemas utilizando cabos elétricos, por sistemas de redes de dados via fibra óptica são estudados e avaliados.

O trabalho tem, portanto, os objetivos de apresentar e avaliar como estão sendo desenvolvidos os projetos de subestações instaladas em usinas termelétricas de energia, focando principalmente os meios de compartilhamento das informações referentes aos sistemas de proteção, supervisão e controle entre as empresas envolvidas na operação destas instalações.

A alternativa proposta neste trabalho, com a utilização dos conceitos apresentados na IEC 61850 para compartilhamento dessas informações, foi avaliada em laboratório, através de uma plataforma de testes que simula parte dos sistemas de uma subestação. Através dessa simulação avaliou-se a segurança na operação das lógicas de proteção, no acesso aos dados, e na troca de dados de supervisão.

A estrutura deste trabalho é composta por cinco capítulos incluindo este primeiro introdutório.

O segundo capítulo aborda os detalhes da evolução dos sistemas de proteção e automação das subestações ao longo dos anos. Primeiramente, é descrita a evolução dos sistemas que compõem as subestações de energia, nas áreas de proteção, supervisão e operação. Em seguida, são apresentados os conceitos da norma IEC 61850, sendo que os tópicos principais de mudança ficam visíveis e permitem a comparação com os projetos convencionais de subestações. 
No terceiro capítulo, o conceito de subestação compartilhada é apresentado. O intuito é mostrar porque há uma divisão de responsabilidades e como são feitas as separações entre os sistemas de proteção e de supervisão das empresas envolvidas na operação e na manutenção da subestação.

No quarto capítulo é apresentada a proposta para compartilhamento dos dados entre os agentes envolvidos. Apresentam-se também os resultados dos testes de laboratório que visam demonstrar que a norma IEC 61850 permite essa troca de dados entre os sistemas, via rede de comunicação, provendo, desde que bem implementada, a segurança desejada entre as partes.

Por último temos o quinto capítulo no qual, os benefícios e as deficiências, tanto do projeto convencional quanto do projeto baseado na nova tecnologia, são identificados e discutidos. 


\section{A modernização das subestações de energia}

A área específica da engenharia elétrica denominada de Sistemas de Potência tem acompanhado a evolução tecnológica durante as últimas décadas, porém de forma mais lenta e conservadora do que a observada em outras áreas, por exemplo, a de telecomunicações. Entretanto, a experiência mundial está demonstrando que a norma IEC 61850, desde seu advento em 2002, tem revolucionado os projetos e a operação das subestações trazendo, para essa área a aplicação da tecnologia dos sistemas de informação, tais como a utilização das redes de comunicação de dados de alta velocidade e de alta disponibilidade.

Os primeiros sistemas de geração, transmissão e distribuição de energia utilizavam equipamentos baseados em tecnologia eletromecânica para proteger, comandar e operar subestações de todos os portes. Estes sistemas trabalhavam isolados e a subestação não fornecia informações suficientes para uma operação remota, por exemplo. Com o surgimento e a aplicação dos semicondutores nas indústrias e com a evolução dos computadores, uma nova realidade começou a tomar conta das empresas de energia. A convergência de diversos sistemas isolados, mostra a tendência futura de criação de um único sistema de automação, controle e proteção para as subestações, denominado pela norma IEC 61850 de Substation Automation System (SAS).

Os sistemas baseados na IEC 61850 utilizam uma modelagem orientada a objetos, dos diversos dados da subestação, disponibilizando assim uma quantidade de informação superior à encontrada nos sistemas baseados na tecnologia eletromecânica ou eletrônica. Ao mesmo tempo, a disponibilidade desta informação permite às empresas de energia elétrica desenvolverem novas aplicações que aumentam a capacidade de gerenciamento de ativos, tornam mais rápidas a localização de faltas e o restabelecimento dos equipamentos afetados, além de reduzirem as perdas. (1)

Nos itens a seguir é discutida a evolução dos sistemas de proteção e automação das subestações.

\subsection{Proteção dos sistemas elétricos de potência}

Denomina-se Sistemas Elétricos de Potência (SEP), o conjunto de equipamentos constituído por geradores, transformadores, disjuntores, linhas de transmissão, subtransmissão e 
distribuição que tem o objetivo de fornecer a energia elétrica aos consumidores de forma contínua, confiável e econômica com o mínimo de interrupção possível. (2)

O objetivo dos sistemas de proteção de um SEP é isolar o equipamento defeituoso de forma rápida, confiável e interrompendo o menor trecho possível da rede, evitando com isso, grandes perdas de carga. Além de salvaguardar os equipamentos que compõe o sistema, também tem o objetivo de salvaguardar as vidas humanas. Para isto devem atender certos requisitos mínimos: (3)

a) confiabilidade: a proteção deve operar corretamente e somente quando solicitada;

b) sensibilidade: a proteção diferencia a mínima condição anormal da máxima normal;

c) velocidade: a proteção isola rapidamente a área defeituosa;

d) seletividade: a proteção deve atuar de forma a desligar o menor trecho possível de rede, necessário para isolar a falta.

As causas dos defeitos no SEP podem surgir sob a forma de: (2)

a) sobrecarga: é o aumento da corrente solicitada pela carga provocando aumento da temperatura dos componentes da rede acima de um limite especificado;

b) curto circuito: são provocados por descargas atmosféricas, falhas de isolação, objetos estranhos sobre as linhas de transmissão etc.;

c) surtos: são tensões ou correntes elevadas provocadas principalmente por correntes de magnetização de transformadores, partidas de motores, chaveamentos, rejeições bruscas de carga etc.

Estes defeitos se não forem prontamente eliminados poderão causar sérias avarias nos equipamentos e comprometer a segurança das pessoas. Os relés de proteção são os dispositivos responsáveis por detectar e localizar a ocorrência de defeitos na rede. Ao longo das décadas, inicialmente os relés de proteção foram implementados baseados na tecnologia eletromecânica, em seguida na tecnologia de estado sólido e atualmente na tecnologia digital. Os equipamentos baseados em cada uma dessas três tecnologias são brevemente comentados a seguir. 
Os relés eletromecânicos foram os primeiros equipamentos a realizarem funções de proteção nos sistemas elétricos e eram compostos de bobinas elétricas e molas, utilizando os princípios do equilíbrio de conjugados. As técnicas utilizadas seguindo estes princípios eram:

a) atração eletromagnética: comparador de amplitude;

b) indução eletromagnética: comparador de fase.

Esses equipamentos, como o mostrado na figura 1, exigiam cuidados na instalação e no seu ajuste pois pequenas peças mecânicas eram usadas na sua montagem. Além disso, um relé suportava apenas uma ou duas funções de proteção, o que exigia a utilização de outros para funções de retaguarda por exemplo, exigindo mais cabos e mais espaço físico nos painéis.
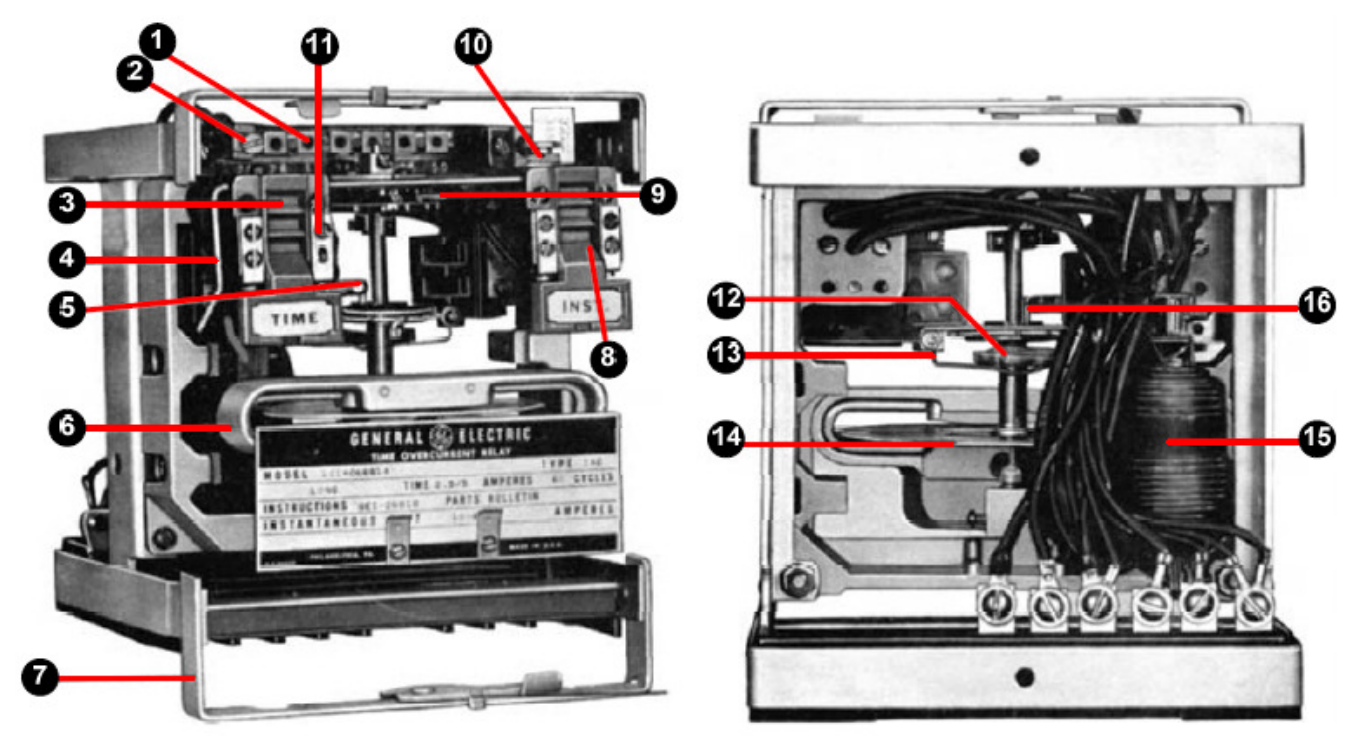

Figura 1 - Relé eletromecânico da General Electric de proteção de sobrecorrente temporizado e instantâneo

Descrição das partes integrantes do relé eletromecânico da figura 1: (4)

1. Conjunto de taps

2. Parafuso de ajuste dos taps

3. Bandeirola de sinalização da unidade temporizada

4. Rearme manual das bandeirolas

5. Contato fixo

6. Freio magnético

7. Moldura 
8. Bandeirola da unidade instantânea

9. Seletor de tempo

10. Parafuso de ajuste para núcleo magnético

11. Ajuste de tap para a bobina da bandeirola

12. Mola espiral

13. Suporte para mola espiral

14. Disco de indução

15. Bobina de corrente montada sobre núcleo magnético em forma de $\mathrm{U}$

16. Contato móvel solidário ao disco de indução

Estes relés ainda são encontrados em uso em diversas empresas tanto no Brasil como em outros países. Porém, a falta de mão de obra especializada e de peças de reposição faz com que aos poucos sejam substituídos por equipamentos mais modernos.

Com o desenvolvimento dos semicondutores, surgiram os primeiros relés eletrônicos, também conhecidos como relés estáticos por não possuírem partes móveis. Estes relés já não utilizavam peças mecânicas em movimento, porém exigiam outros cuidados de instalação, como por exemplo, um melhor controle da temperatura, da umidade e principalmente das interferências eletromagnéticas. Do mesmo modo que ocorre hoje com a IEC 61850, levou-se algum tempo para aceitação desta tecnologia pelas empresas de energia.

Os elementos básicos que constituem um relé eletrônico são: (5)

a) unidade conversora: é a unidade de entrada do relé que permite o condicionamento do sinal de forma a adequar as grandezas aos níveis compatíveis com a eletrônica do relé. Nessa unidade têm-se os transformadores de entrada que possibilitam o isolamento galvânico entre os secundários dos Transformadores de Corrente (TC) ou dos Transformadores de Potencial (TP) e a eletrônica do relé. Os filtros também são instalados nesta unidade;

b) unidade de medição: onde se processa a medição de modo a determinar se há ou não um defeito no equipamento protegido. Nesta unidade é que se implementa a característica do relé;

c) unidade de saída: após a operação da unidade de medição, torna-se necessária a presença de um elemento que permita a realização do disparo no disjuntor. Essa 
unidade é também importante face às solicitações que aparecem no circuito de abertura do disjuntor, que podem vir a danificar a eletrônica do relé. A corrente necessária para energizar a bobina de desligamento do disjuntor requer normalmente contatos robustos;

d) alimentação: a alimentação da eletrônica do relé é normalmente feita pelo sistema de corrente contínua da subestação e o relé normalmente possui em sua unidade circuitos que realizam a regulação de modo a garantir sua operação precisa e eficiente.

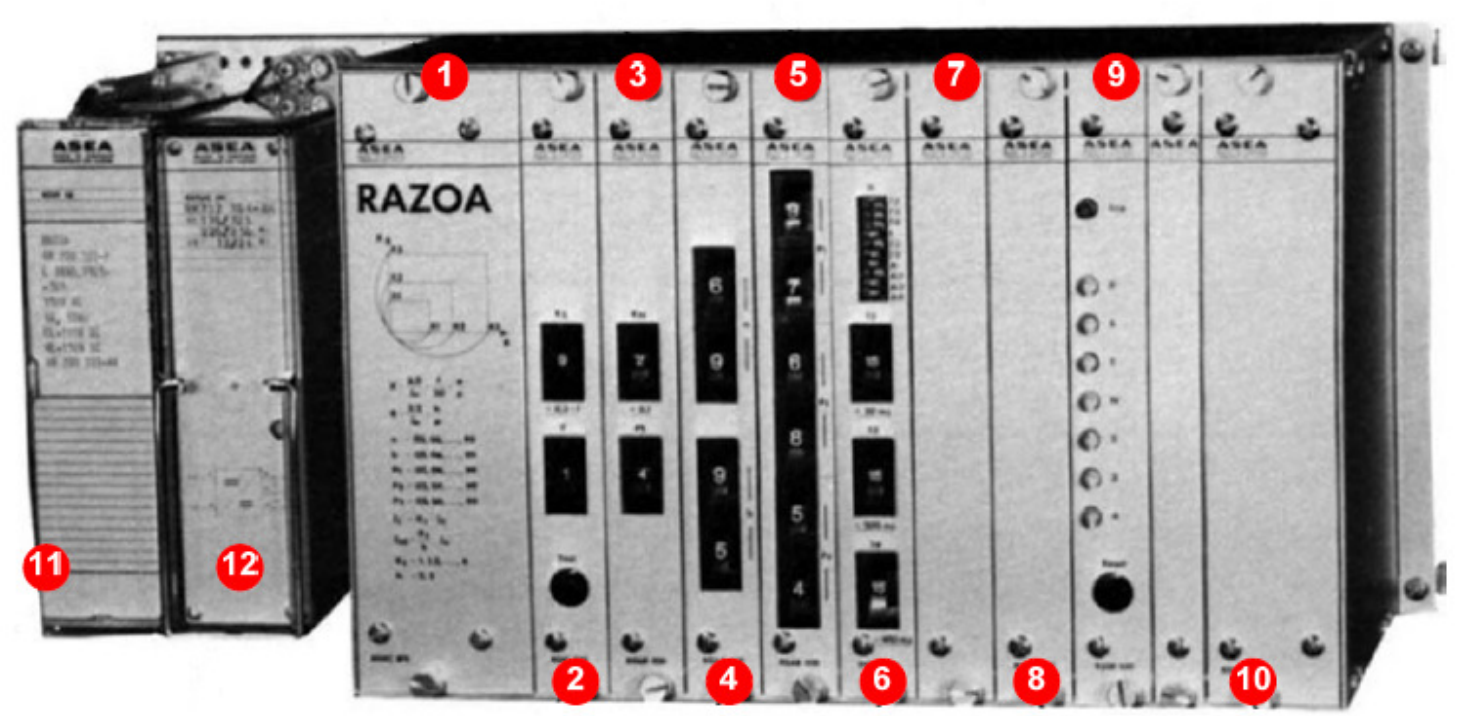

Figura 2 - Relé estático da ASEA de proteção de distância

Descrição das partes integrantes do relé estático mostrado na figura 2: (4)

1. Unidade de entrada

2. Unidade de sobrecorrente

3. Unidade seletora de fase

4. Unidade de ajuste de corrente

5. Unidade de ajuste de tensão

6. Unidade de tempo entre eventos

7. Unidade extra de medição

8. Unidade de memória

9. Unidade de medida e indicação 
10. Unidade de saída

11. Chave de teste

12. Conversor de alimentação auxiliar

Estes equipamentos foram utilizados por pouco tempo no setor elétrico devido à pouca aceitação e ao aparecimento em seguida dos relés de proteção digitais.

Com o advento dos microprocessadores surgiram os primeiros relés digitais. Esses equipamentos utilizam em seus algoritmos os princípios dinâmicos dos relés eletromecânicos somados à evolução da eletrônica digital.

Hoje os relés digitais, como o da figura 3, são denominados de Dispositivos Eletrônicos Inteligentes e agregam além das funções de proteção, funcionalidades adicionais de outros equipamentos, tais como:

a) relés auxiliares;

b) registradores de Sequenciamento de Eventos - Sequence of Events (SOE)

c) registradores de perturbação;

d) medição de grandezas analógicas;

e) monitores de disjuntores;

f) comutadores de tap;

g) monitores de qualidade de energia;

h) Unidades de Medição Fasorial - Phasor Measurement Units (PMU);

i) processadores de comunicação;

j) Controladores Lógicos Programáveis;

k) reguladores de tensão;

1) Controladores de Flexible AC Transmissions Systems (FACTS);

m) anunciadores de alarmes. 


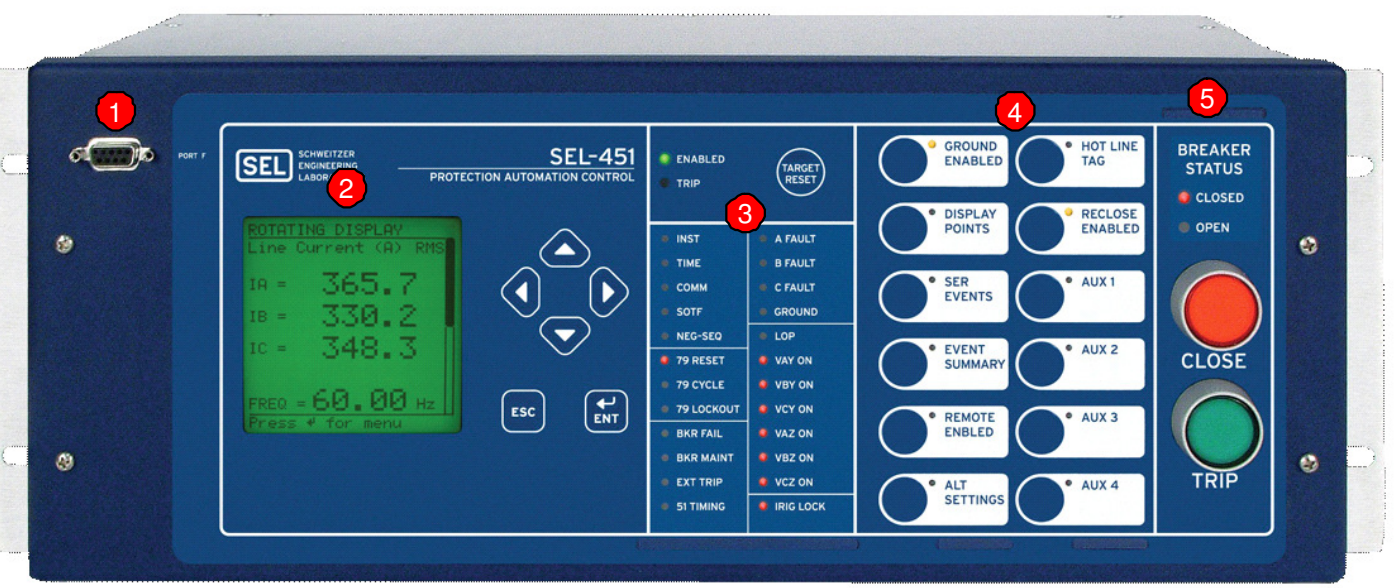

Figura 3 - Relé digital multifunção da Schweitzer Engineering Laboratories

Um exemplo de relé digital, mostrado na figura 3, é o SEL 451 fabricado pela empresa Schweitzer Engineering Laboratories, o qual é composto por:

1. Porta de comunicação serial para acesso à configuração e parametrização

2. Display para acesso às medições e às informações do relé

3. Light-Emmiting Diode (LED) para indicação de alarmes e estados

4. Botões de acesso e controle

5. Botões de controle do bay

Os relés digitais hoje já estão bastante difundidos, sendo aplicados tanto em novos projetos como em substituição aos antigos relés eletromecânicos e estáticos. Entre as vantagens dos relés digitais podemos destacar: (6)

a) custo: no início apresentavam custo de dez a vinte vezes maior que os relés convencionais, porém ao longo dos anos o custo reduziu e o desempenho aumentou consideravelmente;

b) confiabilidade e auto-diagnose: o relé digital monitora constantemente seus sistemas de hardware e software gerando alarmes quando detectada alguma anormalidade. Esta característica é um dos mais importantes argumentos técnicos a favor dessa tecnologia;

c) integração digital: Os computadores e a tecnologia digital têm se tornado a base dos sistemas empregados nas subestações e a integração dos relés digitais ocorre naturalmente; 
d) flexibilidade funcional: $O$ relé digital pode ser programado para executar diversas funções, tornando-se muitas vezes adaptativo às condições do sistema elétrico.

Com a utilização dos relés digitais nas subestações, conjuntamente com a instalação de equipamentos de Global Positioning System (GPS), foi possível obter precisão melhor que um milissegundo no registro dos eventos. Isso representa um ganho considerável para as análises de ocorrências em relação aos sistemas antigos. O sistema GPS consiste de vinte e quatro satélites em seis diferentes órbitas organizados de forma a cobrir qualquer ponto do globo com pelo menos cinco satélites. Estes satélites possuem relógios atômicos sincronizados com outros relógios atômicos em estações de monitoramento na terra. Os satélites transmitem com um nível de potência baixo, dados de posicionamento e pulsos de sincronismo de tempo. Nos SEPs, o GPS é utilizado como fonte de sincronização e não pelas suas facilidades de posicionamento. (6) A informação de sincronização temporal é transmitida do GPS para os IEDs utilizando o sinal Inter Range Instrumentation Group format B (IRIG-B) ou os protocolos de sincronismo Simple Network Time Protocol (SNTP) e o IEEE 1588.

\subsection{Sistemas de automação}

A evolução da automação principalmente em outras áreas da indústria, como a automotiva, trouxe experiência e inúmeros avanços ao setor elétrico.

O desenvolvimento dos Controladores Lógicos Programáveis (CLP), que são dispositivos digitais programáveis para armazenar instruções e executar funções específicas para controlar processos, começou em 1968. Esse desenvolvimento resultou da necessidade constatada pela empresa norte americana General Motors de encontrar um forma rápida e ágil de alterar seus sistemas de controle, naquela época baseada em relés e que demandava dias ou semanas para implementar qualquer alteração em sua linha de montagem. Os primeiros CLPs foram instalados em 1969 e permitiram a redução dos custos de materiais, de mão de obra e de localização de falhas ao reduzirem a quantidade de painéis, relés e fiação. Atualmente as principais características dos CLPs são: (7)

a) linguagem de programação de alto nível;

b) simplificação nos quadros e painéis elétricos;

c) confiabilidade operacional;

d) funções avançadas; 
e) comunicação em rede.

A utilização dos CLP, para realizar funções como o controle de carga e tensão de transformadores de potência e a automação de Grupos Geradores de Emergência do serviço auxiliar da subestação, tornou-se frequente nos primeiros projetos de automação. Estes sistemas de automação trabalhavam isolados dos demais, e poucos recursos de supervisão remota eram oferecidos.

O desenvolvimento da automação elétrica nas subestações está diretamente relacionado ao desenvolvimento dos relés digitais. Muitas aplicações deixaram de trabalhar isoladas e foram incorporadas aos demais sistemas da subestação, através de redes de comunicação ou através de funções agregadas aos relés de proteção.

\subsection{Sistemas de supervisão e controle}

Um Sistema de Supervisão e Controle (SSC) é parte fundamental de praticamente qualquer sistema de automação de processos. O SSC surgiu com a função básica de fornecer uma interface amigável com os operadores do processo.

No final da década de 60 começaram a surgir no setor elétrico brasileiro os primeiros sistemas de telessupervisão, que enviavam informações dos equipamentos instalados nas subestações até os centros de operação das empresas de energia. Nesta época, devido às limitações tecnológicas dos canais de telecomunicações, poucas informações eram encaminhadas de um nível ao outro, tais como:

a) estados dos disjuntores;

b) tensão, corrente, potência ativa e reativa dos bays.

Facilidades de telecontrole sobre os equipamentos não estavam disponíveis nesses primeiros sistemas. Hoje muitas empresas adotam a operação remota de suas subestações a partir dos centros de operação, não mantendo portanto operadores em suas instalações. Esse procedimento leva a uma maior dependência dos sistemas de telecomunicações, que devem ser confiáveis e altamente disponíveis. 


\subsection{Os protocolos de comunicação}

Com o passar dos anos, inúmeros recursos foram surgindo, novos equipamentos foram instalados nas subestações e, dentro deste novo cenário, novos protocolos de comunicação foram sendo implementados no nível do processo, também denominado de comunicação horizontal, e na comunicação entre a subestação e os centros de controle, também denominado de comunicação vertical.

Os protocolos de comunicação são regras entre dois dispositivos capazes de estabelecer um canal de comunicação para troca de dados. Basicamente são definidos por um conjunto de:

a) formato de mensagens;

b) serviços;

c) procedimentos;

d) endereçamento;

e) convenção de nomes.

Até a década de 80, cada fabricante desenvolvia seu próprio protocolo de comunicação, o que provocou a existência de sistemas operando de forma isolada dentro de uma mesma subestação, dificultando a integração, o gerenciamento e a manutenção. As dificuldades geradas por essa profusão de protocolos proprietários deu origem, por pressão dos usuários, a uma tendência no sentido da criação de protocolos abertos como o DNP 3.0 e a IEC 60870.

No início da década de 90, o Electric Power Research Institute (EPRI) e o Institute of Electrical and Electronics Engineers (IEEE), começaram a definir um padrão conhecido por Utility Communications Architecture (UCA). Eles inicialmente focaram em intercontrole entre centros de operação e entre centros e subestações, produzindo então a especificação do Inter-Control Center Communications Protocol (ICCP). Esta especificação, posteriormente adotada pela IEC 60870-6 Telecontrol Application Service Element (TASE.2), tornou-se o protocolo padrão para o intercâmbio de dados em tempo real.

Em 1994, EPRI e IEEE começaram a trabalhar na UCA versão 2.0 para dispositivos de campo. Em 1997, eles combinaram esforços com o Comitê Técnico 57 da IEC para criar um padrão internacional comum. Os esforços conjuntos criaram a atual norma IEC 61850. 
A norma IEC 61850, contém a maioria da especificação da UCA 2.0, como as comunicações cliente/servidor e peer-to-peer, além de funcionalidades adicionais como o projeto e a configuração de subestações, ensaios e padrões.

\subsection{O papel da norma IEC 61850 na modernização das subestações}

Por ser uma norma relativamente recente, a IEC 61850 ainda se encontra em evolução, contando para isso, com o esforço conjunto de fabricantes, instituições de pesquisa e órgãos normativos internacionais. Atualmente esta norma apresenta as seguintes características principais: (1)

a) representa um conjunto de protocolos e critérios;

b) está sendo adotada em diversos países;

c) corresponde ao estado da arte da tecnologia digital na área de automação de subestações;

d) permite uma completa integração entre os diversos equipamentos digitais inteligentes, através do uso de redes Local Area Network (LAN) de alta velocidade e de elevada confiabilidade, baseadas na tecnologia Ethernet;

e) possibilita o compartilhamento das informações através do uso de tecnologias já largamente comprovadas como a linguagem Extensible Mark-up Language (XML), facilitando dessa forma, a implantação de funções de automação e de auxílio à operação e manutenção.

Como elemento facilitador e indutor desta mudança de patamar tecnológico, ocorreram notáveis evoluções nos relés de proteção, nas Unidades de Aquisição e Controle (UAC) e nos outros equipamentos digitais como medidores e oscilógrafos, os quais transformaram-se em dispositivos inteligentes, denominados genericamente como Dispositivos Eletrônicos Inteligentes do inglês Intelligent Electronic Devices (IED). Estes dispositivos, além de agregarem mais recursos às tarefas de proteção, medição, oscilografia, são também capazes de participar das diversas funções de supervisão, controle e automação normalmente utilizadas em uma subestação.

O advento da norma IEC 61850 veio uniformizar o uso de LAN para proteção e automação, permitindo a disponibilização das informações de interesse aos seus diferentes usuários, tais 
como gerências regionais, gestão da manutenção e operação, engenharia da proteção, além das equipes de pré e pós-operação, centros de controle, tecnologia da informação etc.

Adicionalmente, a norma IEC 61850 veio solucionar o problema das expansões dos sistemas digitalizados, oferecendo a garantia de interoperabilidade entre IEDs de fabricantes diferentes, eliminando a dependência de um único fornecedor e reduzindo drasticamente o tempo de implantação e os períodos de desligamentos necessários.

Além de mudar o conceito técnico de operação dos sistemas ela introduz novos benefícios nas diversas fases de desenvolvimento de um sistema, como discutidas a seguir:

a) projeto: o uso de ferramentas de especificação integradas e elementos de projeto padronizados reduzem o esforço envolvido no desenvolvimento de Sistemas de Automação de Subestações, com o beneficio agregado dos processos de documentação automatizados;

b) implantação: geração automática de arquivos de configuração dos equipamentos;

c) construção e instalação: redução significativa de cabos elétricos com a consequente redução dos erros de conexão desses cabos;

d) comissionamento: capacidade de modelar e simular todo o sistema de uma subestação, reduzindo os testes no campo;

e) documentação: fornece acesso digitalizado à documentação, sem a necessidade de recriar continuamente documentos e reduzindo problemas com diferentes bases de dados.

Há de se enfatizar que alguns aspectos da automação de subestações estão fora do escopo da IEC 61850, pois dependem da característica de desenvolvimento de cada fabricante e de cada usuário. São eles:

a) algoritmos internos do IED;

b) funcionalidades de aplicação;

c) topologia das redes de comunicação;

d) métodos de configuração dos IED;

e) métodos de análises e diagnósticos. 
A IEC 61850 aborda diversos aspectos do projeto, implantação e ensaios do sistema de automação da subestação. Os aspectos abordados pela norma de maior interesse para este trabalho são brevemente comentados a seguir.

\subsubsection{Requisitos gerais}

Os requisitos gerais da rede de comunicação são definidos na norma IEC 61850-3, com ênfase nos requisitos de qualidade. Este capítulo da norma também trata das condições ambientais e serviços auxiliares, com recomendações sobre a relevância de determinados requisitos de outras normas e especificações.

Exigências de qualidade são definidas em detalhes, como a confiabilidade, disponibilidade, manutenção, segurança, integridade de dados e outros que se aplicam aos sistemas de comunicação que são usados para monitoramento e controle de processos dentro da subestação. (9)

\subsubsection{A estrutura dos dados}

A norma IEC 61850 padronizou a informação sendo que o transporte dos dados ficou a cargo da tecnologia das redes TCP/IP, largamente difundida e utilizada nos dias atuais.

A IEC 61850, assim como o TASE2/ICCP, são originários da arquitetura UCA 2.0 que é mapeada na especificação Manufacturing Message Specification (MMS), definida nas normas ISO/9506-1 e ISO/9506-2. Também como o TASE2/ICCP, e diferente de todos os outros protocolos, a IEC 61850 não utiliza números ou índices numéricos para endereçamento dos seus objetos de dados de tempo real, mas sim nomes. Contudo, diferente do TASE2/ICCP, cujos nomes de objetos não adotam uma padronização, porque se referenciam a pontos genéricos dos tipos digital, analógico, discreto ou de controle, a IEC 61850 define um dicionário de nomes e uma estrutura hierárquica de objetos que não se referenciam a pontos, mas a equipamentos do sistema elétrico, como chaves, seccionadores, disjuntor, proteção de sobrecorrente, proteção diferencial e outros. Como no exemplo da figura 4 que representa o estado de um disjuntor, os pontos são classificados hierarquicamente em:

a) dispositivo físico ou Physical Device;

b) dispositivo lógico ou Logical Device; 
c) nós lógicos ou Logical Nodes;

d) objeto de dados ou Data Objects;

e) atributos dos dados ou Data Attributes.

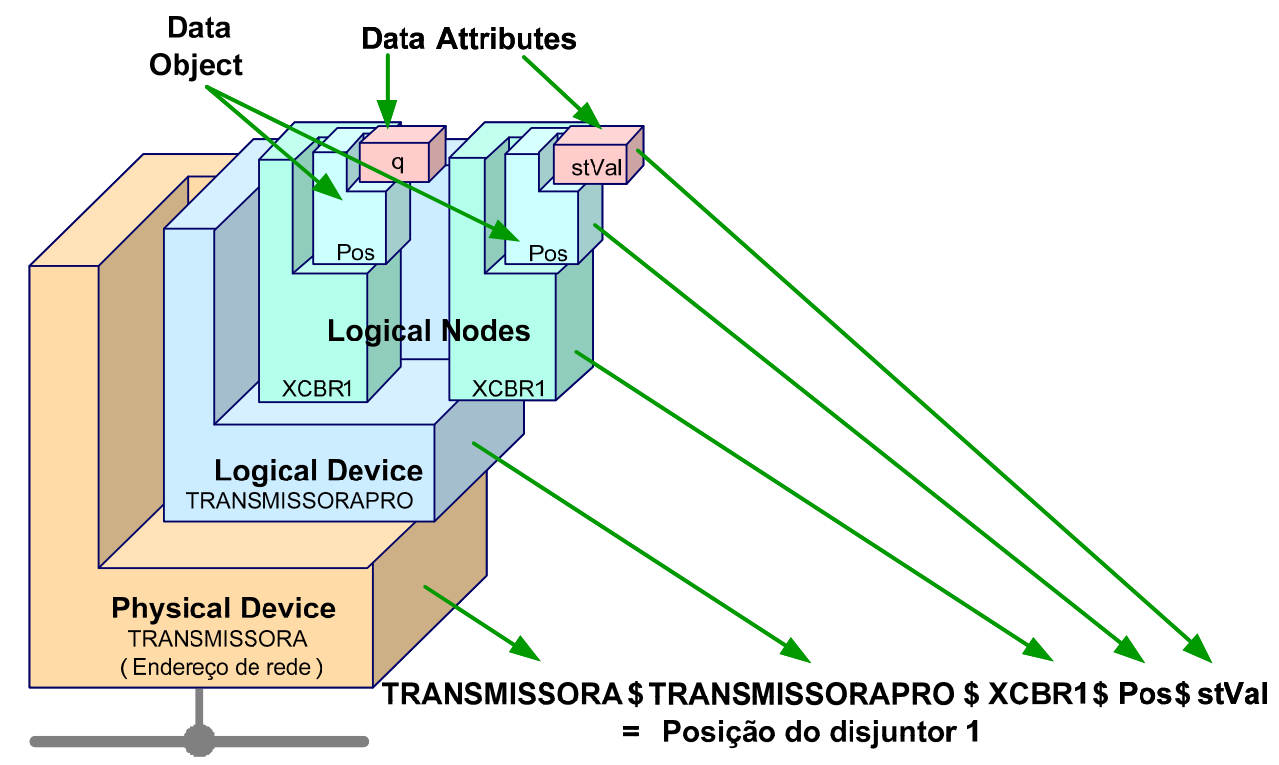

Figura 4 - Estrutura de dados definida pela norma

\subsubsection{Serviços de mensagens da norma IEC 61850}

O serviço de comunicação denominado de Generic Object Oriented Substation Event (GOOSE) disponibiliza ao usuário um serviço de mensagens de controle de alta velocidade. Tem a característica de transmitir mensagens com estados, controles e medidas analógicas através da rede para uso por outros dispositivos em comunicações horizontais - peer-to-peer. Como o GOOSE não opera na camada de transporte do modelo Open Systems Interconnection (OSI), a confirmação do recebimento das mensagens não é realizada. Dessa forma, para aumentar a probabilidade de que outros dispositivos recebam os dados, os IEDs enviam por exemplo uma mensagem GOOSE com um evento, repetidamente conforme os tempos T1, T2 e T3 mostrados na figura 5. (10) 


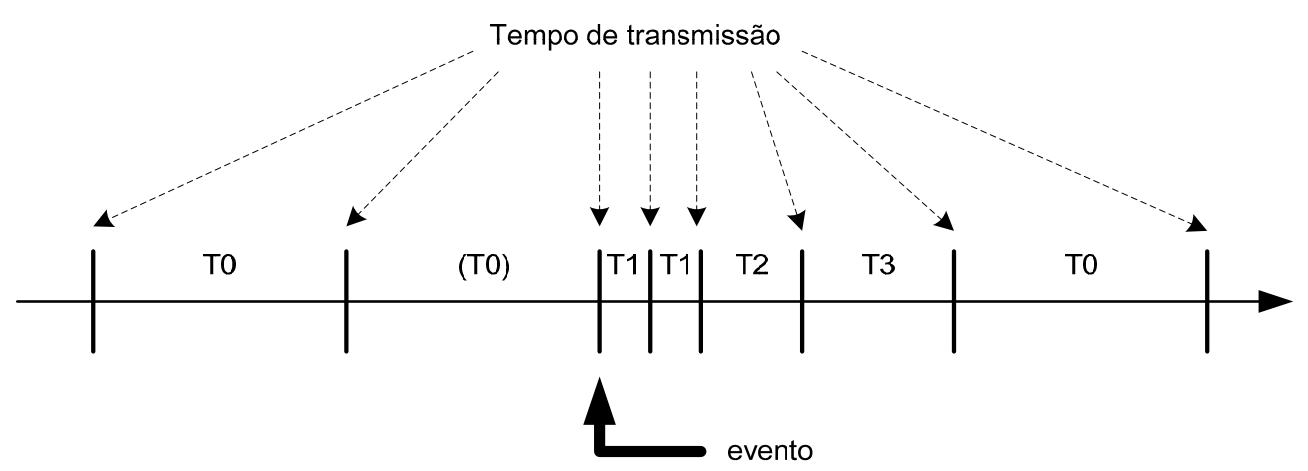

Figura 5 - Característica de transmissão das mensagens GOOSE

Onde:

a) T0: retransmissão do GOOSE em condições estáveis;

b) $\mathbf{T}(\mathbf{0})$ : retransmissão do GOOSE interrompida por um evento;

c) T1: retransmissão do evento em períodos curtos;

d) T2 e T3: retransmissão do evento em períodos curtos até atingir a estabilidade.

O modelo GOOSE utiliza os dados que são publicados de forma agrupada em conjuntos de dados, conhecidos por data sets, conforme mostrado na figura 6. (11) Muitos dados, como por exemplo analógicos, binários ou valores inteiros, e seus atributos de qualidade, podem ser usados para compor os data sets.

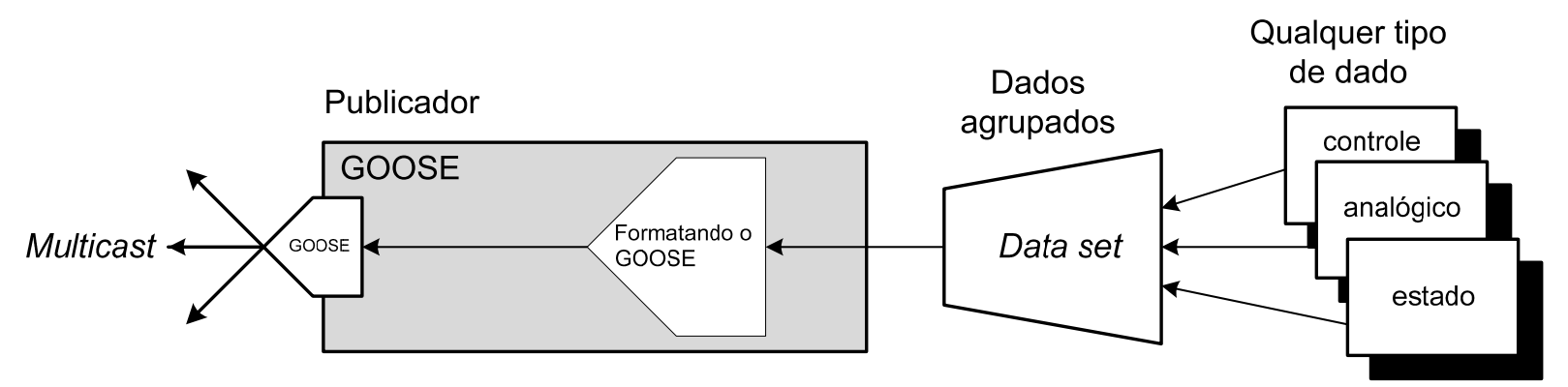

Figura 6 - Mensagem GOOSE publicada em data sets

Cada mensagem GOOSE enviada, também inclui em um único pacote parâmetros de comunicação como VLAN ID, prioridade definida pela norma 802.1Q, e um endereço Media Access Control (MAC) Multicast. Este endereço hexadecimal de seis octetos denominado de Multicast tem pela norma a seguinte recomendação: (10)

a) os três primeiros octetos são definidos pela IEEE como 01-0C-CD; 
b) o quarto octeto deve ser 01 para GOOSE, 02 para Generic Substation Status Event (GSSE) e 04 para Sampled Values;

c) os dois últimos octetos devem ser utilizados individualmente pelo intervalo definido na tabela 1.

Na tabela 1, são apresentados os intervalos dos endereços Multicast.

Tabela 1 -Endereçamento multicast recomendado pela norma

\begin{tabular}{ccc}
\hline Serviço & Início & Fim \\
\hline GOOSE & 01-0C-CD-01-00-00 & 01-0C-CD-01-01-FF \\
\hline GSSE & $01-0 \mathrm{C}-\mathrm{CD}-02-00-00$ & $01-0 \mathrm{C}-\mathrm{CD}-02-01-\mathrm{FF}$ \\
\hline Sampled Values & $01-0 \mathrm{C}-\mathrm{CD}-04-00-00$ & $01-0 \mathrm{C}-\mathrm{CD}-04-01-\mathrm{FF}$ \\
\hline
\end{tabular}

As principais características da mensagem GOOSE são:

a) característica publicador/assinante (publisher/subscriber);

b) múltiplos consumidores requerem endereços MAC multicast;

c) não utiliza IP, portanto não há camada de rede nem camada de transporte do modelo OSI;

d) não é roteável;

e) multicast para muitos consumidores dentro da LAN apenas.

Além do serviço de mensagens prioritárias GOOSE, a IEC 61850 também disponibiliza um serviço de comunicação vertical, cliente/servidor, denominado MMS, que provê serviços em tempo real de transferência de dados na camada de aplicação dentro de uma LAN da subestação. O MMS foi desenvolvido como um protocolo de troca de dados independente para redes industriais na década de 1980 e foi padronizado pela ISO 9506. Características do protocolo MMS:

a) característica cliente/servidor (client/server);

b) um específico consumidor requer endereço MAC unicast;

c) utiliza IP portanto, provê camada de transporte e camada de rede do modelo OSI;

d) MMS é roteável para consumidores da LAN ou WAN. 


\subsubsection{Configuração da arquitetura de comunicação}

Considerando a existência na norma, de um dicionário padronizado de nomes e também de uma estrutura hierárquica de objetos, outra importante funcionalidade introduzida pela IEC 61850 foi a definição de um formato padronizado, derivado do padrão Common Information Model (CIM), para troca de informações de configuração, para ser utilizado em arquivos intercambiados entre as ferramentas de configuração de equipamentos e sistemas de diferentes fabricantes.

Substation Configuration Language (SCL) é uma configuração baseada em XML, linguagem utilizada para apoiar o intercâmbio de dados de configuração do banco de dados entre ferramentas diferentes, que podem ser fornecidos por diferentes fabricantes.

São definidos na parte 6 da norma, quatro diferentes tipos de arquivos SCL utilizados na fase de projeto para compor a arquitetura da subestação, ilustrados na figura 7:

a) System Specification Description (SSD): funções do Sistema de Potência;

b) Substation Configuration Description (SCD): definição completa da subestação, com arquitetura de rede de comunicação;

c) IED Capability Description (ICD): descreve os dados suportados por um tipo de IED;

d) Configured IED Description (CID): descreve a configuração de um IED específico.

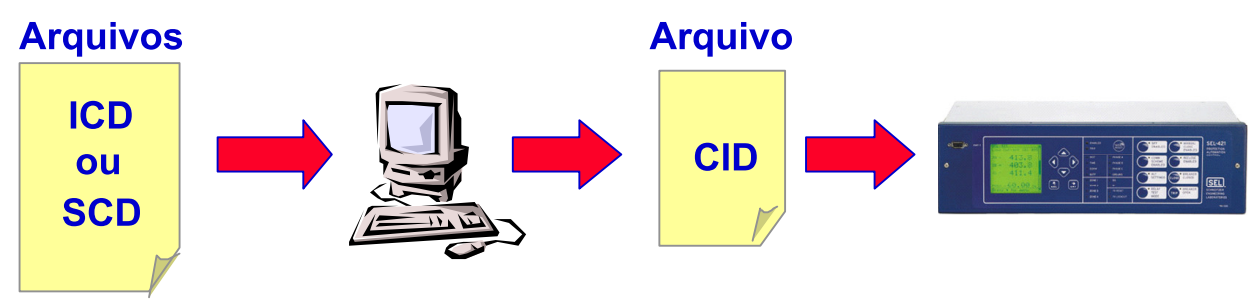

Figura 7 - Arquivos padronizados pela IEC 61850

$\mathrm{O}$ arquivo ICD descreve os recursos de um IED, incluindo informações sobre Logical Nodes (LN) e definição do GOOSE. O arquivo SSD descreve o diagrama unifilar da subestação e os LNs necessários. O arquivo SCD contém informações sobre todos os IEDs, dados da configuração das comunicações, e uma descrição da subestação. $\mathrm{O}$ arquivo CID, que pode existir em várias instâncias em uma arquitetura de subestação, descreve um único IED instanciado dentro do projeto, e inclui informações de endereço. 


\section{Subestações compartilhadas}

São subestações que devido às resoluções da Agência Nacional de Energia Elétrica (ANEEL), têm seus equipamentos e instalações compartilhadas por empresas de geração, transmissão e distribuição de energia envolvidas.

Subestações com esta configuração estão sendo instaladas, no estado de São Paulo, em usinas de biomassa que utilizam turbogeradores movidos através da queima do bagaço da cana-deaçúcar e que acessam o sistema elétrico através do seccionamento de uma linha de transmissão ou através de conexão direta a uma subestação por linha de transmissão de uso exclusivo, com a finalidade de vender a energia excedente da sua produção.

Neste capítulo serão apresentadas as resoluções e leis que determinam os meios para acesso ao sistema de transmissão, as características de uma subestação de seccionamento e os meios de compartilhamento de informações utilizados entre os agentes.

\subsection{O acesso ao SIN}

Segundo o artigo 15 da Lei 9.074, de 1995 o livre acesso é o direito de qualquer agente, carga ou geração, de se conectar e fazer uso da rede elétrica, não condicionada à comercialização de energia, mediante ressarcimento do custo do transporte envolvido. A compra e venda da energia elétrica é contratada separadamente do acesso e uso da rede elétrica conforme o artigo $9^{\circ}$ da Lei 9.648, de 1998.

Para os acessos à rede básica, definida pela ANEEL como os sistemas de transmissão operando com tensões a partir de $230 \mathrm{kV}$, as empresas devem atender à Resolução Normativa (REN) $N^{\circ} 67$ de 8 de junho de 2004 da ANEEL; para os acessos às Demais Instalações de Transmissão (DIT), redes abaixo de $230 \mathrm{kV}$, que é o caso para as usinas de biomassa em estudo, as RENs que se aplicam são a $\mathrm{N}^{\circ} 68$ de 8 de junho de 2004 e a $\mathrm{N}^{\circ} 312$ de 6 de maio de 2008.

O acesso aos sistemas de transmissão e de distribuição, segundo o artigo 10 da REN $\mathrm{N}^{\circ} 281$ de $1^{\circ}$ de outubro de 1999, é regido pelos Procedimentos de Rede, Procedimentos de Distribuição, pelos contratos celebrados entre as partes e pelas normas e padrões específicos de cada concessionária ou permissionária. As empresas concessionárias de energia seguem os 
procedimentos estabelecidos pelos agentes envolvidos, pelo Operador Nacional do Sistema (ONS) e pela ANEEL, iniciando todo o processo pela Consulta de Acesso.

A Consulta de Acesso permite ao acessante iniciar os estudos de viabilidade de seu empreendimento. Nesta fase ele identifica os pontos de conexão de interesse e a transmissora informa as suas características. Os estudos, desenvolvidos pelo acessante, para definição do ponto de conexão, são embasados na melhor alternativa técnica e econômica, isto é, utiliza o critério para avaliação de alternativas tecnicamente equivalentes para integração das centrais geradoras, segundo o qual é escolhida aquela de menor custo global de investimentos. Nesse custo global são considerados as instalações de conexão de responsabilidade do acessante, os reforços nas redes de transmissão e distribuição e os custos das perdas elétricas.

A transmissora em conjunto com a distribuidora local e o ONS elaboram em seguida o Termo de Referência. Após a consulta, são celebrados outros documentos, sendo os principais:

a) Parecer de Acesso;

b) Contrato de Conexão à Transmissão (CCT);

c) Contrato de Conexão à Distribuição (CCD);

d) Contrato de Uso do Sistema de Transmissão (CUST);

e) Contrato de Uso do Sistema de Distribuição (CUSD);

f) Declaração para operação comercial.

\subsection{Resoluções normativas da ANEEL}

Segundo a ANEEL,

as resoluções de caráter normativo são atos regulamentares de alcance ou interesse geral, voltados às atividades do setor elétrico e tem por objeto o estabelecimento de diretrizes, obrigações, encargos, condições, limites, regras, procedimentos, requisitos ou quaisquer direitos e deveres dos agentes e usuários desse serviço público. (12)

Portanto, a ANEEL determina através de duas resoluções, a primeira $\mathrm{N}^{\circ} 68$ de 8 de junho de 2004 e a segunda em atualização à $68, \mathrm{~N}^{\circ} 312$ de 6 de maio de 2008, como devem ser executados os acessos destes auto-produtores de energia ao sistema de transmissão não pertencente à rede básica. 


\subsubsection{Resolução normativa $N^{\circ} 68$ da ANEEL}

Publicada em 2004, esta resolução estabelece os procedimentos para a implementação de reforços nas DITs, não integrantes da Rede Básica, e para a expansão das instalações de transmissão de âmbito próprio, de interesse sistêmico, das concessionárias ou permissionárias de distribuição, e dá outras providências. (13)

\subsubsection{Resolução normativa $\mathbf{N}^{\circ} 312$ da ANEEL}

Publicada em 2008, esta resolução altera a REN nº 68, de 8 de junho de 2004, e estabelece os procedimentos para acesso e implementação de reforços nas DITs, não integrantes da Rede Básica, e para a expansão das instalações de transmissão de âmbito próprio, de interesse sistêmico, das concessionárias ou permissionárias de distribuição, e dá outras providências.

Dentre as principais alterações, ela estabelece o termo "acesso" para o uso dos sistemas de transmissão por empresas e ainda que este acesso deve ser feito através de seccionamento e não mais por derivação de uma linha de transmissão. (14)

\subsection{Acesso às DITs}

Este tipo de acesso é o mais frequente para as usinas de biomassa que se conectam ao sistema de transmissão no estado de São Paulo, já que grande parte da malha elétrica paulista é da classe de $138 \mathrm{kV}$. Conforme REN N ${ }^{\circ} 68$ da ANEEL, já atualizada com a REN $N^{\circ} 312$, as diretrizes para acesso são:

Art. $4^{\circ}$-A A conexão por meio de seccionamento de linha integrante das DIT deverá ser, ressalvado o disposto nos $\S \S 8^{\circ}$ e $9^{\circ}$ deste artigo, autorizada em favor da concessionária de transmissão proprietária da linha.

$\S 8^{\circ} \mathrm{O}$ acessante, no caso de consumidor livre, central geradora ou importador e/ou exportador de energia, a seu critério e mediante manifestação formal até 90 (noventa) dias após a emissão do Parecer de Acesso pelo ONS, poderá implementar o módulo geral, o barramento, o módulo de manobra para sua conexão, as entradas e as extensões de linha, associados ao seccionamento, sendo que:

I - o consumidor livre, central geradora ou importador e/ou exportador de energia deverá elaborar o projeto básico e o executivo, além de especificar os equipamentos, em observância aos Procedimentos de Rede, aos Procedimentos de Distribuição e às normas e padrões técnicos das 
concessionárias ou permissionária para as quais serão transferidas as instalações;

II - o consumidor livre, central geradora ou importador e/ou exportador de energia deverá, sem direito à indenização, transferir à concessionária de transmissão proprietária da linha seccionada, para fins de vinculação à respectiva concessão, as entradas e as extensões de linha associadas ao seccionamento, os equipamentos necessários para adequações nos terminais da linha seccionada, referentes aos sistemas de telecomunicação, proteção, comando e controle, e sobressalentes necessários à manutenção das instalações a serem transferidas;

III - a concessionária de transmissão proprietária da linha seccionada deverá verificar a conformidade das especificações e projetos, participar do comissionamento das instalações que serão vinculadas à sua concessão e instalar os equipamentos necessários para adequações nos terminais da linha seccionada, referentes aos sistemas de telecomunicação, proteção, comando e controle, de forma a não comprometer o cumprimento do cronograma de implantação, sendo essas atividades ressarcidas pelo consumidor livre, central geradora ou importador e/ou exportador de energia, no valor de 3,0\% (três por cento) do custo de construção efetivamente realizado dos ativos transferidos, por este informado;

IV - será estabelecida parcela adicional da Receita Anual Permitida (RAP) em favor da concessionária de transmissão proprietária da linha seccionada, destinada a cobrir os custos de referência para a operação e manutenção das instalações transferidas, a ser considerada no cálculo da tarifa de uso;

V - o consumidor livre, central geradora ou importador e/ou exportador de energia deverá, sem direito à indenização, transferir à concessionária ou permissionária de distribuição responsável pela área relativa ao acesso, para fins de vinculação à respectiva concessão ou permissão, o módulo geral, o barramento e o módulo de manobra para conexão;

VI - a concessionária ou permissionária de distribuição responsável pela área relativa ao acesso deverá verificar a conformidade das especificações e projetos e participar do comissionamento das instalações que serão vinculadas à sua concessão ou permissão, de forma a não comprometer o cumprimento do cronograma de implantação, não cabendo cobrança pela execução destes serviços;

VII - o consumidor livre, central geradora ou importador e/ou exportador de energia deverá celebrar CCD com a concessionária ou permissionária de distribuição responsável pela área relativa ao acesso;

VIII - a concessionária ou permissionária de distribuição se tornará acessante a DIT e deverá celebrar CCT com a concessionária de transmissão proprietária da linha seccionada;

IX - os custos de referência para operação e manutenção das instalações transferidas à concessionária ou permissionária de distribuição serão considerados no cálculo da tarifa de uso; e

$X$ - as transferências ocorrerão pelo custo de construção efetivamente realizado, sendo estes custos informados pelo cedente, e se darão de forma não onerosa para a concessionária ou permissionária, devendo ser registradas no ativo imobilizado da cessionária e ter como contrapartida Obrigações 
Vinculadas à Concessão do Serviço Público de Energia Elétrica (Obrigações Especiais)".

$\S 9^{\circ} \mathrm{O}$ acessante, no caso de concessionária ou permissionária de distribuição para atendimento ao seu mercado cativo, deverá implementar o módulo geral, o barramento e o módulo de manobra para sua conexão, que passarão a fazer parte de sua concessão ou permissão.”

Art. $4^{\circ}-\mathrm{C} \mathrm{O}$ acesso de central geradora às DIT somente será permitido por meio de seccionamento de linha ou conexão em barramento existente, conforme estabelecido nos arts. $4^{\circ}$-A e $4^{\circ}$-B.

Conforme também o artigo $4^{\circ} \mathrm{G}$, inciso III, a conexão em derivação, e não através de seccionamento, só é permitida em linhas pertencentes às concessionárias e permissionárias de distribuição em tensões iguais a $69 \mathrm{kV}$.

\subsection{Resoluções autorizativas da ANEEL}

Resolução Autorizativa (REA) é a publicação da ANEEL, correspondente a cada empreendimento, onde são especificadas as características técnicas das instalações para a geração de energia elétrica, bem como das instalações de transmissão de interesse restrito da central geradora, prazo de vigência da outorga correspondente e, quando devido, o cronograma de implantação a ser cumprido.

\subsection{Cogeração}

Segundo o artigo $3^{\circ}$ da resolução ANEEL N 235 de 14 de novembro de 2006, cogeração é o “processo operado numa instalação específica para fins da produção combinada das utilidades calor e energia mecânica, esta geralmente convertida total ou parcialmente em energia elétrica, a partir da energia disponibilizada por uma fonte primária”. Ou seja, é uma prática de conservação de energia e de racionalidade energética.

Até meados do século passado a cogeração era muito usada nas indústrias, devido ao fato de ser rara a produção de energia elétrica em grande escala pela inexistência de uma tecnologia eficiente. Naquela época era comum o próprio consumidor instalar sua central de geração de energia. Com o avanço da tecnologia surgiram novos métodos de produção de energia, a construção de grandes centrais de geração de energia elétrica e a interligação de sistemas elétricos. Com o apoio dessas grandes centrais, tornou-se possível o fornecimento de energia 
elétrica em abundância e com baixo custo, tornando o sistema de cogeração limitado a sistemas isolados, o que o levou a perder gradualmente a participação no mercado.

Por outro lado, com o aumento da demanda de energia elétrica, somado às cobranças da qualidade do fornecimento, às preocupações com o meio ambiente e à sustentabilidade, os grandes sistemas centralizados de geração de energia passaram a ser requisitados em novas condições de operação e começaram a dar indícios de vulnerabilidade. Os olhares então se voltaram novamente para o sistema de cogeração, que passou a ser estimulado e, consequentemente aperfeiçoado.

A cogeração, por apresentar proximidade com a unidade consumidora, dispensa a instalação de longas linhas de transmissão, reduzindo os impactos ao meio ambiente.

\subsubsection{Programa de Incentivo às Fontes Alternativas de Energia Elétrica}

Dentre os inúmeros projetos de usinas de biomassa alguns são participantes do Programa de Incentivo às Fontes Alternativas de Energia Elétrica (PROINFA), do Ministério de Minas e Energia do Governo Federal, que conforme descrito no Decreto $\mathrm{n}^{\mathrm{o}} 5.025$, de 2004, o PROINFA foi instituído com o objetivo de aumentar a participação da energia elétrica produzida por empreendimentos concebidos com base em fontes eólica, de biomassa e pequenas centrais hidrelétricas (PCH) no SIN.

Coube ao Ministério de Minas e Energia (MME) definir as diretrizes, elaborar o planejamento do Programa e definir o valor econômico de cada fonte e às Centrais Elétricas Brasileiras S.A. (Eletrobrás) o papel de agente executora, com a celebração de contratos de compra e venda de energia.

Para tanto, foi estabelecido que o valor pago pela energia elétrica adquirida, além dos custos administrativos, financeiros e encargos tributários incorridos pela Eletrobrás na contratação desses empreendimentos, fossem rateados entre todas as classes de consumidores finais atendidas pelo SIN, com exceção dos consumidores classificados na subclasse residencial Baixa Renda (consumo igual ou inferior a $80 \mathrm{kWh} / \mathrm{mês}$ ).

O Programa prevê a implantação de cento e quarenta e quatro usinas, totalizando 3.299,40 MW de capacidade instalada, sendo 1.191,24 MW provenientes de sessenta e três pequenas centrais hidrelétricas, 1.422,92 MW de cinquenta e quatro usinas eólicas, e 685,24 MW de 
vinte e sete usinas a base de biomassa. Toda essa energia tem garantia de contratação por vinte anos pela Eletrobrás. (15)

Embora algumas ações do governo para impulsionar a cogeração tenham ocorrido, tais como planos de financiamentos especiais criados pelo Banco Nacional de Desenvolvimento Econômico e Social (BNDES) e a criação do PROINFA, estas ações ainda não foram suficientes para aumentar a oferta deste tipo de energia, devido, muitas vezes, à burocracia e aos problemas com licenças ambientais. (16)

\subsubsection{Usinas termelétricas de biomassa}

Em geral, denominam-se biomassa aqueles recursos naturais que podem ser processados para fornecer formas bioenergéticas mais elaboradas e adequadas para o uso final. Portanto, seriam exemplos de fontes de bioenergia a lenha e os resíduos de serrarias, o bagaço da cana-deaçúcar, o carvão vegetal, o biogás resultante da decomposição anaeróbia de lixo orgânico e outros resíduos agropecuários, bem como os biocombustíveis líquidos, como o bioetanol e o biodiesel. (17)

Tendo em vista que a matriz elétrica brasileira passa por uma fase de transição devido à necessidade de complementação da geração hídrica com fontes eficientes de energia elétrica, a bioeletricidade gerada pelas usinas de açúcar torna-se uma fonte de energia intrinsecamente complementar à geração hídrica. Isto ocorre porque a safra de cana-de-açúcar coincide com o período de seca, isto é, quando os níveis dos reservatórios das usinas hidrelétricas localizadas no sul e sudeste do país, estão mais baixos. (18)

O princípio de funcionamento de uma usina termelétrica de energia (UTE), consiste em utilizar a queima de combustíveis, através do ciclo Rankine, para aquecer a água em uma caldeira e utilizar o vapor em alta pressão resultante para movimentar as turbinas, gerando assim eletricidade. No caso das usinas de açúcar, cada tonelada de cana utilizada na produção de açúcar e álcool, gera em torno de duzentos e cinquenta quilos de bagaço que é queimado neste processo. (19) Além do bagaço também é comum utilizar a palha e a ponta da cana para queima.

Atualmente (2011) existem trezentas e trinta e quatro usinas termelétricas de cana-de-açúcar em todo o país, gerando $6.455 .556 \mathrm{~kW}$ (20), sendo todas auto-suficientes em energia elétrica. No estado de São Paulo, maior produtor de cana-de-açúcar do país, responsável por $60 \%$ de 
toda produção (21), existem cento e setenta e nove usinas (20), e dez destas usinas, hoje já conectadas através de seccionamentos, injetam energia diretamente no sistema de transmissão da Companhia de Transmissão de Energia Elétrica Paulista (CTEEP). Informações destas dez usinas, em ordem de entrada em operação, estão no anexo A.

Dados da ANEEL de 2011 apontam dezesseis usinas em construção e trinta e cinco com outorga para construção, totalizando $2.830 .011 \mathrm{~kW}$ de geração. Destas cinquenta e uma usinas, dezessete estão no estado de São Paulo. (21)

\subsection{Arranjo físico das subestações compartilhadas}

Como já mencionado, a subestação em estudo é inserida no sistema através do seccionamento de uma linha de transmissão existente, próxima à usina de açúcar. $\mathrm{O}$ arranjo padrão de uma subestação, conforme a figura 8 , que atende a um acessante é composto de: (22)
a) dois bays de linhas de transmissão;
b) duas barras;
c) um bay de disjuntor de paralelo;
d) um bay de transformador.

Além dos equipamentos auxiliares:

a) dois serviços auxiliares de corrente contínua;

b) um serviço auxiliar de corrente alternada;

c) um grupo gerador de emergência.

A área e os equipamentos internos da subestação que se conectam ao turbo gerador do acessante não serão detalhados neste trabalho. 


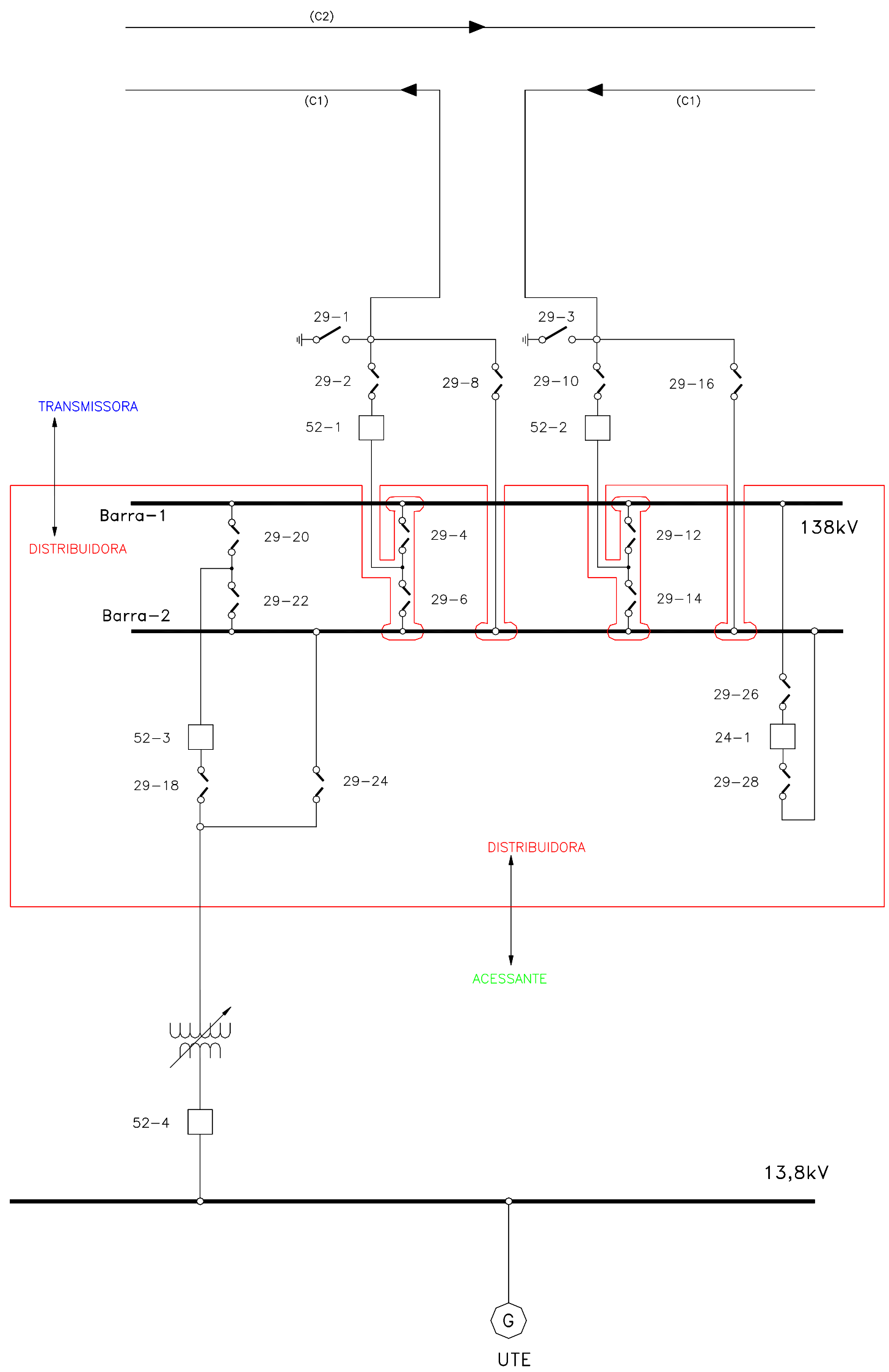

Figura 8 - Diagrama unifilar de uma subestação padrão para seccionamento em 138kV 
Descrição dos equipamentos da subestação de $138 \mathrm{kV}$ :

29-1: Chave de aterramento do bay da linha de transmissão 1

29-2: Seccionador de entrada do bay da linha de transmissão 1

29-3: Chave de aterramento do bay da linha de transmissão 2

29-4: Seccionador de conexão da linha de transmissão 1 à barra 1

29-6: Seccionador de conexão da linha de transmissão 1 à barra 2

29-8: Seccionador de bay-pass do disjuntor 1 da transmissora

29-10: Seccionador de entrada do bay da linha de transmissão 2

29-12: Seccionador de conexão da linha de transmissão 2 à barra 1

29-14: Seccionador de conexão da linha de transmissão 2 à barra 2

29-16: Seccionador de bay-pass do disjuntor 2 da transmissora

29-18: Seccionador de entrada do bay da UTE

29-20: Seccionador de conexão da UTE à barra 1

29-22: Seccionador de conexão da UTE à barra 2

29-24: Seccionador de bay-pass do disjuntor 3 da distribuidora

29-26: Seccionador da barra 1 para isolar o disjuntor de paralelo da distribuidora

29-28: Seccionador da barra 2 para isolar o disjuntor de paralelo da distribuidora

52-1: Disjuntor do bay da linha de transmissão 1

52-2: Disjuntor do bay da linha de transmissão 2

52-3: Disjuntor do bay da UTE pertencente à distribuidora

24-1: Disjuntor de paralelo da distribuidora para interligação das barras 1 e 2

\subsection{Funções de proteção aplicadas na subestação compartilhada}

As funções de proteção presentes em um projeto de subestação compartilhada, são aplicadas segundo estudos da característica de carregamento da região, da seletividade, dos níveis de curto circuito, das condições operativas e conforme requisitos estabelecidos nos procedimentos de rede do ONS que são documentos de caráter normativo elaborados com 
participação dos agentes, e aprovados pela ANEEL, que definem os procedimentos e os requisitos necessários à realização das atividades de planejamento da operação eletroenergética, administração da transmissão, programação e operação em tempo real no âmbito do SIN.

Para o nível de tensão de $138 \mathrm{kV}$, as funções de proteção utilizadas na subestação de seccionamento são descritas a seguir.

\subsubsection{Proteção de Distância}

Proteção de distância é a proteção primária das linhas de transmissão da subestação. Tem a função de detectar curto circuitos ao longo do circuito através do cálculo da impedância. Basicamente, através da medição da tensão e da corrente de curto, para uma falta em qualquer ponto da linha, a proteção calcula a relação entre estas medidas, indicando a impedância do curto, que é proporcional à distância da instalação ao local da perturbação.

Os relés de proteção são configurados normalmente com quatro zonas de alcance para detecção de curtos fase-terra e curtos fase-fase, sendo uma zona reversa.

\subsubsection{Religamento automático das linhas}

A maioria dos defeitos nas linhas aéreas de transmissão são transitórios, como os produzidos por descargas atmosféricas. Nesse caso, basta desligar e ligar novamente a linha para que o defeito seja eliminado. O emprego do religamento automático nestas linhas, para atuações da proteção de distância quando detectado o defeito dentro da primeira zona, traz uma significativa melhoria na continuidade dos serviços de transmissão.

\subsubsection{Proteção de sobrecorrente direcional}

Em certas configurações do SEP verifica-se que com simples relés de sobrecorrente temporizados, protegem-se adequadamente linhas de transmissão radiais. No entanto, a proteção de linhas alimentadas por ambas as extremidades, ou em anel, requer relés de sobrecorrente temporizados com elementos adicionais de direção. Isto quer dizer que o disparo do disjuntor deve ocorrer somente quando a corrente de curto circuito tem uma 
direção particular em cada localização. Esta direção não tem relação com a direção da corrente normal de carga, que poderá circular ora num sentido, ora no outro. (3)

Para faltas de alta impedância, que provocam correntes de curto circuito cujos valores estão na mesma ordem de grandeza das correntes normais de carga, o que pode fazer com que o relé não seja sensibilizado, são instalados relés de sobrecorrente direcionais de neutro.

Para faltas próximas ao terminal de saída da linha de transmissão, o tempo de operação da função sobrecorrente direcional geralmente deverá ser igual ou superior a 0,3 segundos, evitando assim que esta opere antes das proteções de distância, o que comprometeria o religamento automático. E para faltas no final da linha, deve possuir tempo superior ao da segunda zona da proteção de distância.

Esta proteção age como retaguarda das proteções de distância das linhas de transmissão.

\subsubsection{Teleproteção}

Um esquema de teleproteção atua em conjunto com as proteções de distância e com a proteção de sobrecorrente direcional de neutro através da utilização de equipamentos auxiliares de telecomunicações. Também denominada de proteção piloto, ela é usada para acelerar a atuação da proteção de distância, permitindo o isolamento da falta sem atraso ao longo de todo o comprimento da linha de transmissão. (6)

\subsubsection{Proteção de sobretensão}

Na função de sobretensão a atuação ocorre quando a detecção de sobretensão persiste em uma ou mais fases por um tempo ajustado. Os valores de ajuste do nível de atuação da sobretensão, e da sua temporização são definidos pelo estudo do sistema elétrico da região.

As sobretensões que podem ocorrer no SEP, normalmente são ocasionadas pelo rompimento do equilíbrio energético entre a geração e o consumo quando da saída de um bloco considerável de carga, através da abertura do disjuntor do circuito correspondente. Tal fenômeno é conhecido como rejeição de carga.

Uma vez que a geração normalmente encontra-se a grandes distâncias dos centros de carga, as linhas de transmissão, que interligam geração e carga, são longas e portanto seu efeito 
capacitivo quando operando a vazio, o que ocorre quando da abertura do disjuntor do lado da carga, fará com que apareça sobretensões danosas aos equipamentos.

\subsubsection{Proteção de subtensão}

Também denominada de subtensão de manobra, esta proteção é necessária quando da ocorrência de grandes perturbações no sistema - blecaute. Nessa situação a abertura dos disjuntores das linhas facilita a recomposição do sistema afetado. A atuação para desligar o disjuntor ocorre quando a detecção de subtensão persiste nas três fases por um tempo ajustado.

\subsubsection{Proteção de fechamento sob falta}

A lógica de fechamento sob falta, mais conhecida por Switch Onto Fault (SOTF), permite que elementos de proteção de sobrecorrente específicos efetuem o disparo por um período de tempo ajustável, após fechamento do disjuntor. A lógica SOTF trabalha em dois estágios: validando uma possível condição de SOTF e permitindo a atuação da proteção SOTF durante o tempo ajustado.

A validação da condição de SOTF é feita pela detecção da condição de pólos abertos, quando da abertura ou fechamento do disjuntor. O procedimento de validação pode ser feito escolhendo-se uma destas condições ou ambas. O relé habilita a proteção SOTF nos seguintes instantes:

a) quando da abertura do disjuntor: após o tempo ajustado em temporizador específico;

b) quando do fechamento do disjuntor: após o tempo ajustado em temporizador específico e com a ordem de fechamento manual ou por religamento automático do disjuntor.

\subsubsection{Proteção de barras}

A proteção de barras em uma subestação é um elemento crítico para a estabilidade do sistema elétrico, devido ao risco de desligamento de múltiplas linhas e transformadores conectados ao 
barramento. O desligamento rápido e o isolamento da falha são importantíssimos, mas ao mesmo tempo a operação da proteção para falhas externas ao barramento protegido deve ser evitada, a fim de reduzir a probabilidade de ocorrência de uma perturbação maior no sistema.

A configuração da subestação de seccionamento, segundo os critérios da ANEEL, estabelece que as barras pertençam à empresa de distribuição, portanto, esta proteção é de responsabilidade deste agente.

\subsubsection{Proteção de Falha de Disjuntor}

O aumento do grau de redundância da proteção de uma instalação pode ser justificado em função do custo e da importância elétrica do componente protegido. O grau de redundância deve ser analisada em termos de relés, transformadores de corrente e potencial, fontes de corrente contínua, fiação e circuitos de disparo dos disjuntores. A duplicação do disjuntor de

alta tensão, como meio de interrupção de corrente é economicamente inviável. É muito raro um disjuntor bem dimensionado e bem construído deixar de interromper uma corrente de curto circuito, quando convenientemente acionado pela proteção. O fato é que uma recusa de atuação ou incapacidade de interrupção de um disjuntor, por improváveis que sejam, transformam uma falta em um equipamento, em um defeito de consequências análogas às de um curto circuito no barramento associado, implicando a abertura de um número apreciável de disjuntores. Os barramentos múltiplos são menos afetados pelas consequências de uma falha de disjuntor, visto que só haverá uma seção de barra envolvida com cada evento. Esta é a razão para se associar a proteção para falha de disjuntor à lógica de imagem dos seccionadores nos barramentos de configuração variável, de modo a prover atuação seletiva.

Para prover a correta detecção, a proteção contra falha de disjuntor deve ser composta por relés sensores de sobrecorrente de fase e de neutro ajustáveis, temporizadores e relés de bloqueio, com os seguintes requisitos:

a) partida por atuação de todas as proteções que acionam o disjuntor exceto subtensão de manobra, sobretensão temporizado, sobretensão instantâneo; 
b) a abertura ou fechamento manual do disjuntor que ocasione atuação da discordância de pólos não deve iniciar a contagem do tempo para o disparo, porém deve ocasionar alarme;

c) promover um novo comando de abertura do disjuntor (retrip) antes do acionamento do esquema de falha de disjuntor;

d) comandar a abertura e o bloqueio de fechamento de todos os disjuntores necessários, e somente estes, para a isolação da falta;

e) os acionamentos do disjuntor por proteções que independam de corrente, por exemplo baixa pressão de Hexafluoreto de Enxofre, devem partir o esquema de falha de disjuntor.

A proteção contra falha de disjuntor deverá permitir também os seguintes bloqueios através de chaves seletoras bloqueio-desbloqueio, ou botoeiras com LEDs de sinalização, instaladas no painel de proteção:

a) bloqueio geral da proteção de falha de disjuntor, local e por telecomando;

b) bloqueio por bay da proteção de falha de disjuntor.

\subsubsection{Proteção do transformador e dos geradores}

Estas proteções pertencem ao acessante e não serão detalhadas neste trabalho.

\subsection{O compartilhamento de informações entre os agentes}

Cada empresa possui normas operativas e possivelmente diferentes filosofias de manutenção e de proteção, além de políticas internas de segurança, tanto na área de TI como no acesso à subestação e aos painéis da subestação.

Entretanto os agentes necessitam, para operação dos seus sistemas, de informações dos sistemas de supervisão, controle e proteção da subestação, tais como estado dos disjuntores e seccionadores e medidas analógicas. Estes dados portanto devem ser trocados entre as empresas. 
A seguir são relacionados todos os esquemas de proteção, de lógicas e de intertravamentos que utilizam informações que devem ser compartilhadas pelos agentes envolvidos no empreendimento.

\subsubsection{Intertravamentos}

Os intertravamentos elétricos são necessários para se evitar a manobra indevida de equipamentos, evitando danos materiais e às pessoas. Na configuração da subestação, alguns intertravamentos são executados no próprio bay, por exemplo:

a) abertura dos seccionadores de saídas das linhas dependem do disjuntor de linha desligado;

b) fechamento dos seccionadores de aterramento dependem do disjuntores de linha desligados e da ausência de tensão.

Outros intertravamentos envolvem os agentes de transmissão e de distribuição. São eles:

a) fechamento dos seccionadores de bay-pass dependem do disjuntor de paralelo de barras ligado;

b) para ligar o disjuntor de paralelo de barras depende de todos os seccionadores de barra conectados na barra 1.

\subsubsection{Esquema de falha de disjuntor}

O esquema de falha de disjuntor é implementado tanto pela transmissora quanto pela distribuidora. Ela monitora o disparo de todos os disjuntores conectados nas barras. Caso ocorra o disparo de alguma proteção de linha sem a abertura do respectivo disjuntor do elemento protegido, a proteção de falha de disjuntor, envia novamente um sinal de abertura, denominado de retrip, e caso ainda o disjuntor permaneça ligado, a proteção de falha de disjuntor desliga todos os demais disjuntores conectados nas barras. Deste modo os sinais de partida do esquema de falha de disjuntor presente nos IEDs da transmissora devem ser enviados ao IED de proteção da distribuidora. 


\subsubsection{Proteção diferencial de barras}

A proteção de barras implementada pela distribuidora é adaptativa pois, monitora todos os disjuntores e seccionadores conectados nas barras da subestação. Caso ocorra uma diferença na somatória das correntes dos bays, a proteção envia sinal de desligamento para todos os disjuntores conectados. Dessa forma, para esta proteção os estados de todos os seccionadores e os sinais de corrente de todos os bays da transmissora devem ser enviados para o IED de proteção de barras da distribuidora.

\subsubsection{Transferência de proteção}

A transferência de proteção é a condição operativa onde um dos disjuntores dos bays de linha está liberado para manutenção sendo, desta forma, substituído pelo disjuntor de paralelo que pertence à distribuidora. Nesta condição, através de chaves de transferência de proteção, os IEDs das linhas enviam sinais de disparo para o IED da distribuidora que gera o comando de abertura para o disjuntor do paralelo.

Para as manobras de liberação do disjuntor 1, por exemplo, todos os demais bays devem estar transferidos para a barra 1, isto é seccionadores 4, 12 e 20 fechados, sendo então necessárias as seguintes operações em coordenação com a distribuidora e a transmissora:

a) DISTRIBUIDORA - Fechar os seccionadores 29-26 e 28;

b) DISTRIBUIDORA - Ligar o disjuntor 24-1;

c) TRANSMISSORA - Bloquear o religamento automático do disjuntor 52-1;

d) TRANSMISSORA - Passar a chave de transferência da proteção do 52-1 para posição “intermediária” (desliga por atuação de proteção os disjuntores 52-1 e 24-1);

e) TRANSMISSORA - Fechar 29-8;

f) TRANSMISSORA - Desligar 52-1;

g) TRANSMISSORA - Passar a chave de transferência da proteção do 52-1 para posição "transferida" (desliga por atuação de proteção somente o disjuntor 24-1);

h) TRANSMISSORA - Abrir seccionadores 29-2 e 4; 
i) TRANSMISSORA - Desbloquear o religamento automático do 52-1 (Atua somente sobre o 24-1);

j) TRANSMISSORA - Manter aberta 29-6;

k) TRANSMISSORA - Bloquear elétrica e mecanicamente os seccionadores 29-2, 4 e 6. Após o disjuntor transferido, a configuração da subestação fica conforme a figura 9.

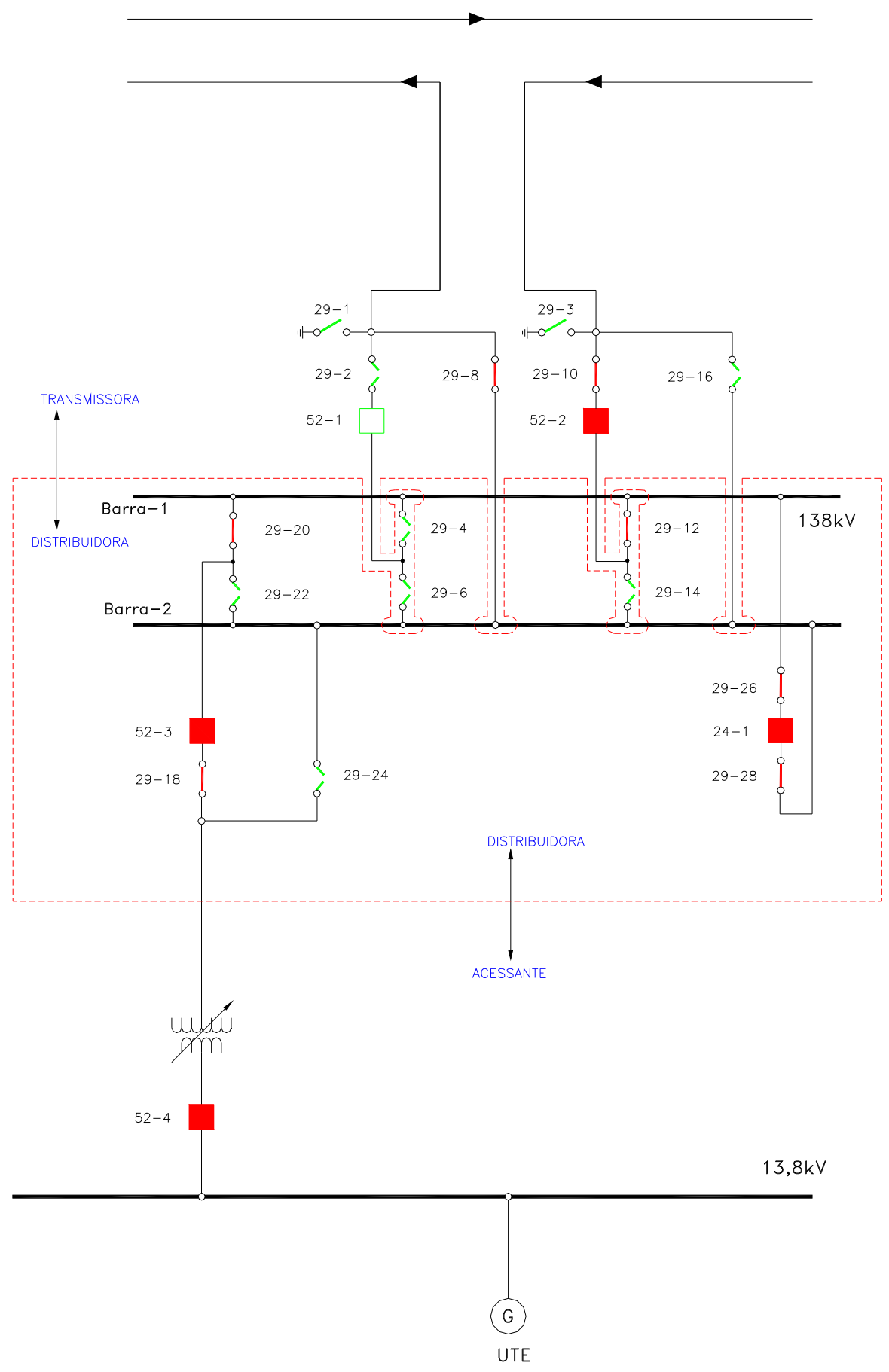

Figura 9 - Configuração final dos disjuntores na transferência de proteções 
Para as manobras de normalização do disjuntor 1, são necessárias as seguintes operações:

a) TRANSMISSORA - Desbloquear elétrica e mecanicamente os seccionadores 29-2, 4 e 6

b) TRANSMISSORA - Fechar os seccionadores 29-2 e 4;

c) TRANSMISSORA - Bloquear o religamento automático do 52-1

d) TRANSMISSORA - Passar a chave de transferência da proteção do disjuntor 52-1 para posição "intermediária" (desliga por atuação de proteção os disjuntores 52-1 e 24-1);

e) TRANSMISSORA - Ligar o disjuntor 52-1;

f) TRANSMISSORA - Abrir o seccionador 29-8;

g) TRANSMISSORA - Passar a chave de transferência da proteção do disjuntor 52-1 para posição "normal”;

h) TRANSMISSORA - Desbloquear o religamento automático do disjuntor 52-1;

i) TRANSMISSORA - Fechar o seccionador 29-6;

j) TRANSMISSORA - Abrir o seccionador 29-4.

\subsubsection{Medidas analógicas}

As medidas analógicas são importantes para a transmissora e para a distribuidora, tanto para a proteção quanto para a supervisão dos equipamentos. As medidas importantes para a transmissora são:

a) tensões fase-fase das barras da distribuidora: utilizadas para realizar o fechamento sincronizado dos disjuntores das linhas. Neste caso a tensão é enviada diretamente para o IED de controle através de cabos de cobre; e para a operação através do sistema de supervisão;

b) corrente do disjuntor paralelo da distribuidora: utilizada apenas para a supervisão;

c) potências ativa e reativa do transformador do acessante: necessárias para a operação através do sistema de supervisão. 
Para a distribuidora são necessárias para o sistema de supervisão as correntes, potências e tensões das linhas de transmissão. Para a proteção, as correntes das linhas da transmissora são enviadas diretamente no IED diferencial de barras, através de cabos de cobre.

\subsubsection{Estados dos disjuntores e seccionadores}

Os estados ligado/desligado e aberto/fechado dos equipamentos da subestação são importantes para as manobras, tanto as realizadas localmente, quanto as realizadas pelo nível superior (centros de operação remotos dos agentes). Todos os equipamentos dos agentes devem ser supervisionados e as informações trocadas entre os agentes. Os telecomandos só são habilitados nos sistemas supervisórios, tanto locais como remotos, de cada agente, única e exclusivamente para atuação no seu sistema elétrico.

\subsubsection{A interface física para o compartilhamento de informações}

Atualmente os projetos que estão sendo desenvolvidos, utilizam uma interface física para troca de informações entre bays, comumente denominada de Painel de Interface, conforme mostrada nas figuras 10 e 11 .

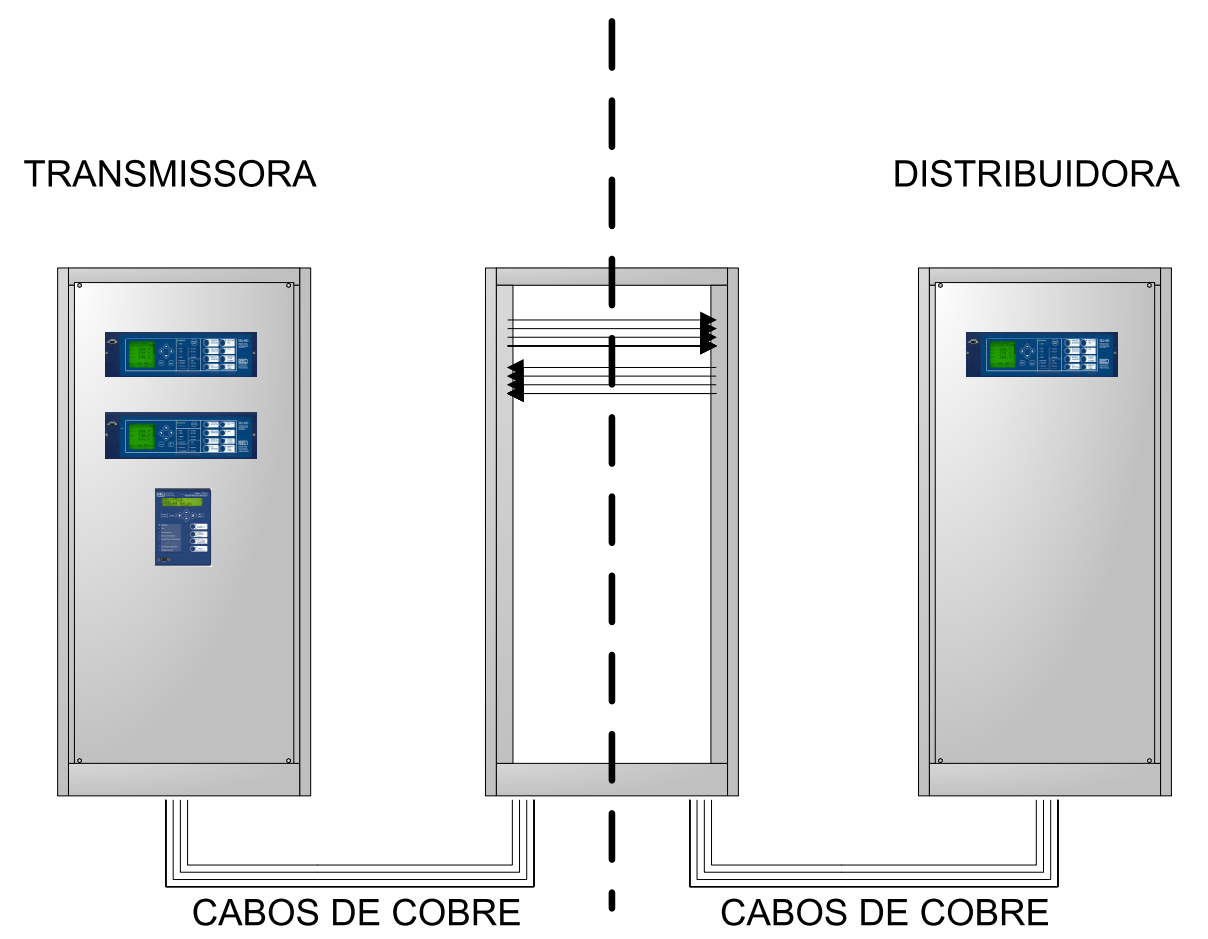

Figura 10 - Interface física de compartilhamento de informações 


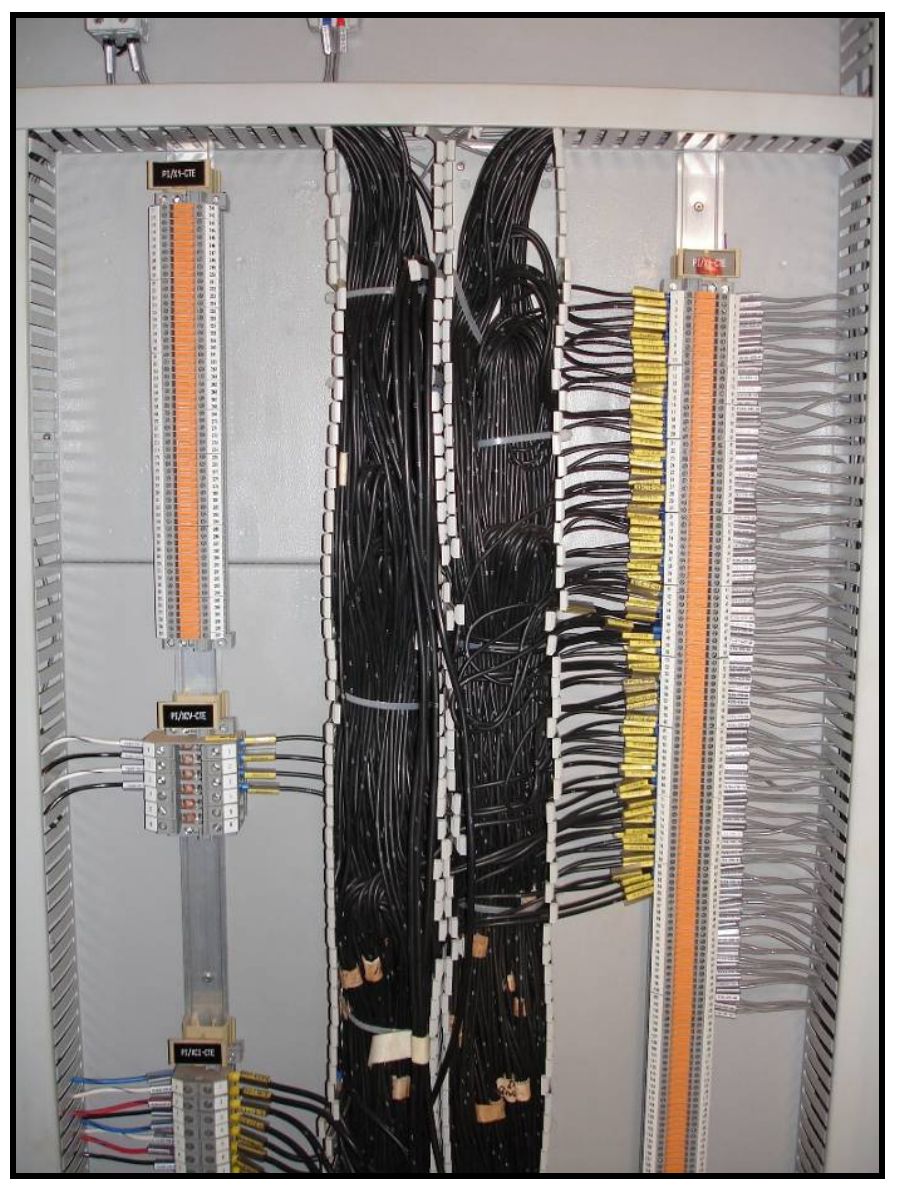

Figura 11 - Painel de interface com pontos de proteção, supervisão e circuitos de tensão e corrente

Para atender às funções de proteção e outras informações para a operação da subestação, a interface física de compartilhamento, utiliza na sua concepção padrão:

a) as saídas digitais dos IEDs, conforme figura 12;

b) aproximadamente seiscentos bornes seccionáveis no painel de interface - lado da distribuidora e lado da transmissora, conforme figuras 13 e 14;

c) aproximadamente dois mil metros de cabos multicondutores, conforme figura 15;

d) aproximadamente trezentos bornes seccionáveis para cada painel dos agentes;

e) relés auxiliares para multiplicar contatos, mostrados nas figuras 16, 17 e 18;

f) aproximadamente seis mil e quinhentos metros de cabo $1,5 \mathrm{~mm}^{2}$;

g) aproximadamente trezentos e cinquenta metros de cabo $2,5 \mathrm{~mm}^{2}$.

Para interligação de todas as informações necessárias entre os agentes são utilizados em torno de dois mil e setecentos pontos de contato e conexões elétricas. 


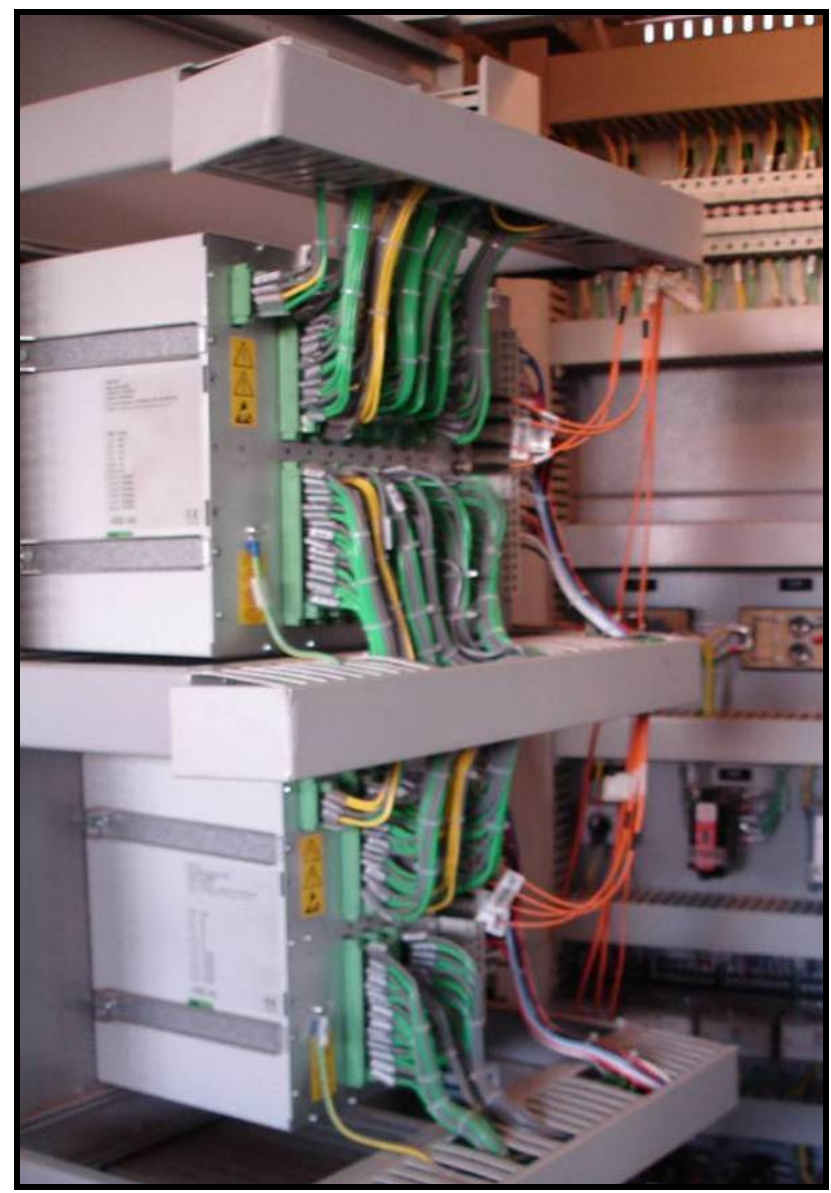

Figura 12 - Quantidade de cabos nas entradas e saídas dos IEDs

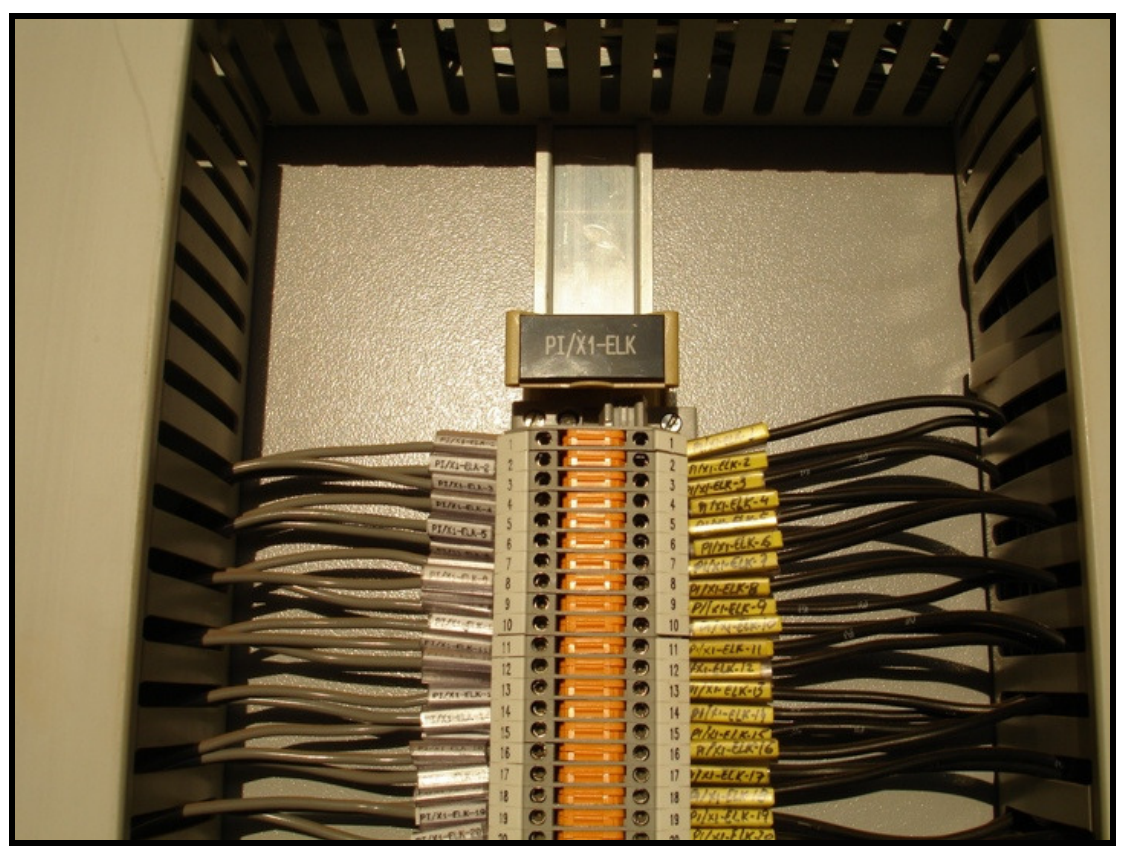

Figura 13 - Detalhe dos bornes seccionáveis no painel de interface lado da distribuidora 


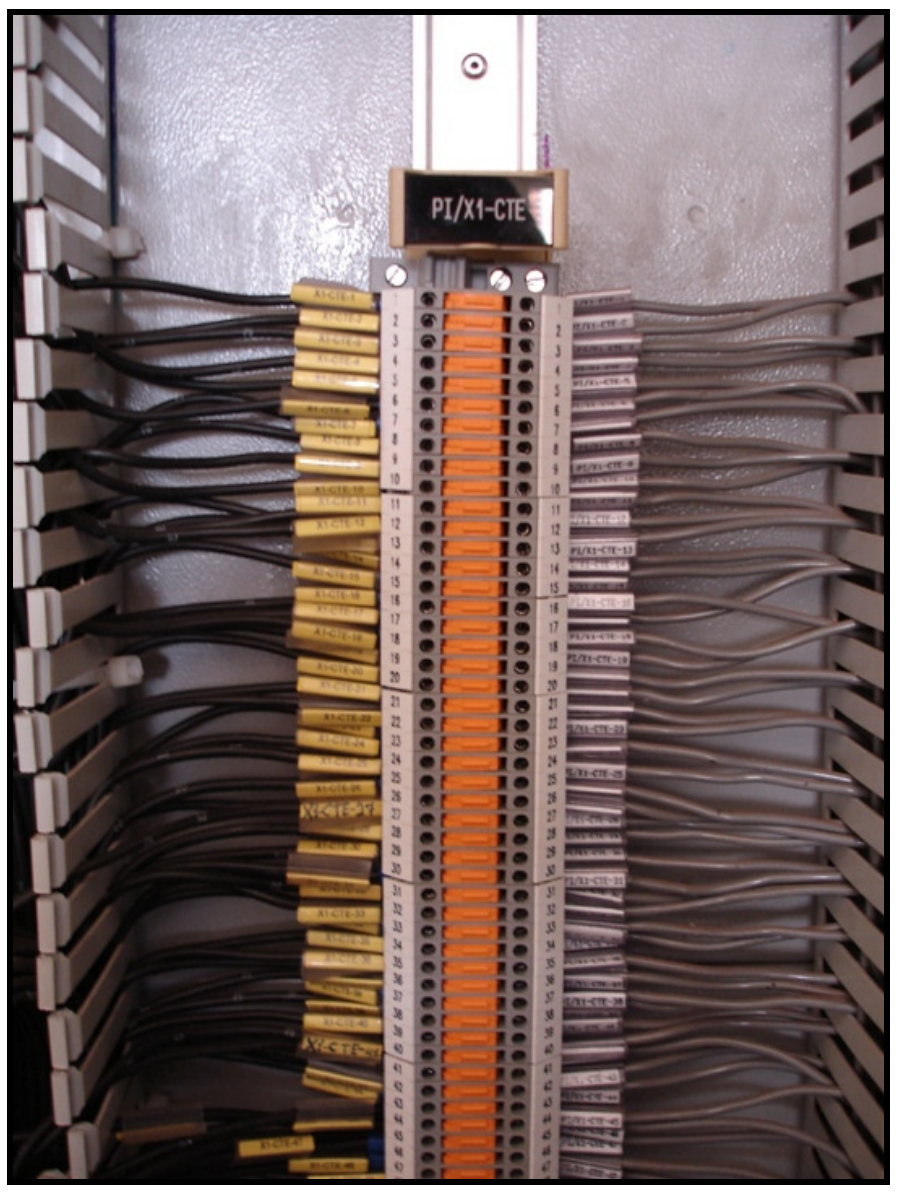

Figura 14 - Detalhe dos bornes seccionáveis no painel de interface lado da transmissora

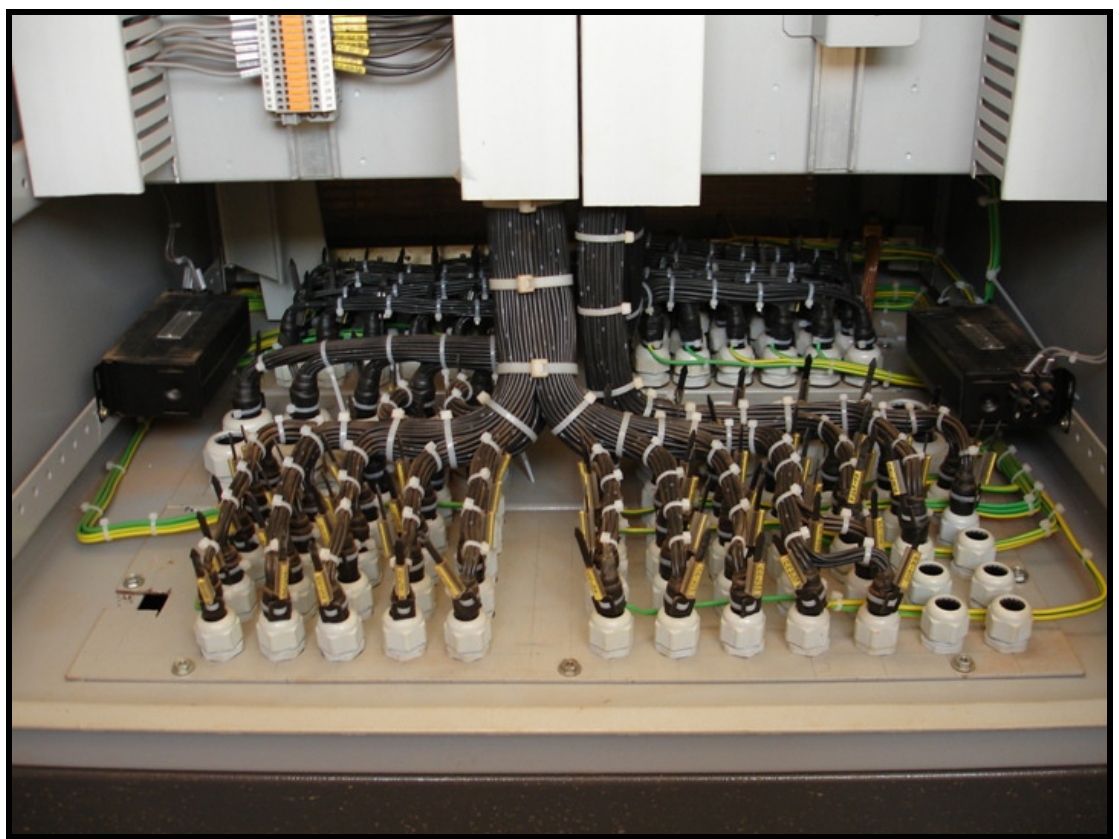

Figura 15 - Quantidade de cabos no painel de interface para efetuar as interligações 


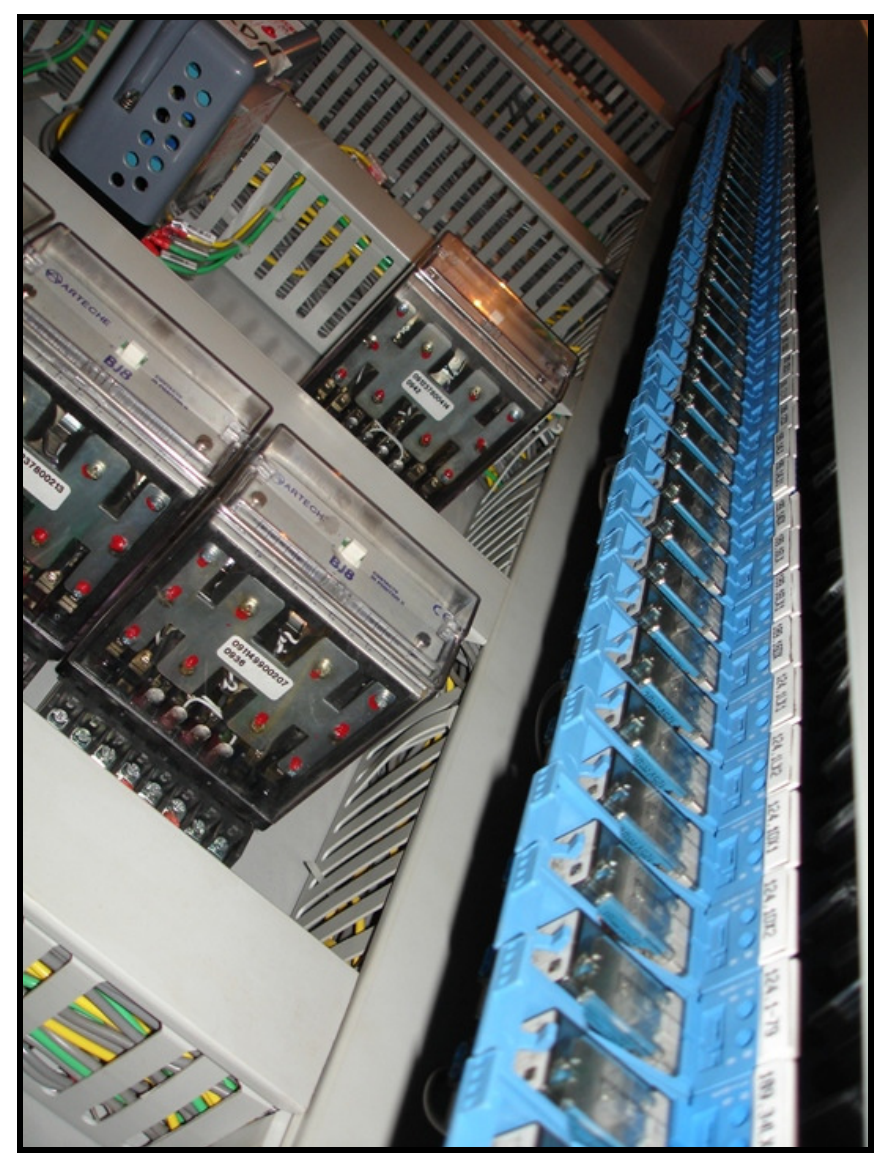

Figura 16 - Quantidade de relés auxiliares nos painéis

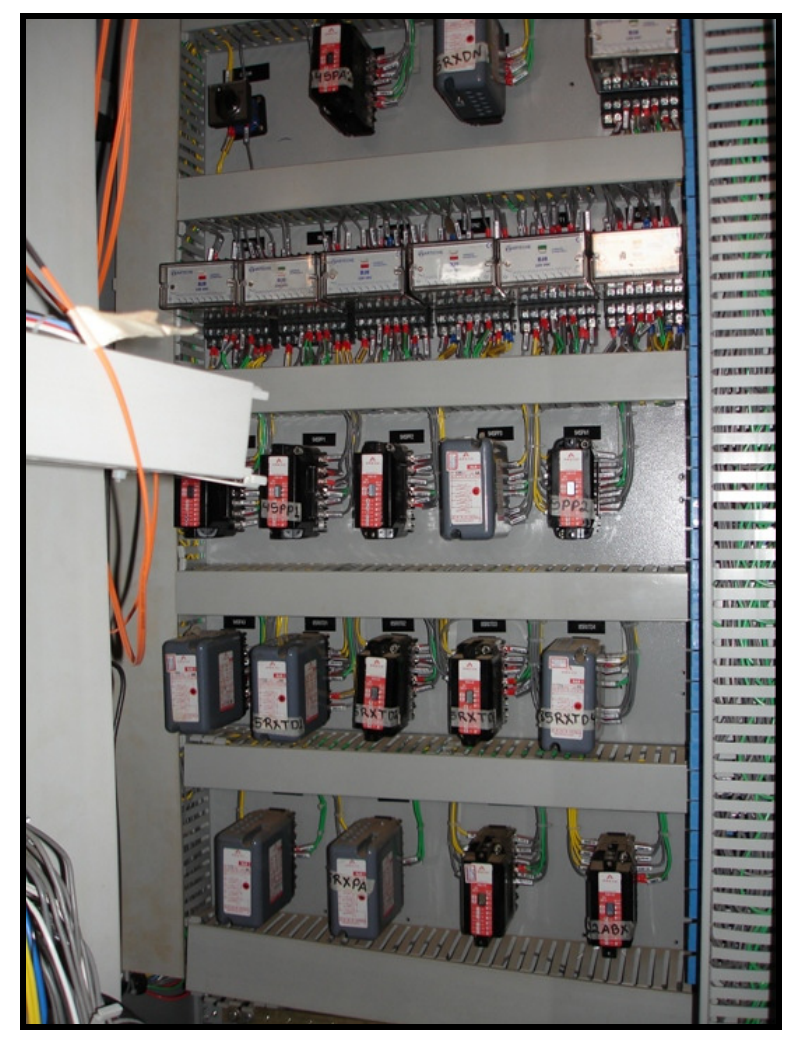

Figura 17 - Quantidade de relés auxiliares no painel de linha de transmissão 


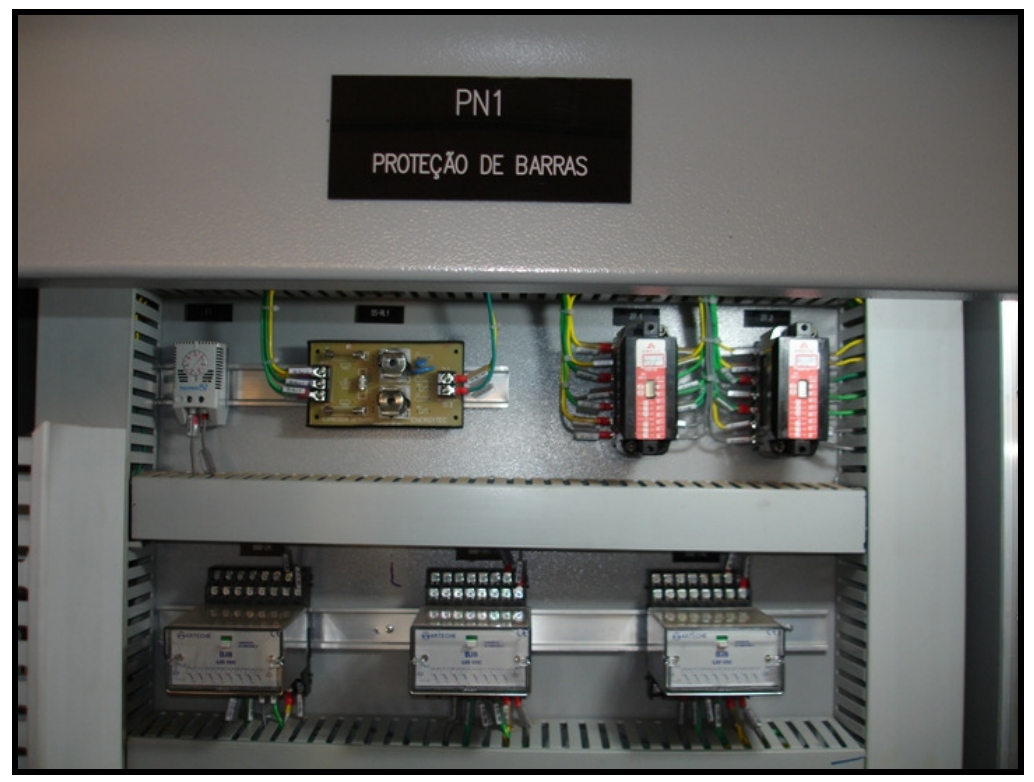

Figura 18 - Relés auxiliares no painel da proteção de barras

A solução baseada na interface física apresenta as seguintes vantagens:

a) fronteira entre as empresas é bem definida por painéis e bornes seccionáveis;

b) isolação de funções de proteção e disparo dos disjuntores através de bornes seccionáveis;

c) utilização de ferramentas auxiliares simples para análise de problemas;

d) equipe técnica das empresas com experiência consolidada;

e) pontos de rápido acesso na localização de problemas.

Todavia, tendo como base de comparação a nova tecnologia digital, algumas desvantagens são relacionadas:

a) utilização de muitos relés auxiliares para multiplicar contatos de funções de interesse da outra empresa;

b) utilização de muitos cabos de cobre para interligação dos painéis das empresas;

c) utilização de fiação para interligar réguas dentro do painel de interface;

d) identificação dos cabos e pontos de conexão efetuadas manualmente o que pode gerar erros ou a perda da identificação ao longo do tempo;

e) número limitado de entradas e saídas dos IEDs; 
f) mais pontos de possíveis falhas e perigo para os circuitos de tensão e corrente dos bays;

g) necessidade de conferência de todas as interligações, o que demanda mais tempo durante a instalação, o comissionamento e a manutenção;

h) possibilidade de oxidação dos contatos elétricos de relés e dos bornes das réguas de interligação, o que aumenta a resistência de contato;

i) vida útil dos contatos das saídas dos relés digitais;

j) vida útil limitada dos relés auxiliares (vida mecânica de $50 \times 10^{6}$ ciclos e vida elétrica a carga nominal de $\left.100 \times 10^{3}\right)$; (24)

k) expansão requer muitas modificações e espaço extra nos painéis e na sala da subestação.

\subsubsection{A interface lógica para o compartilhamento de informações}

Outra forma de se montar essa estrutura para uma subestação compartilhada é utilizar os serviços de comunicação da norma IEC 61850 para a troca de informações através de uma rede ethernet. As redes ethernet de subestações de energia devem de preferência utilizar conexões em fibra óptica para evitar interferências eletromagnéticas do ambiente.

As fibras ópticas são guias de onda constituída por uma parte central, conhecida como núcleo e por uma parte externa denominada de casca. Estas duas partes elementares possuem diferentes índices de refração o que permite que os raios de luz reflitam nas paredes internas e sejam assim transmitidos de uma extremidade à outra, (6) conforme ilustrado na figura 19 abaixo:

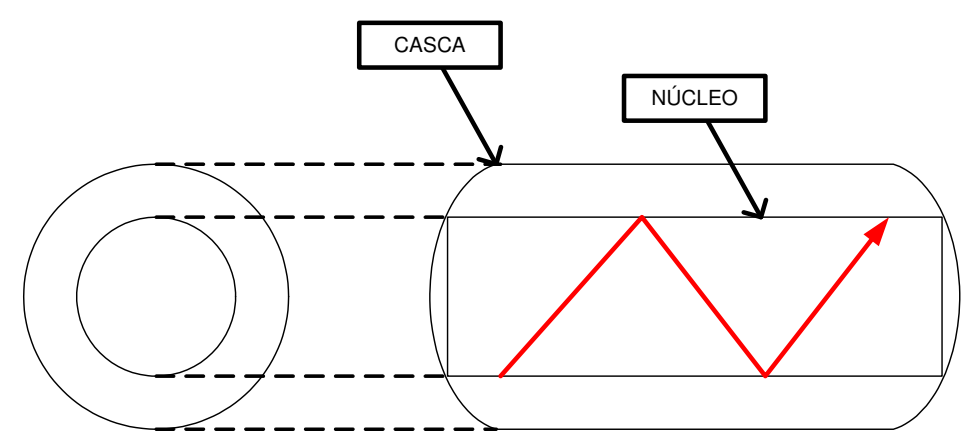

Figura 19 - Princípio da transmissão de luz no interior de uma fibra 
Existem basicamente dois tipos de fibras ópticas disponíveis comercialmente, as fibras multimodo e as fibras monomodo. A multimodo possui baixa largura de banda e é utilizada em conexões de média distância (vinte quilômetros). A monomodo apresenta menor atenuação e largura de banda consideravelmente maior. Sendo portanto conveniente para uso em conexões de grande distância (cinquenta quilômetros). (6)

Apesar de exigirem um cuidado maior na instalação e no manuseio, ao contrário de outras tecnologias, as fibras apresentam as seguintes vantagens:

a) possuem alta largura de banda permitindo tráfego maior de dados;

b) as fibras são dielétricas, não sendo afetadas, portanto, por surtos indutivos ou descargas atmosféricas;

c) são pequenas e leves;

d) apresentam baixas perdas na transmissão.

Por estas principais razões as fibras ópticas estão sendo amplamente utilizadas nas redes internas e externas de comunicação das subestações.

Outro ponto a ser discutido, quando se deseja conectar através de interfaces lógicas duas redes de empresas diferentes em subestações compartilhadas, é a segurança cibernética. Para resolver essa questão, há algumas soluções tecnológicas que serão apresentadas a seguir, e que já são amplamente utilizadas na área de TI.

O objetivo de um sistema de segurança em redes de comunicação é o de minimizar a probabilidade de ataques intencionais ou acidentais, aumentar o tempo necessário para intrusão e diminuir as áreas e redes a serem atacadas. Se os requisitos de segurança digital disponíveis hoje podem ser implementados em sistemas baseados na IEC 61850 sem impactar na performance e nos custos, sua utilização trará significativas vantagens para os sistemas de proteção e controle das subestações. (25)

Para montar uma subestação com equipamentos compartilhados em redes de comunicação alguns requisitos devem ser atendidos:

a) as redes das empresas devem trocar apenas as informações necessárias;

b) todos os acessos devem ser controlados, monitorados e registrados;

c) a fronteira física e digital deve ser clara e bem definida. 
Um dos equipamentos utilizados nesse tipo de arquitetura capazes de atender aos requisitos acima, são os switches gerenciáveis fabricados para o ambiente das subestações. Em relação aos switches convencionais esses switches gerenciáveis disponibilizam os seguintes recursos:

a) interface para usuário via RS232, Telnet, Hypertext Transfer Protocol (HTTP);

b) facilidades de monitoração do estado de funcionamento, estatísticas, e localização de defeitos através do Simple Network Management Protocol (SNMP);

c) recurso de Rapid Spanning Tree Protocol (RSTP) previsto na norma IEEE 802.1w, para reconfiguração rápida quando utilizando arquiteturas em anel;

d) Quality of Service (QoS) da norma IEEE 802.1p;

e) requisitos de construção semelhante aos IEDs com destaque para:

i. imunidade às interferências eletromagnéticas e à surtos elétricos;

ii. norma IEC 61850-3;

iii. faixa de temperatura de operação de $-40^{\circ} \mathrm{C}$ à $+85^{\circ} \mathrm{C}$ sem ventiladores internos;

iv. gabinetes em aço galvanizado.

No aspecto de segurança, a utilização de switches gerenciáveis fornece quatro principais características de segurança para a rede:

a) segurança de gerenciamento: habilidade de monitorar e/ou configurar os switches (Secure Socket Layer - SSL ou Secure Shell - SSH);

b) segurança nas portas: habilidade de negar acesso à rede (IEEE 802.1x);

c) limitação de taxa de transmissão: habilidade de limitar tráfego de entrada e saída;

d) Virtual Local Area Network - (VLAN) (IEEE 802.1Q): habilidade de segregar a rede e consequentemente o tráfego.

Virtual Local Area Networks ou redes virtuais locais é definido pela norma IEEE 802.1Q como a concatenação de LANs individuais interconectadas através de um switch gerenciável. Este switch é capaz de reconhecer, inserir ou remover pacotes com tags de VLAN, estabelecendo desta forma a comunicação entre equipamentos através de canais dedicados, como se estivessem em um mesmo domínio de broadcast, independentemente de sua localização física. Na figura 20, há um exemplo de isolamento das redes de duas empresas através do uso de duas VLANs configuradas em um mesmo switch. 


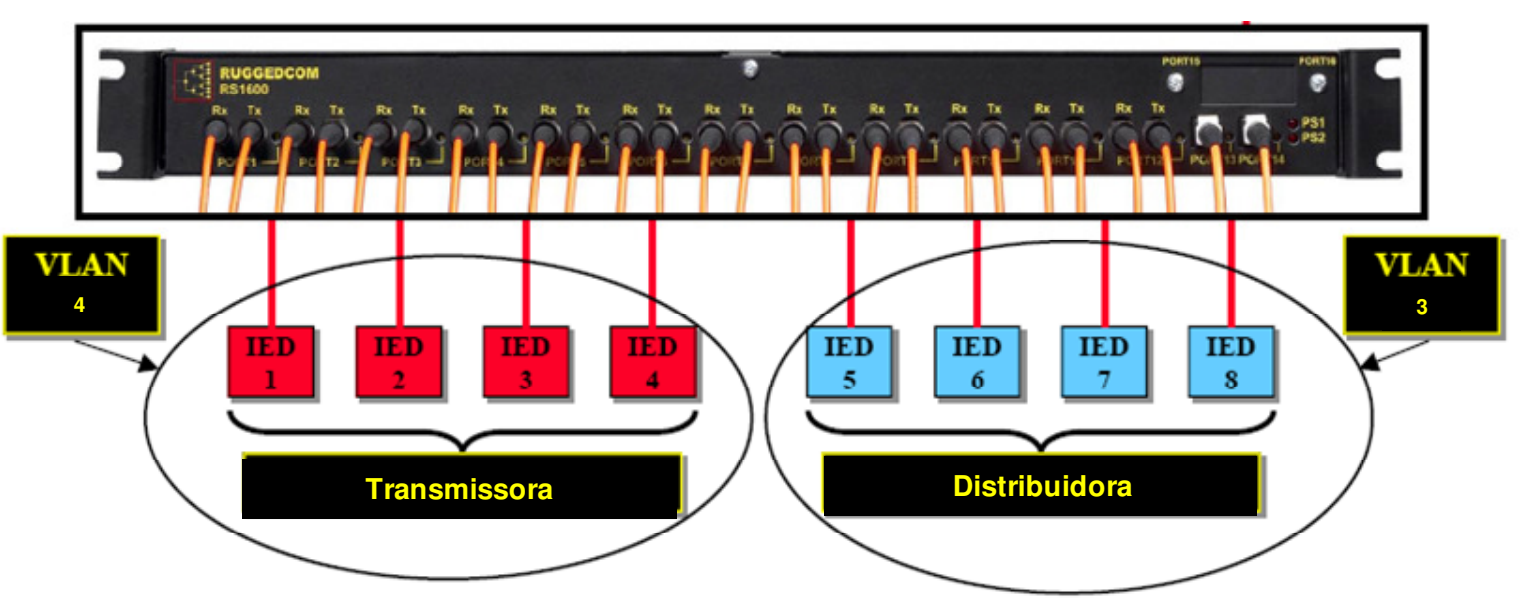

Figura 20 - Exemplo de segmentação de uma rede através de VLANs

A figura 21 ilustra os pacotes de dados com as tags de VLAN. As tags carregam a VLAN Identification (VID), que é um número de doze bits, hexadecimal entre 000 e FFF, mais a informação de prioridade dos pacotes de dados, definida pela norma IEEE 802.1p.

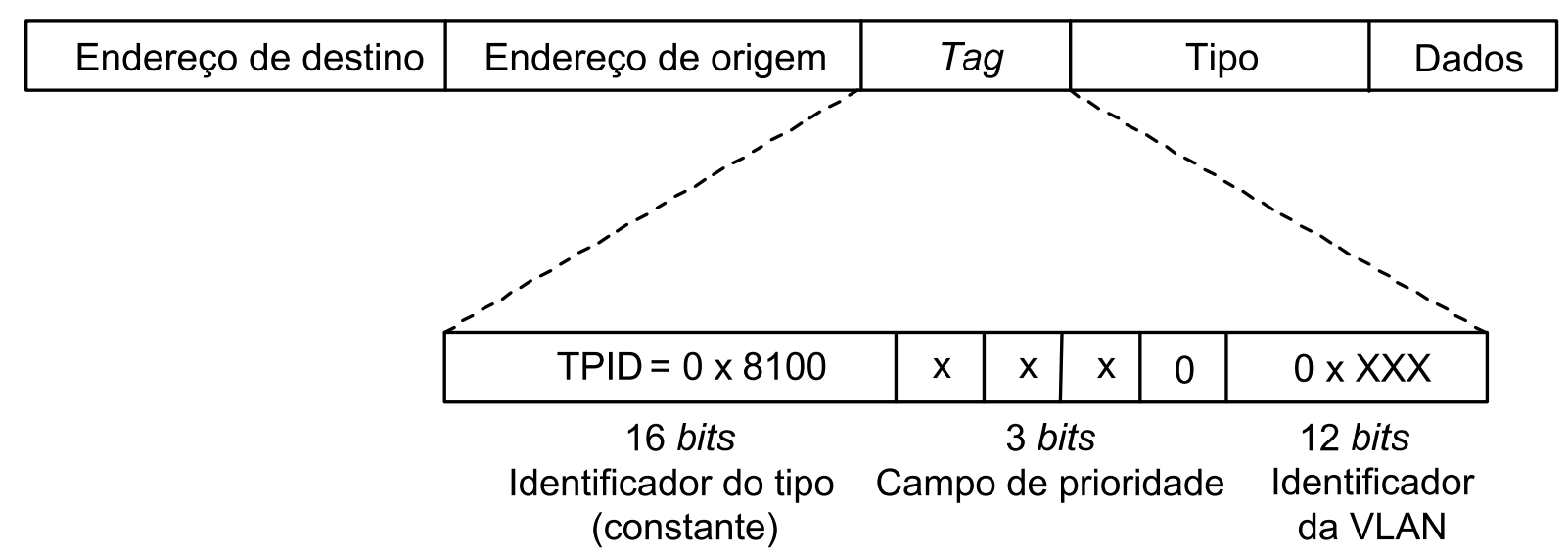

Figura 21 - Identificação do identificador de VLAN no pacote de dados

Algumas VIDs são específicas:

a) $\quad$ VID = 0: indica que o pacote tem apenas classificação de prioridade;

b) VID = 1: (padrão) usada para gerenciamento;

c) VID = FFF: (reservada) esta VID não deve ser configurada.

Outra forma de segurança é a baseada em filtros por endereços MAC, a qual é a habilidade de alguns switches de configurar que apenas alguns equipamentos, com a declaração dos seus endereços de MAC, possam comunicar por determinada porta. 
Endereços MAC são identificadores únicos que possibilitam as interfaces dos equipamentos de se conectarem em rede. Utilizado pela camada 2 do modelo OSI, este identificador é composto de quarenta e oito bits declarados em hexadecimal onde os três primeiros conjuntos identificam o fabricante e os três últimos identificam o equipamento, conforme nos exemplos mostrados abaixo:

00:30:A7:01:E2:11 = endereço MAC unicast

00:30:A7 = Schweitzer Engineering Laboratories

01:E2:11 = identificador único

00:02:B3:87:00:77 = endereço MAC unicast

00:02:B3 = Intel Corporation

87:00:77 = identificador único

Como nos exemplos anteriores, os endereços MAC podem ser, conforme definido pelo IEEE, do tipo:

a) unicast: endereço único utilizado para as interfaces físicas dos equipamentos;

b) multicast: endereço utilizado para encaminhar pacotes somente as interfaces configuradas para recebimento;

c) broadcast: endereço utilizado para encaminhar pacotes a todas as interfaces de rede conectadas.

\subsubsection{Considerações finais sobre as interfaces de compartilhamento}

Nos projetos utilizando as interfaces lógicas não é utilizado o painel de interface, portanto não são utilizados relés auxiliares, cabos de cobre para interligação interna e entre painéis nem réguas borne. Desta forma as vantagens deste tipo de interface são:

a) custo menor devido a quantidade menor de equipamentos auxiliares;

b) comissionamento mais rápido;

c) menos pontos de falha.

A longo prazo os principais benefícios da interface lógica podem se resumir em: (6)

a) menor custo na operação através do acesso remoto até o nível do bay; 
b) maior disponibilidade do sistema devido ao menor tempo de interrupção necessário para manutenção e maior agilidade na identificação de faltas;

c) maior tempo de vida de equipamentos através de manutenções programadas e análise de dados estatísticos;

d) ampliações na subestação requerem menos intervenções e adaptações nos sistemas existentes.

Atualmente algumas empresas ainda enfrentam resistência na implementação total da interface lógica, pois:

a) necessita de equipe de projetos capacitada tanto na área de proteção como na área de redes de comunicação;

b) ainda existem poucos profissionais de manutenção com domínio nesta nova plataforma. 


\section{Avaliação da solução baseada na interface lógica para compartilhamento de informações entre os agentes}

Este capítulo tem por objetivo demonstrar que, conforme discutido no capítulo anterior, a utilização da interface lógica, seguindo os padrões da norma IEC 61850 e outros padrões de segurança cibernética, para interligar duas redes de empresas distintas, pode ser um avanço nos projetos de subestações compartilhadas, quebrando de vez paradigmas sobre a segurança de funcionamento e operação.

A avaliação da solução proposta para compartilhamento de informações, apresentada neste capítulo, foi baseada em testes em laboratório, utilizando uma plataforma simplificada de comunicação. Essa avaliação procurou identificar quais são as possíveis falhas de segurança e de operação.

A arquitetura de testes utilizada nos ensaios de laboratório é mostrada nas figuras 22 e 23 . Essa arquitetura simula a troca de informações entre os IEDs dos agentes configurados em diferentes redes lógicas, pois cada empresa pode adotar critérios segundo suas normas internas de TI.

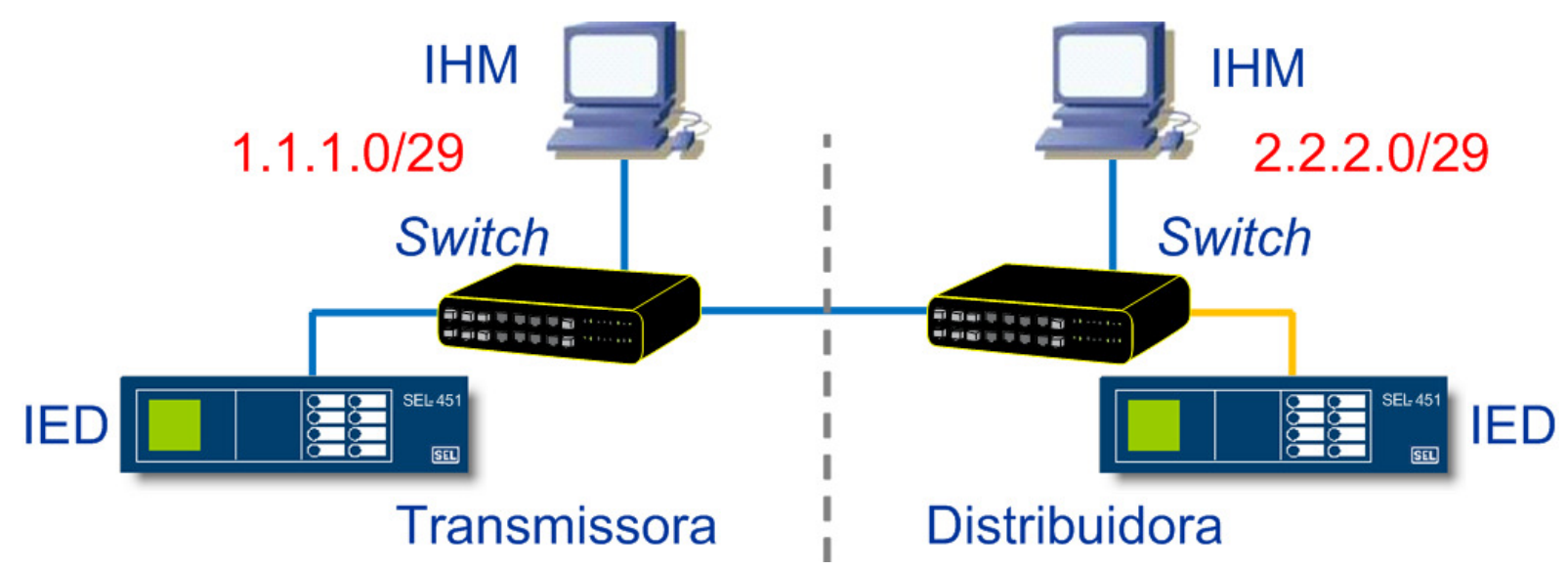

Figura 22 - Arquitetura de testes 


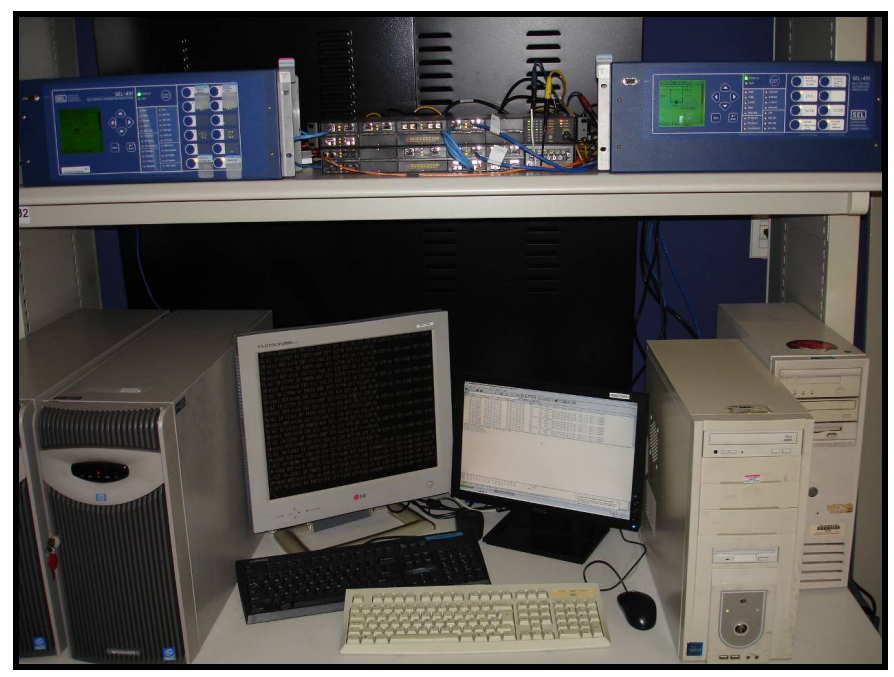

Figura 23 - Arquitetura de testes montada em laboratório

O laboratório foi montado em ambiente climatizado a $22^{\circ}$ Celsius e controlado por alarmes de incêndio e câmeras de vídeo, e foi composto dos seguintes equipamentos:

a) um IED da SEL, modelo 451-5. Part Number 451-5-615XC0X4H344XX1, Firmware 451-5-R303-V0-Z013012-D20101221;

b) um IED da SEL modelo 451-4. Part Number 451-4-615A2B4H224XXXX, Firmware 451-4-R123-V0-Z011011-D20090930;

c) um switch RUGGEDCOM modelo RSG2100. Part Number RSG2100-R-RMHIXXX-FX01-FX01-XXXXXXXX-CG01-XXXXX-TX01-T;

d) um switch RUGGEDCOM modelo RSG2100. Part Number RSG2100-F-RM-HIXXXTX01-TX01-TX01-XXXXFG02-XXXXX-TX01-X;

e) quatro cabos Unshielded Twisted Pair (UTP) com conectores RJ-45;

f) um cabo óptico com conectores tipo Straight Tip (ST);

g) um cabo serial com conectores DB-9 e RJ-45 para acesso inicial à configuração dos switches;

h) um cabo serial cruzado com conectores DB-9 para acesso inicial à configuração dos IEDs;

i) dois computadores com Windows XP Service Pack 2; 
j) uma interface de rede para computador da marca Intel modelo $\mathrm{PRO} / 100+$ com disponibilidade para configuração de VLANs através do Intel Advanced Network Services Protocol;

k) uma interface de rede para computador da marca Intel modelo PRO/1000 MT com disponibilidade para configuração de VLANs através do Intel Advanced Network Services Protocol.

Nessa plataforma foram utilizados os seguintes programas computacionais:

a) Ethereal MMS versão 0.10.12: programa gratuito para análise de protocolos nas redes Ethernet;

b) SEL-5032 Acselerator Architect versão 1.1.98.0: programa da SEL, para configurar a arquitetura dos IEDs em subestações com IEC 61850. Cria e mapeia as mensagens GOOSE, utiliza reports pré-definidos, cria e edita bases de dados e lê arquivos SCD, ICD e CID;

c) SEL-5030 Acselerator Quickset versão 5.0.1.1: programa da SEL para configurar lógicas e os ajustes de proteção dos IEDs;

d) AX-S4 MMS Object Explorer: programa de demonstração da SISCO utilizado para testar a comunicação cliente-servidor da norma IEC 61850;

e) ReLab OPC Console 2.2.1.2: programa utilizado para visualizar o MMS;

f) Internet Explorer 6: programa para acessar a interface Web de configuração dos switches.

\subsection{Implantação da arquitetura de testes}

Para a arquitetura simplificada montada em laboratório, foram atribuídos IPs diferentes para as empresas de forma a manter um primeiro isolamento das redes. Além dos IPs, e das sub redes limitadas a seis endereços de host, foi implementada a segurança por VLANs, supondo que ambas as empresas utilizam este recurso em suas redes, e os filtros de endereço MAC nos switches, conforme mostrado na figura 24. 


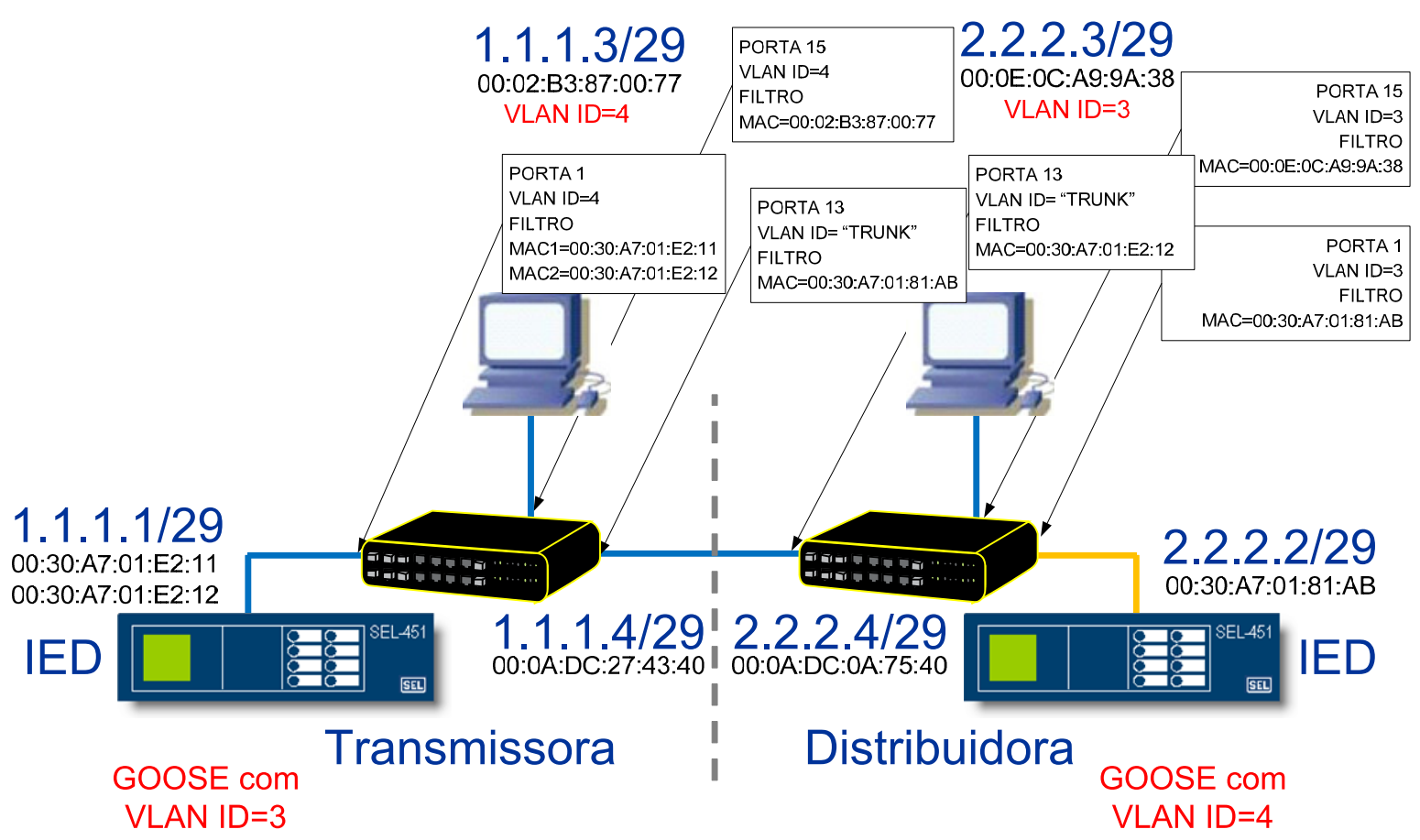

Figura 24 - Portas, IPs e VLANs configuradas para a arquitetura de testes

\subsubsection{Configuração dos switches}

Foram utilizados no laboratório dois switches gerenciáveis da marca RUGGEDCOM por atenderem aos requisitos das normas IEC 61850 e da North American Electric Reliability Corporation (NERC) Critical Infrastructure Protection (CIP).

Uma das características desse tipo de switch é a configuração de VLANs nas portas de comunicação. Para a RUGGEDCOM as portas que utilizam VLAN podem ser classificadas por tipo:

a) edge: configuração que atende à um único equipamento conectado, computador ou IED por exemplo. Apenas uma VLAN, denominada de nativa, pode então ser configurada;

b) trunk: configuração que suporta todas as VLANs configuradas no switch. Utilizada para conexões com outros switches ou computadores.

Na tabela 2 são mostradas as características destes dois tipos de classificação das portas. (26) 
Tabela 2 - Tipo de portas do switch

\begin{tabular}{|c|c|c|c|}
\hline $\begin{array}{l}\text { Tipo da } \\
\text { porta }\end{array}$ & $\begin{array}{c}\text { VLANs } \\
\text { suportadas }\end{array}$ & $\begin{array}{c}\text { Parâmetro da } \\
\text { porta }\end{array}$ & Uso \\
\hline \multirow[t]{2}{*}{ Edge } & 1 (nativa) & Untagged & $\begin{array}{c}\text { Se o switch estiver com o } \\
\text { reconhecimento de VLANs desabilitado } \\
\text { todos os pacotes são recebidos e } \\
\text { transmitidos sem verificação }\end{array}$ \\
\hline & & Tagged & $\begin{array}{l}\text { Se o switch estiver com o } \\
\text { reconhecimento de VLANs habilitado o } \\
\text { tráfego é forçado a uma só VLAN }\end{array}$ \\
\hline Trunk & Todas configuradas & $\begin{array}{l}\text { Tagged ou } \\
\text { Untagged }\end{array}$ & $\begin{array}{c}\text { Conexões entre switches e conexões } \\
\text { com equipamentos que suportam } \\
\text { múltiplas VLANs }\end{array}$ \\
\hline
\end{tabular}

Desta forma dependendo do tipo da porta, são definidas algumas regras de egresso e ingresso conforme as tabelas 3 e 4 abaixo: (26)

a) Regras de egresso: são válidas para todos os pacotes que saem das portas do switch;

Tabela 3 - Regras de egresso das portas do switch

\begin{tabular}{|c|c|c|c|}
\hline & $\begin{array}{c}\text { Pacote enviado pela } \\
\text { porta com a VLAN } \\
\text { nativa }\end{array}$ & $\begin{array}{l}\text { Pacote enviado com } \\
\text { uma outra VLAN } \\
\text { e porta é membro da } \\
\text { VLAN }\end{array}$ & $\begin{array}{c}\text { Pacote enviado com } \\
\text { uma outra VLAN e } \\
\text { porta não é membro } \\
\text { da VLAN }\end{array}$ \\
\hline Porta Edge & $\begin{array}{l}\text { Se o parâmetro da } \\
\text { porta for tagged o } \\
\text { switch adiciona o tag }\end{array}$ & O pacote é descartado & O pacote é descartado \\
\hline Porta Trunk & $\begin{array}{l}\text { porta. Se for untagged, } \\
\text { não. }\end{array}$ & Pacote Tagged & Descartado \\
\hline
\end{tabular}


b) Regras de ingresso: são válidas para todos os pacotes que entram nas portas do switch. As ações não dependem das configurações da porta.

Tabela 4 - Regras de ingresso das portas do switch

\begin{tabular}{cccc} 
Pacote recebido & Untagged & $\begin{array}{c}\text { Priority Tag } \\
\text { VLAN ID=0 }\end{array}$ & Tagged \\
\hline VLAN ID associada ao pacote & VLAN ID da & VLAN ID da & VLAN ID do \\
& porta & porta & pacote \\
\hline Pacote descartado se está com tag ou não & Não & Não & Sim \\
\hline Pacote descartado se a VLAN ID do pacote não & Não se aplica & Não se aplica & Não \\
\hline está declarada no switch & & Não se aplica & \\
\hline pacote descartado se a porta de ingresso não & Não se aplica & & \\
\hline
\end{tabular}

Pela última característica mostrada na tabela 4, onde um pacote é recebido com tag diferente da VLAN configurada na porta de ingresso, foi possível enviar mensagens GOOSE para uma rede de VLAN ID = 4, estando em uma rede de VLAN ID = 3.

Na figura 25 está exemplificada a configuração utilizada nas portas do switch da transmissora:

a) porta do IED: VLAN ID = 4 e untagged

b) porta do computador: VLAN ID $=4$ e tagged

Como a interface de rede do computador está configurada com VLAN ID $=4$, todos os pacotes que saem do switch devem possuir tags para ingressar no computador, por isso a configuração tagged na porta do switch.

Entretanto a interface de rede do IED não possui tal configuração devendo a porta de conexão do switch ser configurada como untagged. Neste caso os pacotes saem do switch sem tags. 


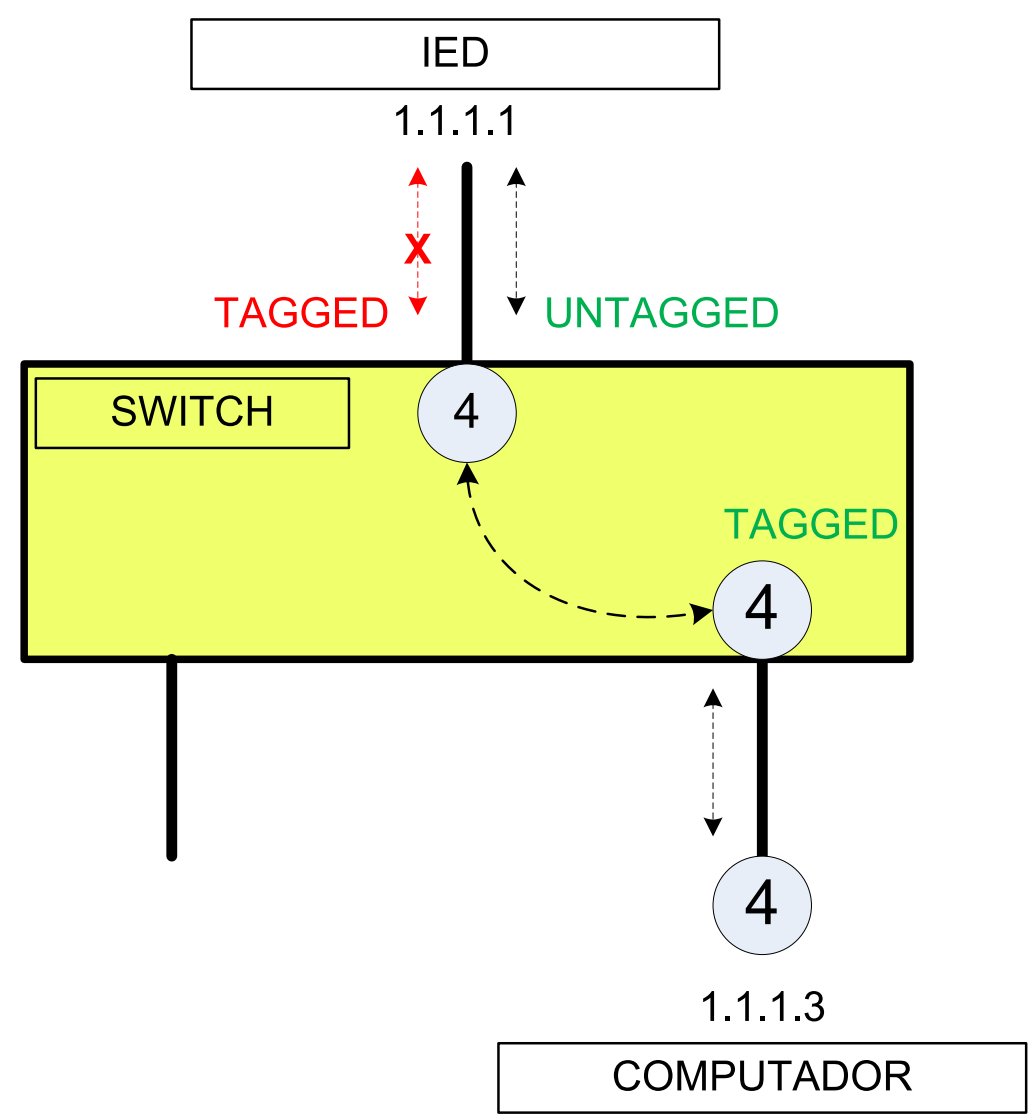

Figura 25 - Característica da configuração de VLANs nas portas do switch

Como mencionado, a RUGGEDCOM atende em seus switches alguns dos requisitos de segurança da NERC CIP. Outras soluções são disponibilizadas por ela em complemento aos requisitos de segurança.

O objetivo das recomendações de segurança da NERC é garantir que todas as entidades responsáveis pela confiabilidade dos sistemas elétricos da América do Norte identifiquem e protejam seus sistemas críticos de possíveis falhas e ameaças que poderiam afetar a confiabilidade dos sistemas elétricos em massa. O padrão de segurança cibernética da NERC foi originalmente chamado NERC 1300, mas mudou para oito padrões distintos, do CIP-002 a CIP-009. Conforme resumido na tabela 5, essas recomendações contêm definições, políticas, apresentação de relatórios e questões relacionadas à segurança pessoal, eletrônica e a física. 
Tabela 5 - Normas NERC CIP de segurança cibernética

\begin{tabular}{lcc}
\hline Nova norma & Título & Antiga norma \\
\hline CIP-002-4 & Critical Cyber Assets & 1302 \\
\hline CIP-003-4 & Security Management Controls & 1301 \\
\hline CIP-004-4 & Personnel and Training & 1303 \\
\hline CIP-005-4 & Electronic Security & 1304 \\
\hline CIP-006-4 & Physical Security & 1305 \\
\hline CIP-007-4 & Systems Security Management & 1306 \\
\hline CIP-008-4 & Incident Reporting and Response Planning & 1307 \\
\hline CIP-009-4 & Recovery Plans & 1308
\end{tabular}

As diretrizes da NERC estão sendo utilizadas como referência para a implantação de sistemas seguros nas subestações também em outros países.

Finalizando a configuração dos switches, foram desativadas as demais portas não utilizadas e alteradas também as senhas originais de fábrica para acesso à configuração dos switches.

Deve-se atentar para toda alteração que vier acontecer na arquitetura de rede montada na subestação, pois a substituição de um equipamento por outro implica mudanças de configuração das portas, principalmente nos filtros por endereço MAC.

\subsubsection{Configuração dos IEDs}

O IED 451-5 da SEL apresenta uma característica no funcionamento de suas duas portas de comunicação, a qual permite que elas trabalharem de três formas diferentes, utilizando apenas um endereço IP:

a) fixed: apenas uma das duas portas fica ativa no IED, mantendo a outra desativada;

b) failover: trabalha com as duas portas, sendo uma definida como primária. Somente haverá comutação para a porta secundária se houver falha na primária e depois de decorrido o tempo de ajuste;

c) switched: trabalha com as duas portas ativas mantendo uma configuração de switch para implementação com redes em anel;

O outro IED utilizado, modelo 451-4 da SEL, possui também duas portas de comunicação ethernet, porém dispõe apenas da característica de failover, isto é, definida uma porta 
primária, o chaveamento ocorrerá somente quando não houver mais comunicação por esta porta e depois de transcorrido um período de tempo pré ajustado.

Foram desativadas as portas que não estavam sendo utilizadas em ambos os IEDs de forma a evitar conexões indevidas de outros equipamentos à arquitetura.

Outra particularidade do IED 451-5 detectada nos testes foi a forma que o endereço MAC físico das portas se comporta. Cada porta ethernet do IED possui um endereço MAC, conforme verificado pelo comando mac durante acesso ao IED via telnet:

a) porta $5 \mathrm{C}=00: 30: \mathrm{A} 7: 01: \mathrm{E} 2: 11$

b) porta $5 \mathrm{D}=00: 30: \mathrm{A} 7: 01: \mathrm{E} 2: 12$

Neste primeiro teste mostrado na figura 26, apenas a porta 5D está conectada ao switch. Corretamente os pacotes visualizados pelo programa Ethereal mostram o MAC físico da porta 5D como a fonte do envio do GOOSE.

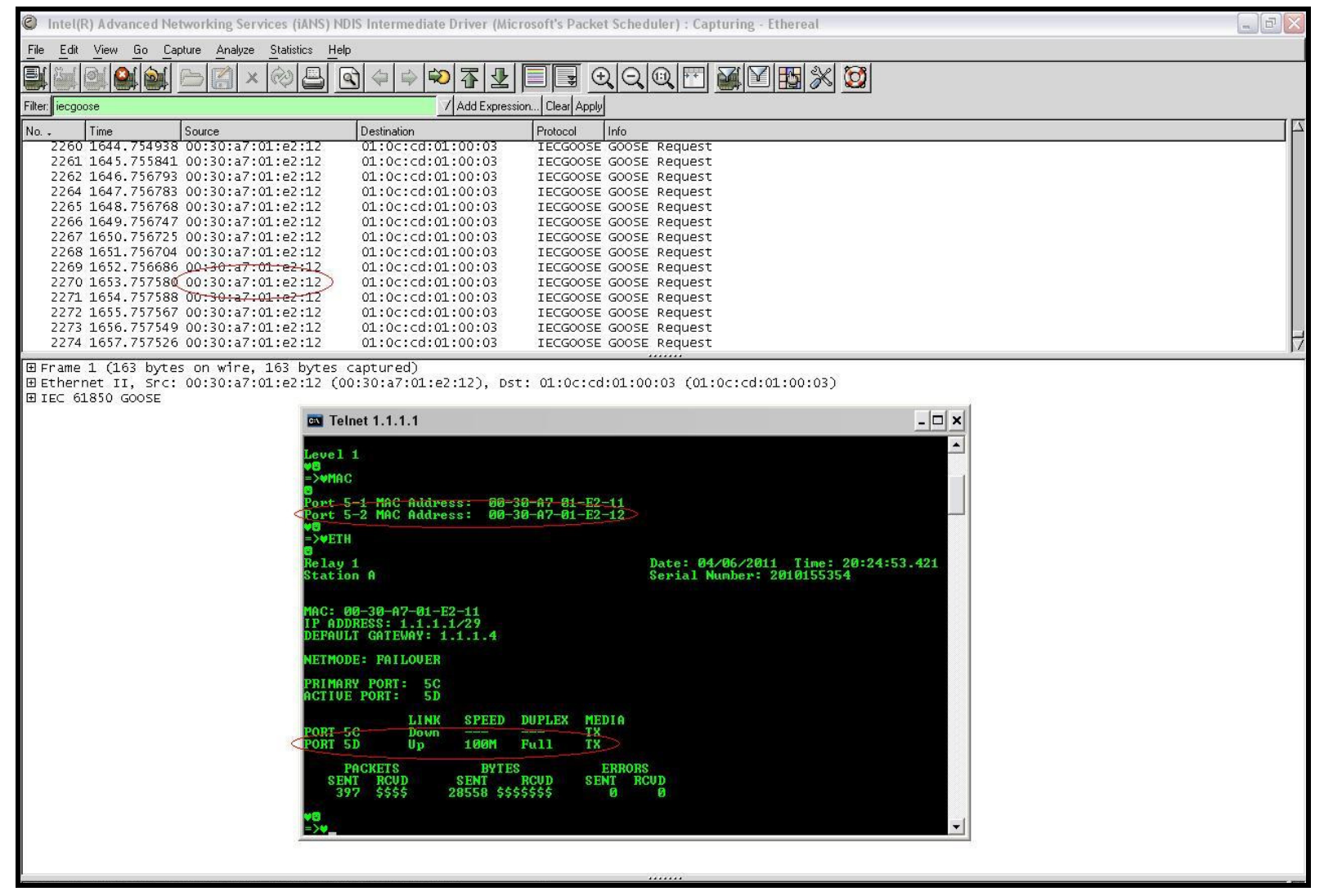

Figura 26 - Endereços MAC das portas e o envio de GOOSE pela porta 5D

No segundo teste mostrado agora na figura 27, apenas a porta 5C está conectada e os pacotes continuam mostrando o MAC físico da porta 5D como a fonte de envio do GOOSE. Isto 
acontece em todas as configurações de porta disponíveis no SEL 451-5, fixed, failover ou switched.

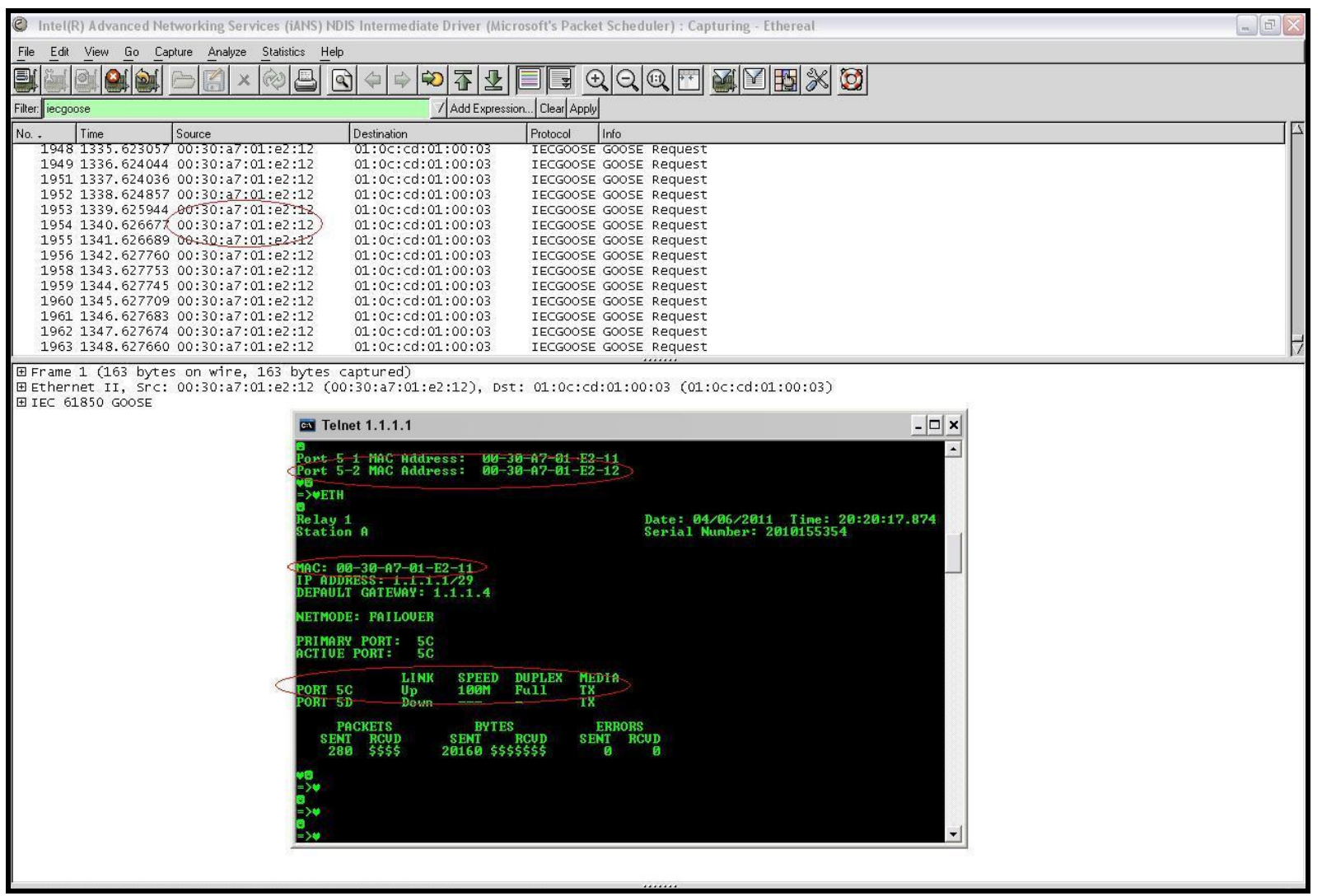

Figura 27 - Porta 5C ativa e o envio de GOOSE permanece com o endereço MAC da 5D

Já no terceiro teste, com apenas a porta 5D ativa foi executado o comando ping. Diferentemente, os pacotes mostram o MAC físico da porta $5 \mathrm{C}$, conforme pode ser visto na figura 28. 


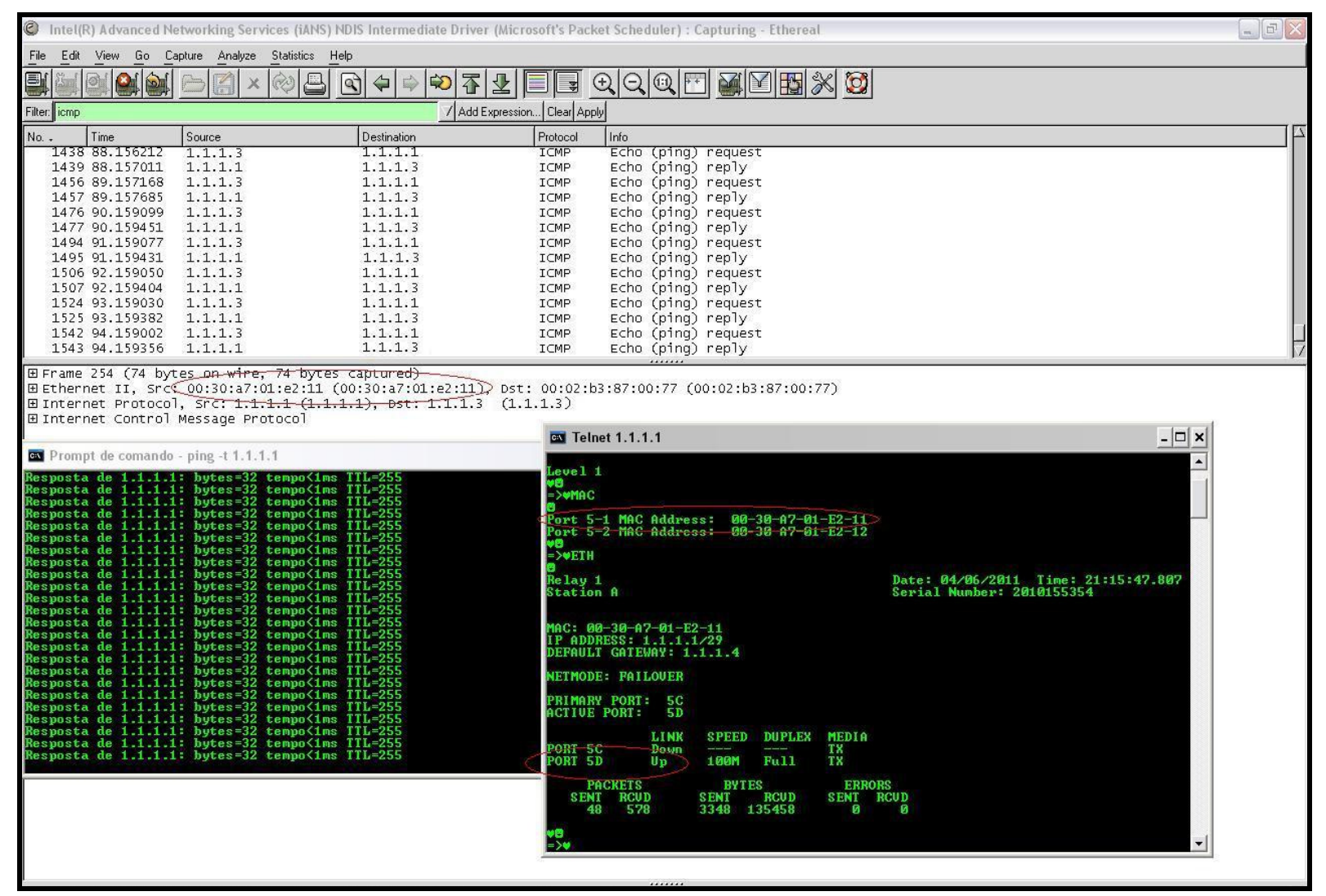

Figura 28 - Teste de ping com apenas uma porta ativa no IED

Estes testes demonstraram que as portas ethernet do SEL-451-5 funcionam como um switch não gerenciável, tendo cada porta um endereço MAC diferente. Como estratégia para segregação dos níveis 2 e 3 de rede, a SEL adotou esse comportamento, onde o GOOSE utilizará o MAC da segunda porta independente da configuração ou estado da mesma. Já para os demais protocolos como MMS ou Internet Control Message Protocol (ICMP), o MAC será sempre o da primeira porta. Desta forma é preciso configurar os filtros de endereços MAC nas portas do RUGGEDCOM com os dois endereços, 00:30:A7:01:E2:12 para troca de GOOSEs e 00:30:A7:01:E2:11 para acesso à parametrização e configuração dos IEDs, conforme mostrado na figura 29. 


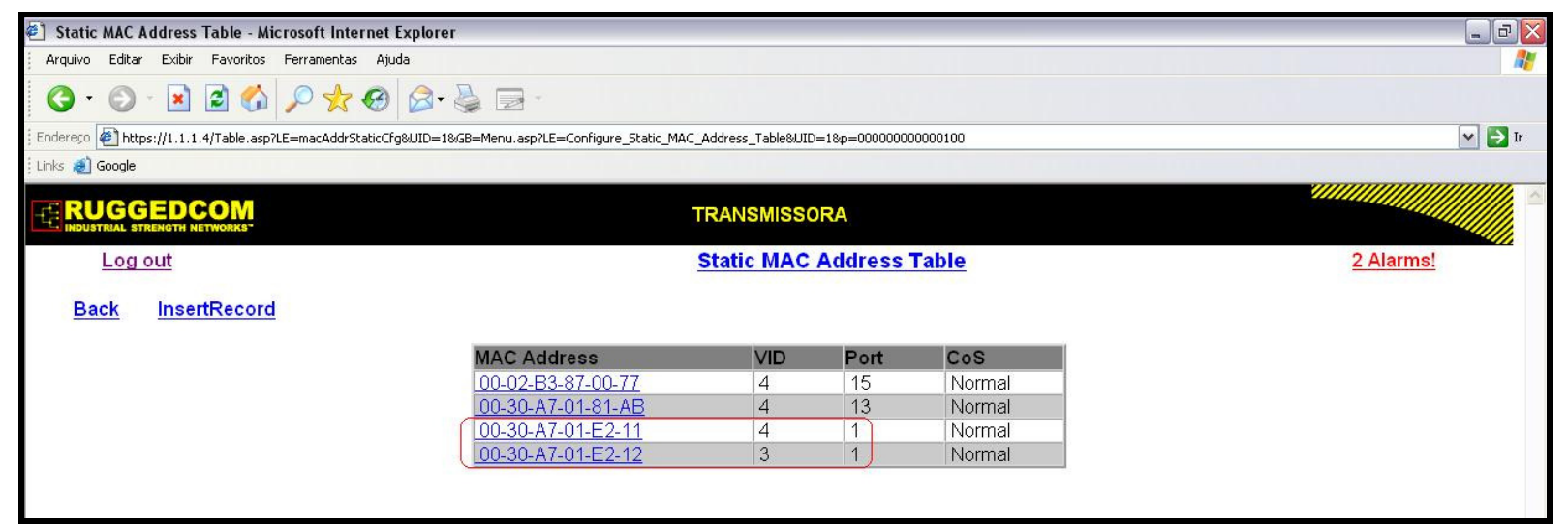

Figura 29 - Configuração do filtro por endereço MAC nas portas do switch

O endereço 00:30:A7:01:E2:11 foi configurado com a VLAN = 4 para poder comunicar com o computador da transmissora, que tinha interface nesta VLAN; já o endereço 00:30:A7:01:E2:12, está com a VLAN = 3 para poder transmitir o GOOSE para o IED da distribuidora.

Por fim foram alteradas as senhas originais de fábrica para acesso à configuração dos IEDs.

\subsubsection{Configuração das interfaces de rede dos computadores}

Uma forma de isolar e priorizar o tráfego de rede entre a comunicação dos computadores e os sistemas de proteção, foi utilizar placas de rede na marca Intel que dispõem de configuração de VLANs. A placa de rede do computador da transmissora foi configurada com VLAN ID = 4 e a placa de rede do computador da distribuidora com VLAN ID $=3$.

Nas figuras 30 e 31 é mostrada a configuração da VLAN = 4 no computador da transmissora, através do acesso às propriedades da interface de rede da Intel. 


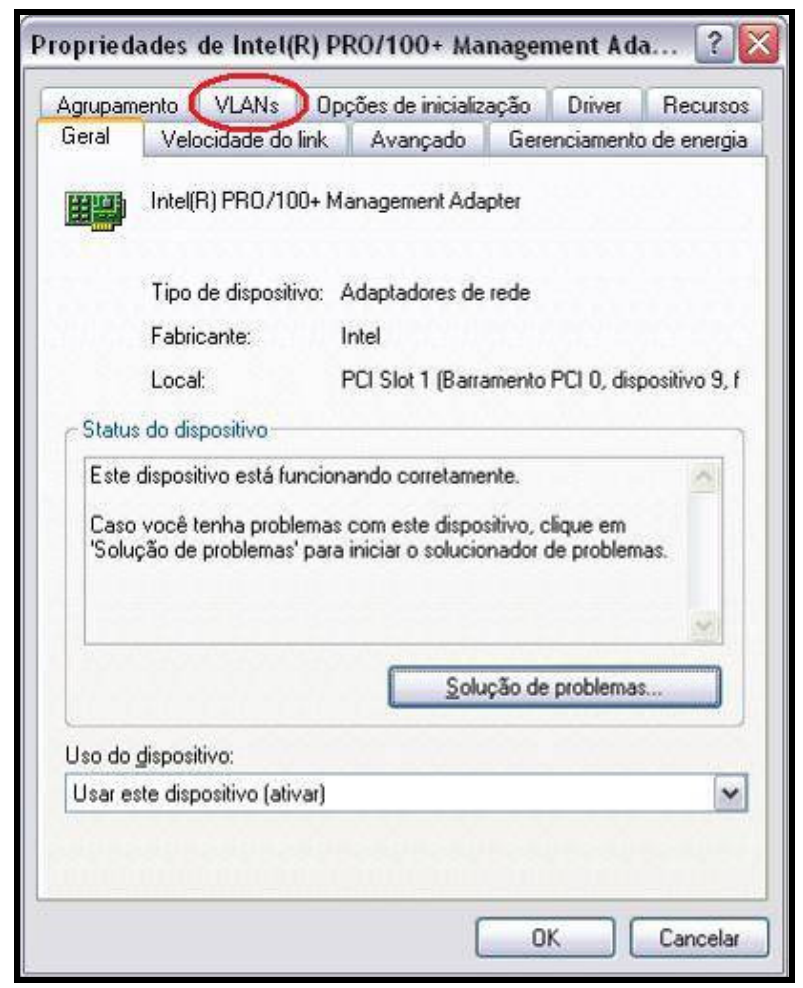

Figura 30 - Acesso às propriedades da placa Intel PRO/100

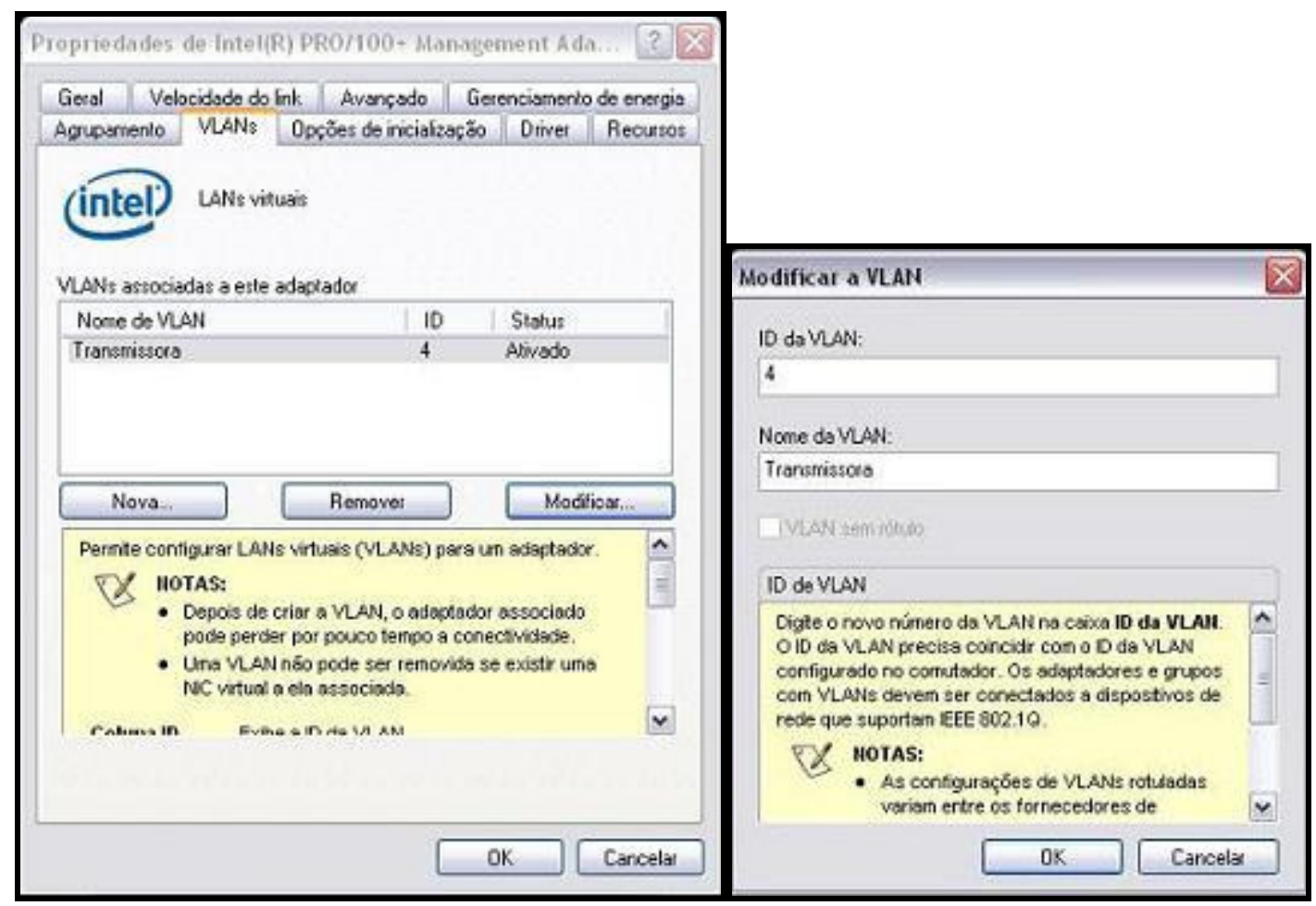

Figura 31 - Configuração da VLAN na placa de rede do computador da transmissora 
Desta forma foi mantido o isolamento entre o sistema da transmissora e o sistema da distribuidora.

\subsection{Testes realizados}

Com o intuito de demonstrar que é possível interligar fisicamente e trocar dados através de duas redes logicamente diferentes, foram implementados mensagens GOOSE em cada IED representando as funções que são compartilhadas neste tipo de subestação:

a) funções de proteção: esquema de falha de disjuntor e a transferência de proteção para o disjuntor paralelo;

b) funções de supervisão: o estado do disjuntor de paralelo, os seccionadores deste bay e a medida analógica de tensão de barra.

\subsubsection{Simulação da proteção de falha de disjuntor}

Neste teste, conforme figura 32, é realizada a troca de mensagem GOOSE entre o IED da distribuidora e o IED da transmissora simulando a atuação da proteção de falha de disjuntor.

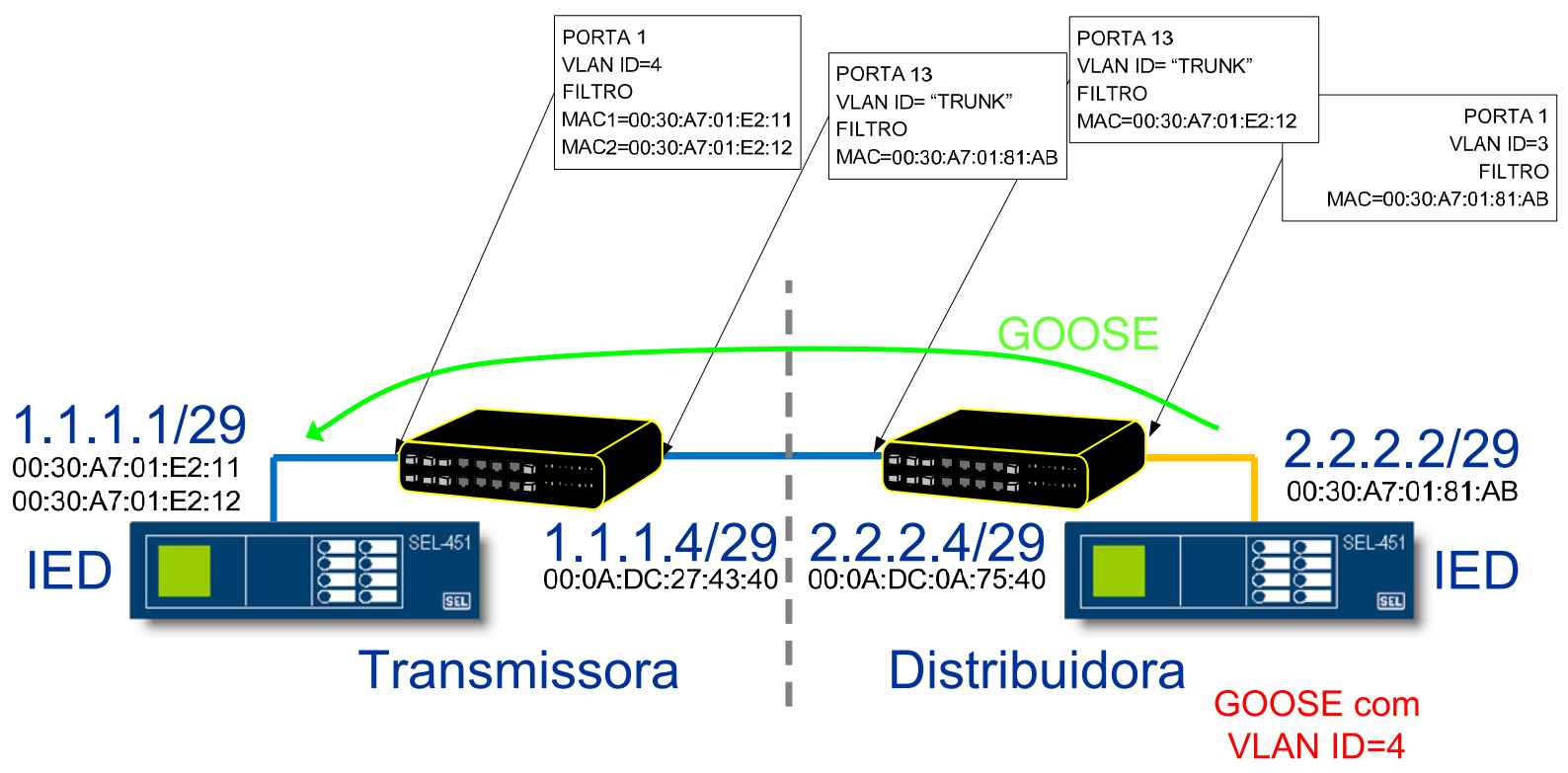

Figura 32 - Teste da proteção de falha de disjuntor 
A figura 33 mostra que com o auxílio do programa Acselerator Architect, foi configurado o data set contendo a saída que enviará o sinal de atuação da proteção de falha de disjuntor do IED da distribuidora para o IED da transmissora. Foi utilizada a saída CCOUT01 do IED 4514 da SEL pois segundo o fabricante somente estas saídas virtuais de comunicação são destinadas aos GOOSEs de alta velocidade. (28)

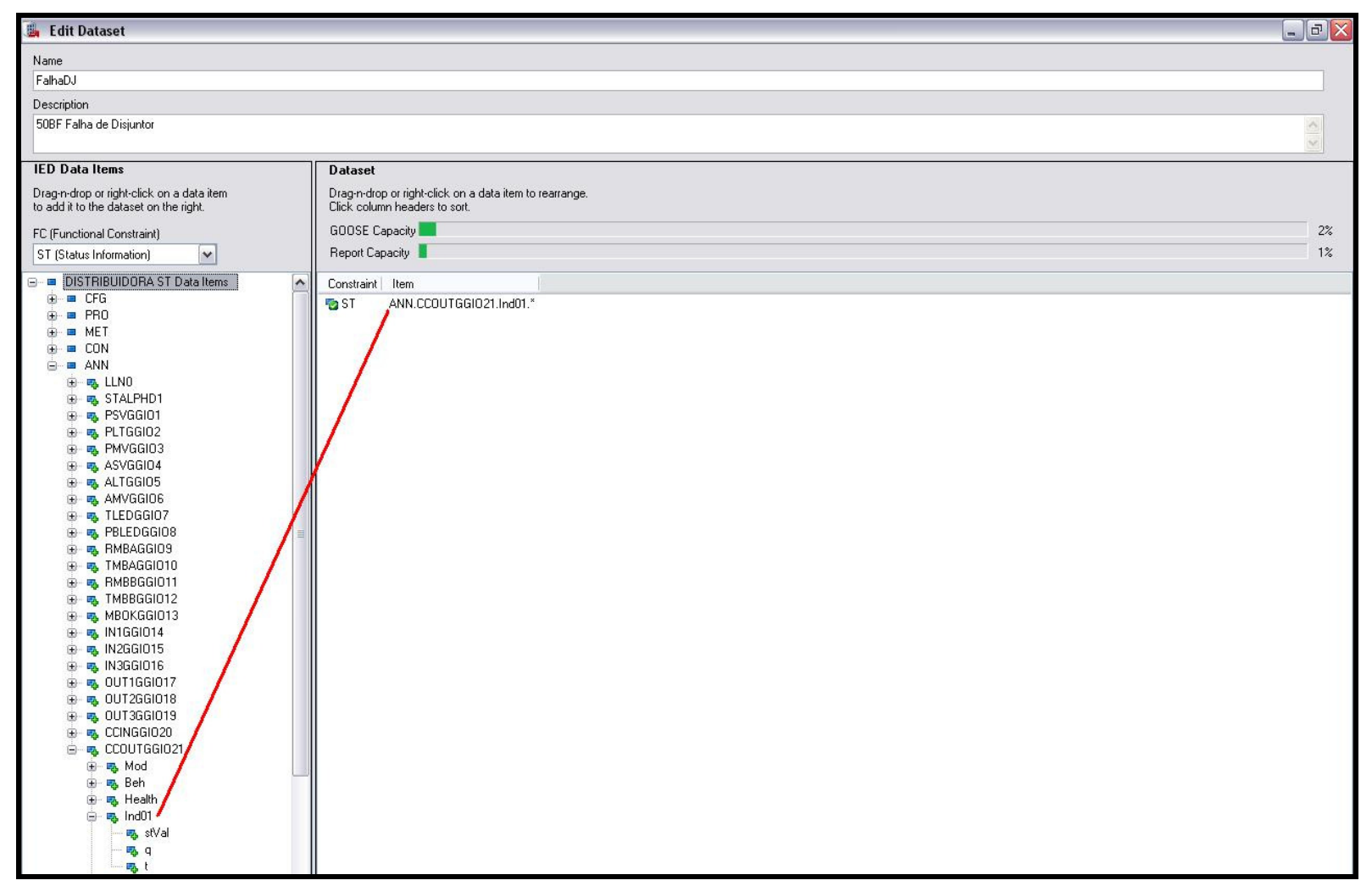

Figura 33 - Configurando o data set com o ponto CCOUT1 simulando o disparo da proteção de falha de disjuntor

A configuração para publicação do GOOSE é realizada na aba GOOSE transmit deste mesmo programa, conforme verificado na figura 34.

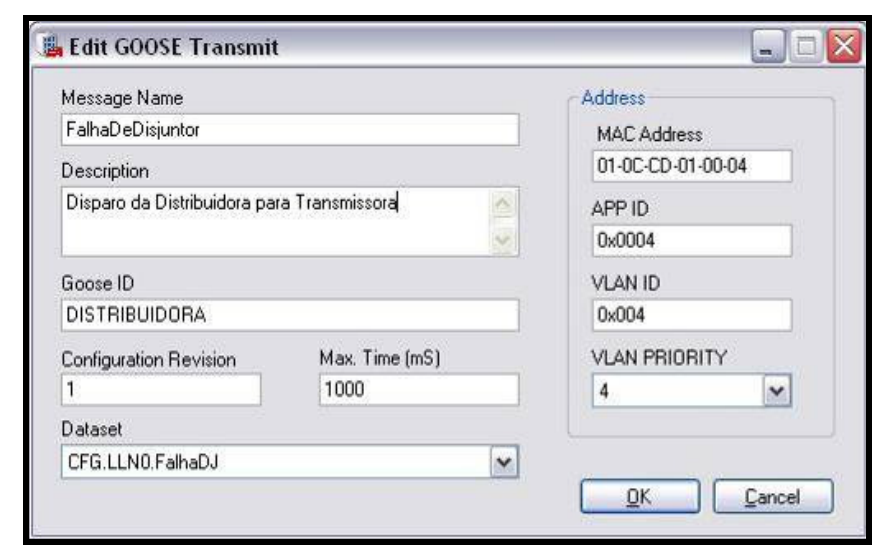

Figura 34 - Configurações para publicação do GOOSE de falha de disjuntor 
$\mathrm{Na}$ janela de configuração do GOOSE a ser transmitido constam dez campos a serem preenchidos, sendo alguns essenciais para o funcionamento correto do envio da mensagem. A descrição desses campos é apresentada a seguir:

a) message name: identificador único de um até dezesseis caracteres onde o primeiro deve ser obrigatoriamente alfabético. Este campo somente aceita os caracteres alfanuméricos e underscore;

b) description: campo de cento e vinte e oito caracteres aberto para comentários onde não são aceitos os símbolos $<$ ou $>$;

c) GOOSE ID: identificador de um a sessenta caracteres obrigatórios. Este campo somente aceita os caracteres alfanuméricos e underscore;

d) configuration revision: identifica a configuração de uma instância de dispositivo lógico conforme IEC 61850-7-3;

e) max. time (ms): valor numérico de quatro a sessenta mil que representa um período de tempo em milissegundos. Este período é o intervalo entre as mensagens GOOSE após o decaimento exponencial e onde não há mudanças no GOOSE;

f) data set: agrupamento de nós lógicos;

g) MAC Address: um único endereço MAC para o qual múltiplos dispositivos podem se inscrever para a entrega simultânea de um fluxo de dados comum. Vide capítulo 2, tabela 1;

h) APP ID: identificador de aplicação. O usuário define este identificador na definição de uma mensagem GOOSE de saída conforme IEC 61850-8-1;

i) VLAN ID: identificador numérico de doze bits que identifica uma rede logicamente independente;

j) VLAN priority: valor numérico de zero a sete em que sete é a maior prioridade. Pacotes Ethernet com tags de prioridade são priorizados pelos switches e outros dispositivos de rede de tal forma que os pacotes de maior prioridade são processados antes dos pacotes de menor prioridade.

É possível forçar que o endereço MAC multicast e o APP ID ou a VLAN ID sejam únicas no projeto, através da configuração das preferências conforme figura 35. 


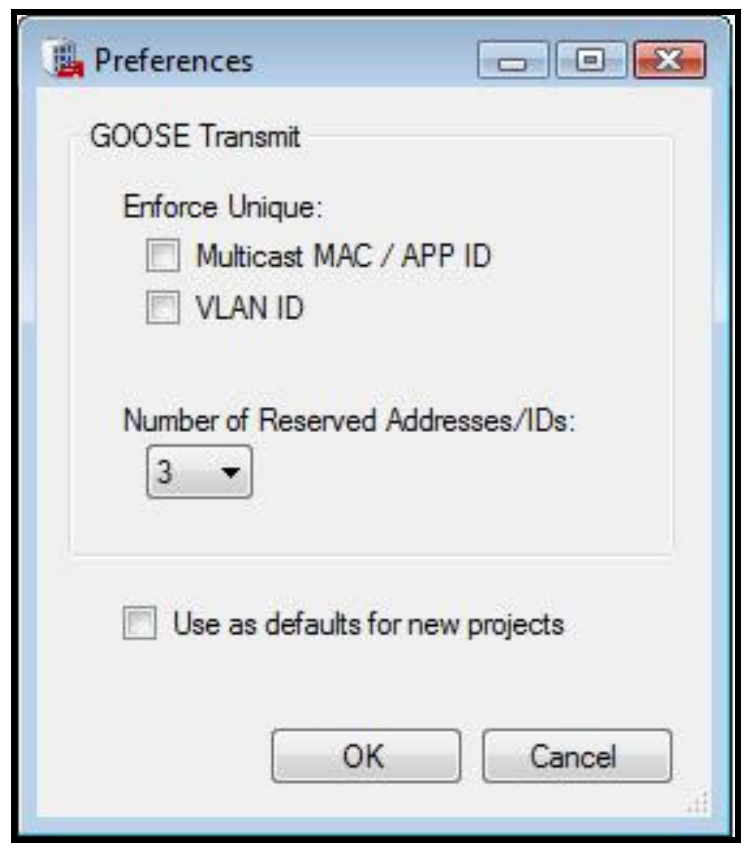

Figura 35 - Janela de preferências da transmissão do GOOSE

Também com o programa Acselerator Architect foi configurada a assinatura do GOOSE da distribuidora através do mapeamento na entrada VB001 do IED da transmissora, conforme figura 36. 


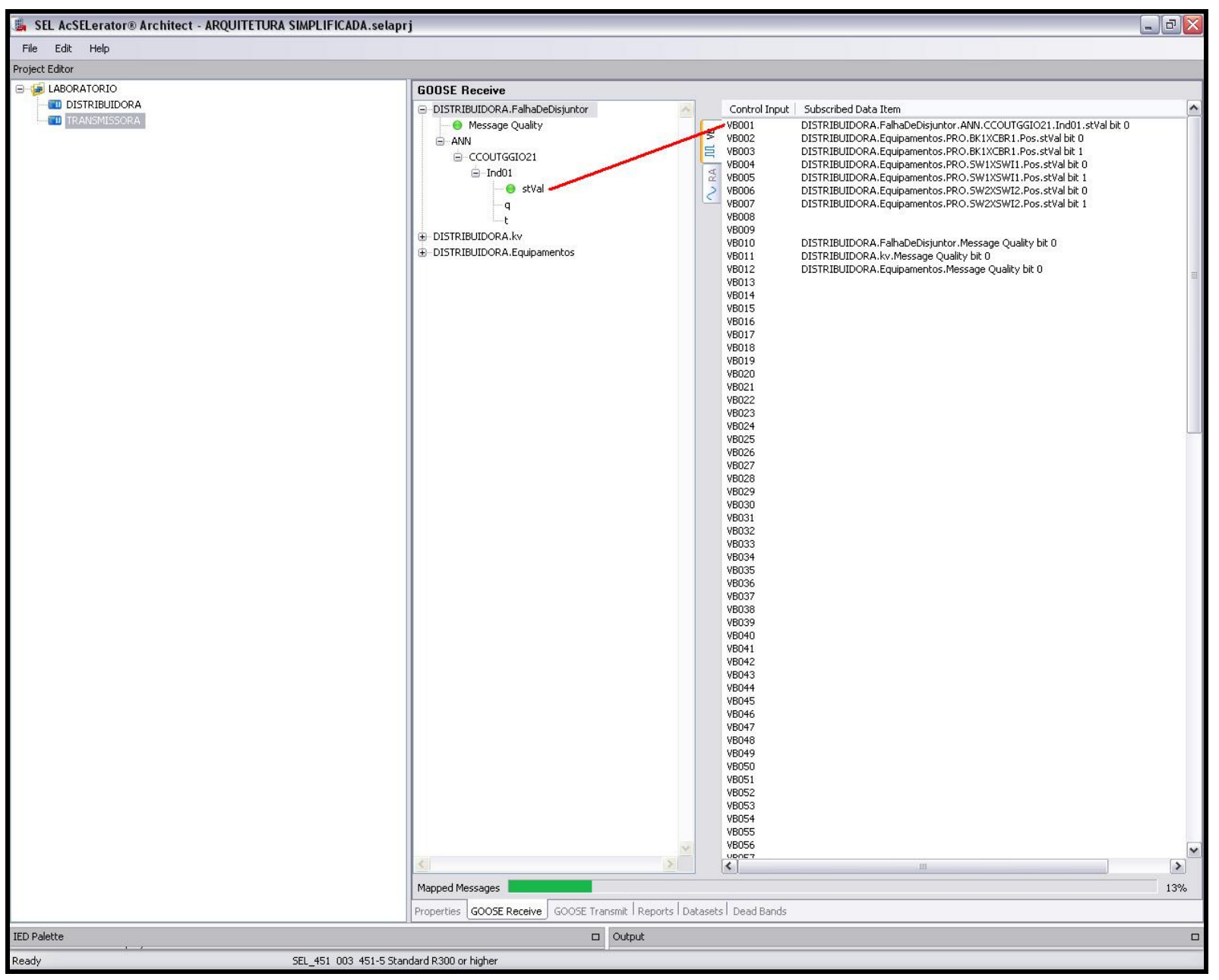

Figura 36 - Assinatura do GOOSE pela transmissora com o ponto para disparo da proteção de falha de disjuntor

Da mesma forma é possível verificar ainda na figura 36 o mapeamento na VB010 da qualidade da mensagem deste data set. Este ponto de qualidade foi mapeado em um LED frontal do IED para monitorar a disponibilidade do GOOSE na rede.

Depois de configurados e descarregados nos IEDs, o GOOSE passou a ser publicado na rede. Através do aplicativo Ethereal foi possível verificar o envio do GOOSE, com o estado false da saída CCOUT1, do IED da distribuidora (endereço MAC 00:30:A7:01:81:AB) para o IED da transmissora, conforme figura 37. 


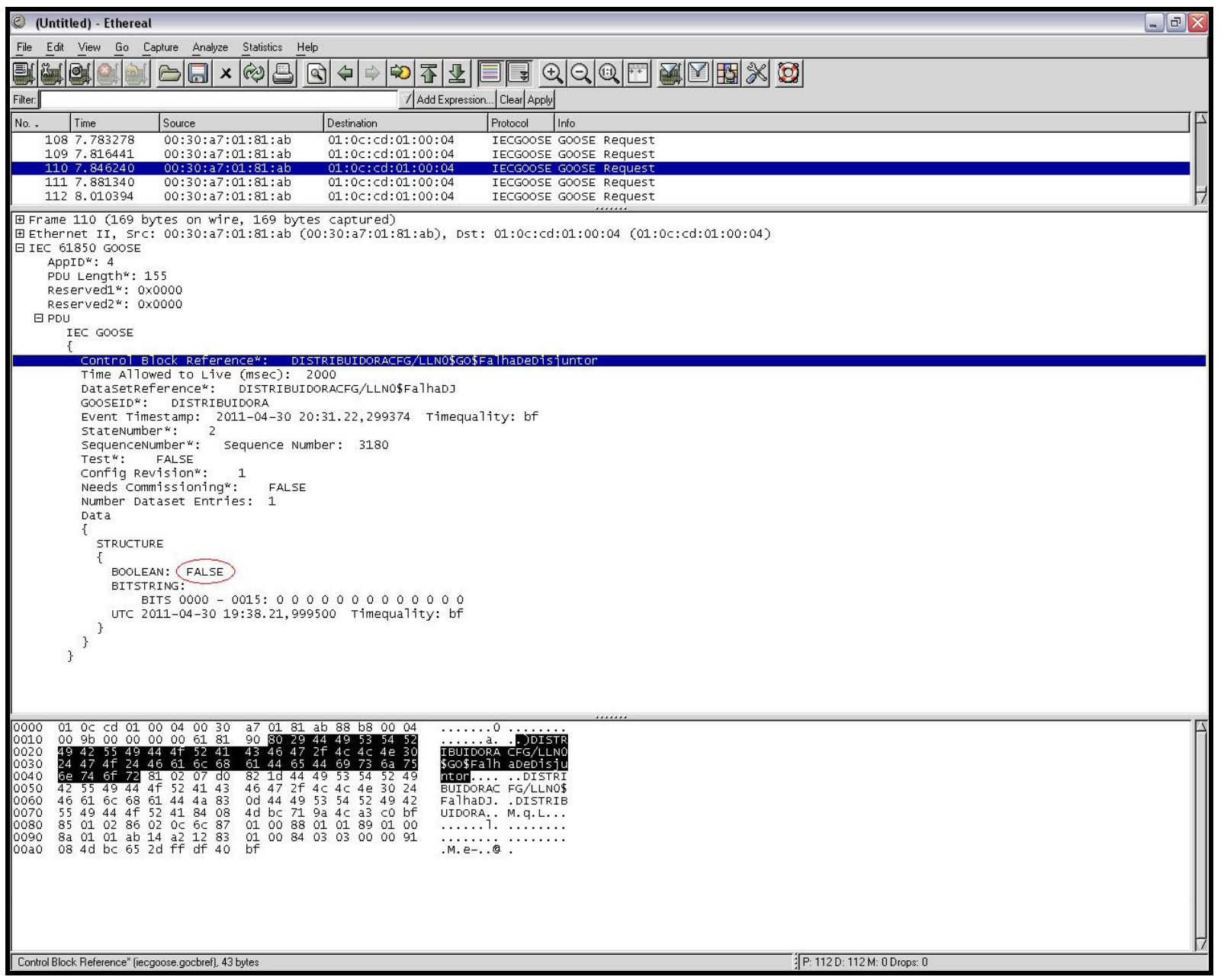

Figura 37 - Pacotes com o GOOSE de falha de disjuntor capturados pelo programa Ethereal

Comprovou-se que as mensagens GOOSE, por serem desenvolvidas na camada de enlace de dados do modelo OSI, podem ser enviadas do IED da distribuidora para o IED da transmissora mesmo estando em redes lógicas diferentes.

A lógica da função de falha de disjuntor disponível no IED da SEL não foi testada neste trabalho, pois não fazia parte do escopo. Nos testes foi associado então o pressionar do botão de número 1 do frontal do IED, com a saída CCOUT1, condicionado também a outro botão que mantinha a função em serviço, simulando assim o disparo da função. Para a aplicação real, deve-se mapear o ponto de disparo da função de falha de disjuntor diretamente para a saída CCOUT01. 


\subsubsection{Simulação da transferência de proteção}

Troca de mensagens GOOSE do IED da transmissora para o IED da distribuidora simulando a transferência do disparo da proteção das linhas de entrada para o disjuntor de paralelo, conforme arquitetura da figura 38.

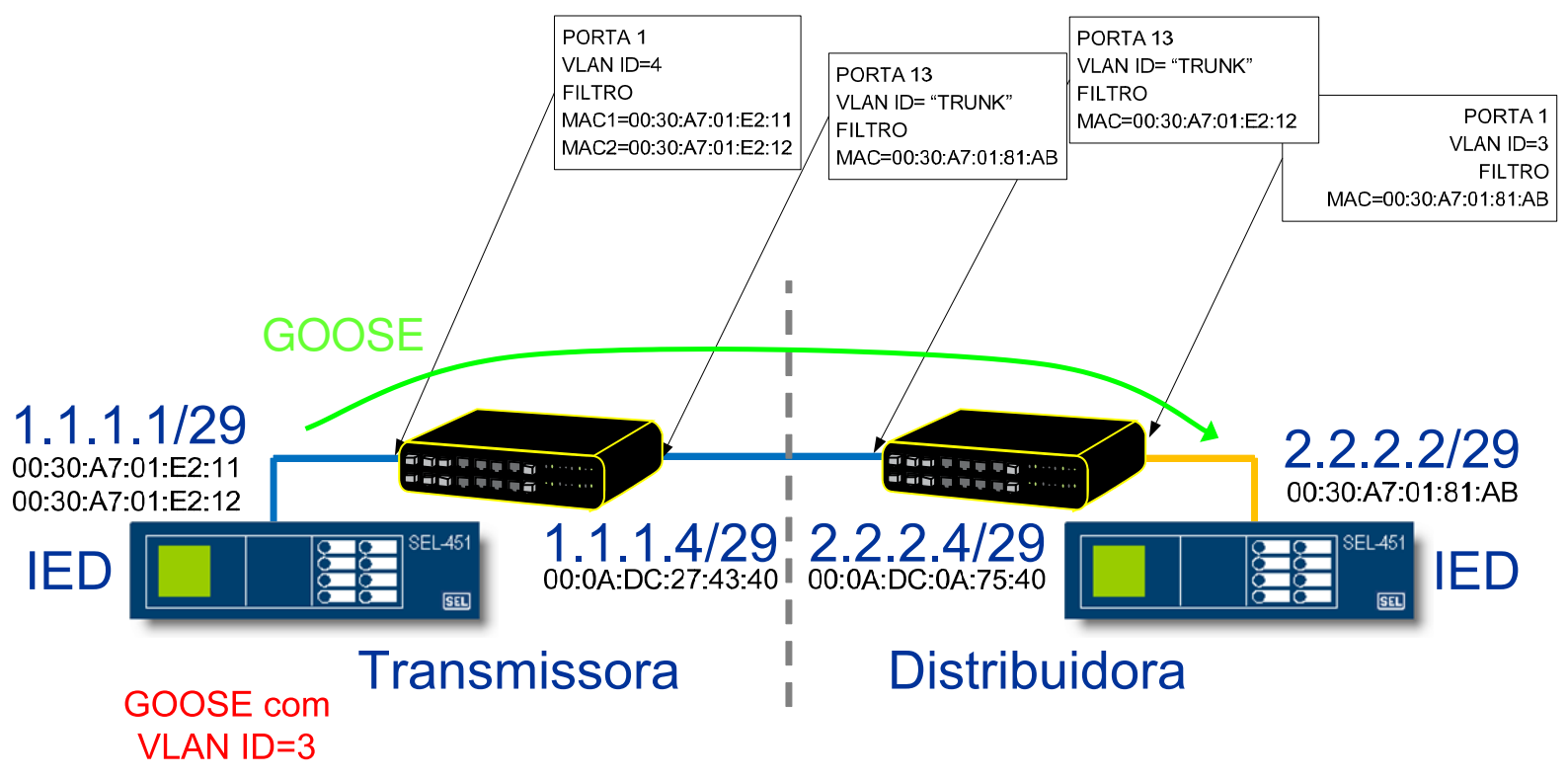

Figura 38 - Teste da transferida do disparo da proteção para o disjuntor paralelo

Com o auxílio do programa Acselerator Architect, foi configurado o data set contendo o sinal de trip do IED 451-5 e que atuará desligando o disjuntor de paralelo. Foi utilizado o próprio sinal de trip do IED denominado de TRIPPTRC1, como pode ser visto na figura 39.

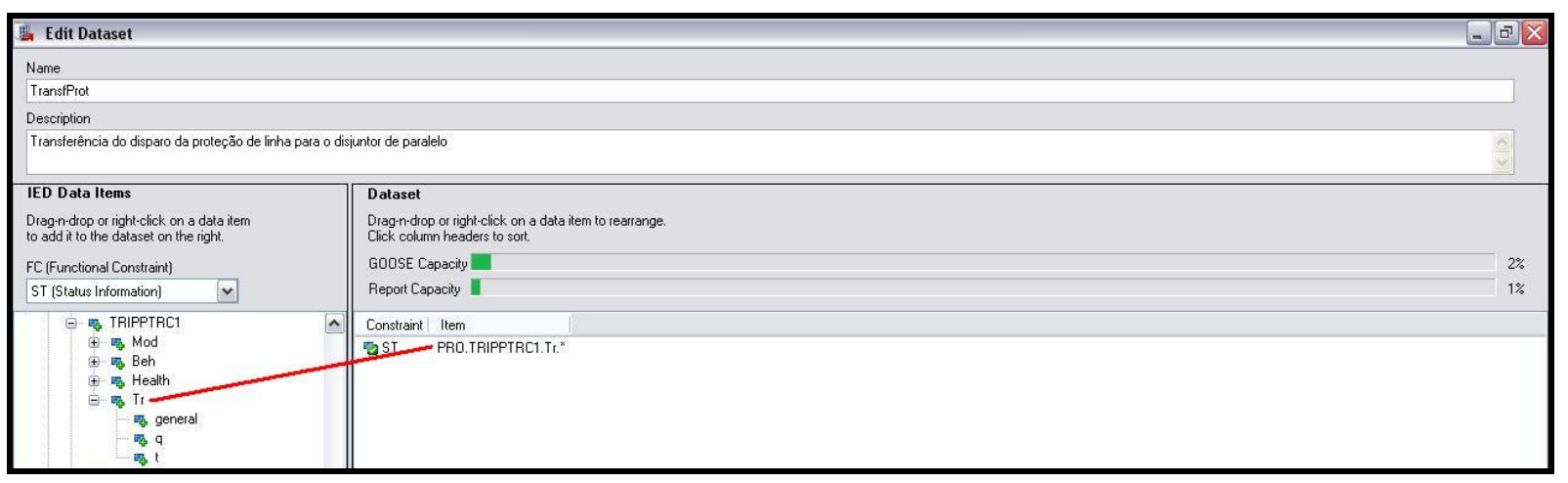

Figura 39 - Configurando o data set com o ponto de trip do IED da transmissora

$\mathrm{Na}$ aba GOOSE transmit este data set foi publicado com o endereço MAC multicast 01-0CCD-01-00-03, conforme pode ser visto na figura 40. 


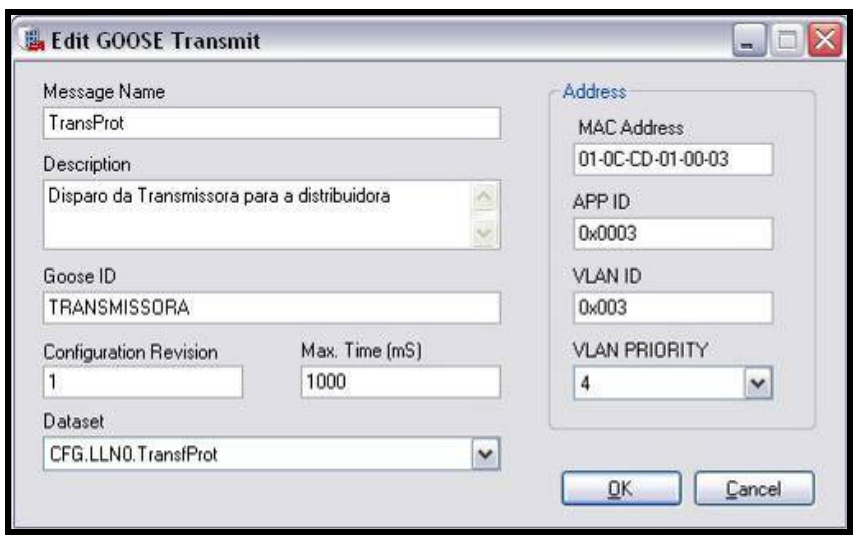

Figura 40 - Configurações para publicação do GOOSE de disparo para a transferência de proteção

Ainda no programa Acselerator Architect foi configurada a assinatura do GOOSE da transmissora através do mapeamento na entrada CCIN001 do IED da distribuidora, conforme figura 41 .

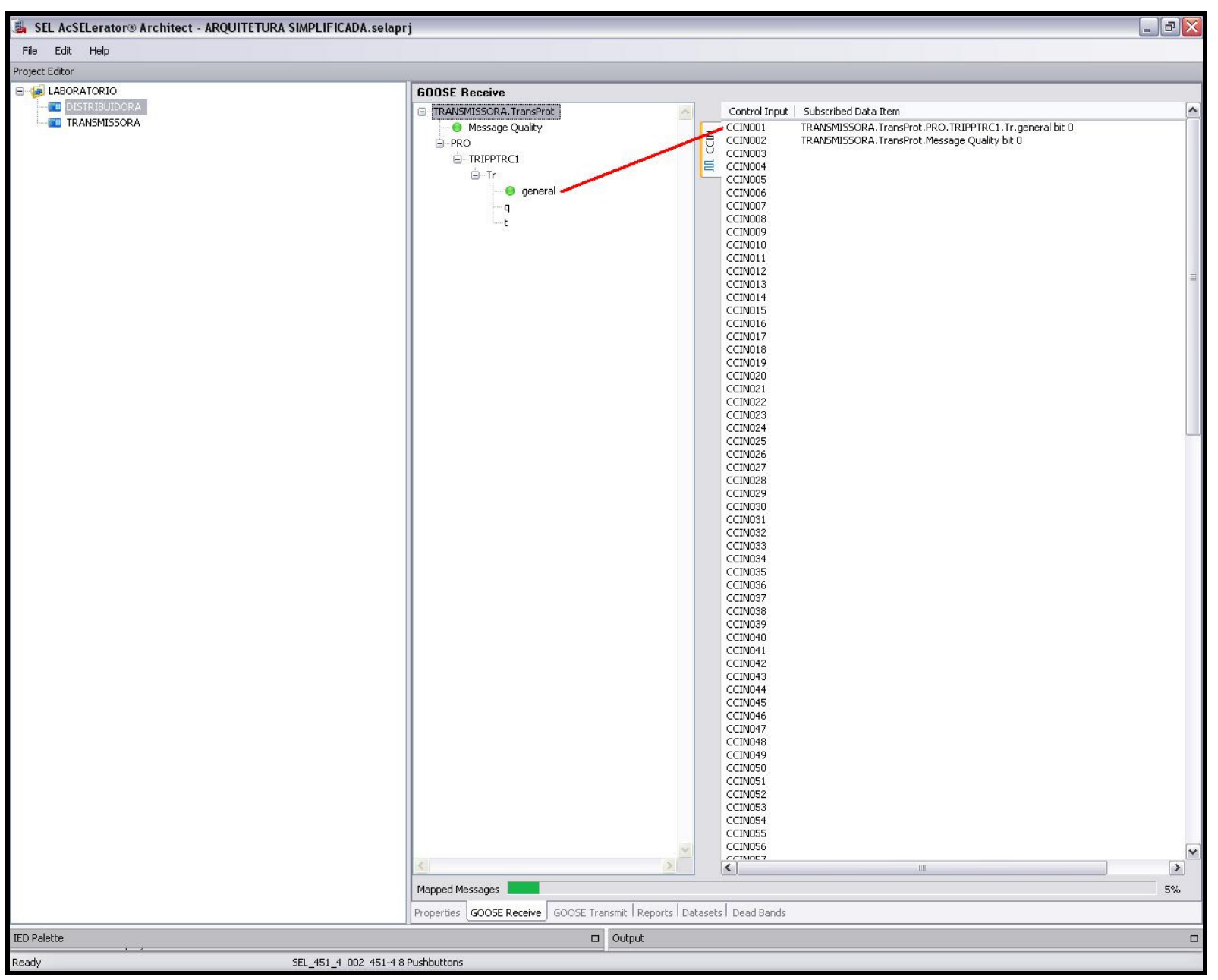

Figura 41 - Assinatura do GOOSE pela distribuidora com o ponto de disparo para a transferência de proteção 
Do mesmo modo que foi realizado no IED da distribuidora, o mapeamento na CCIN002 da qualidade da mensagem deste data set, disponibilizou em um LED frontal do IED o monitoramento do GOOSE na rede.

Através do aplicativo Ethereal foi possível verificar a publicação na rede do GOOSE, com o estado false do trip, do IED da transmissora (endereço MAC 00:30:A7:01:E2:12) para o IED da distribuidora, conforme figura 42.

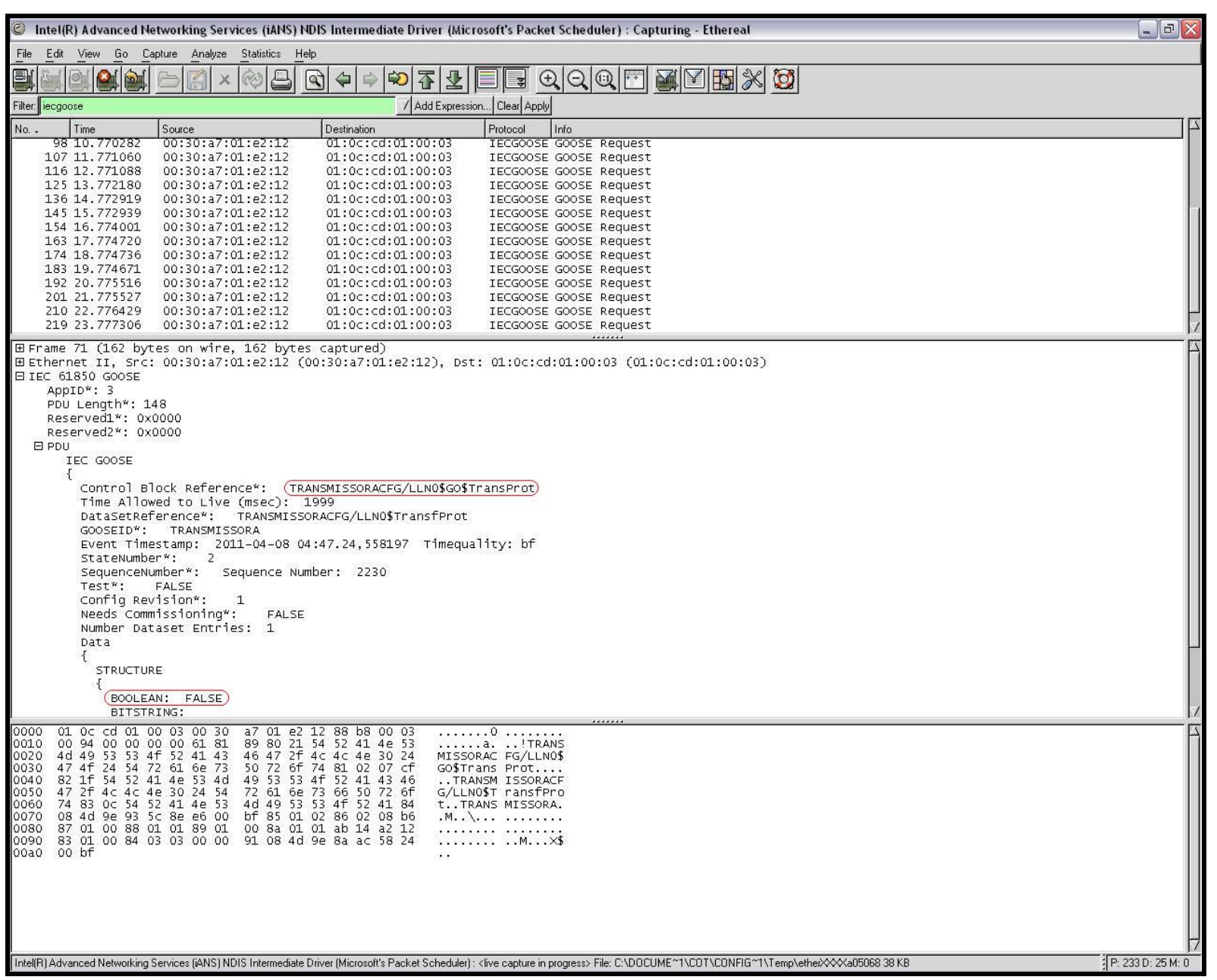

Figura 42 - Pacotes com o GOOSE da transferência de proteção capturados pelo programa Ethereal

Conforme figura 43, a atuação do trip foi realizada através da associação do botão 1 , (Push Button 1-PB1) do frontal do IED 451-5, condicionado também a outro botão que mantinha a função em serviço. 


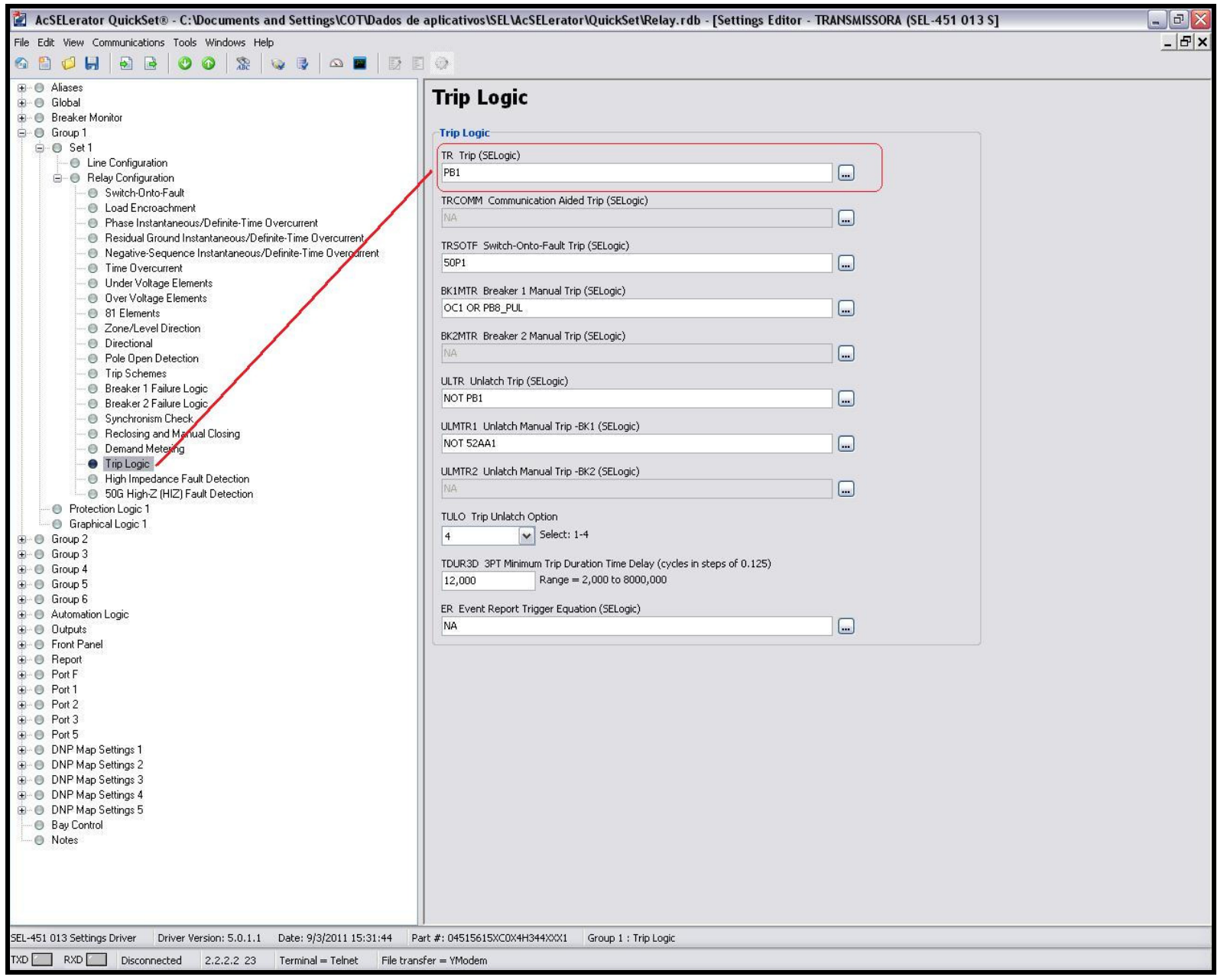

Figura 43 - Associação do Push Button 1 ao trip do IED da transmissora

O trip no IED da transmissora foi realizado pressionando o botão frontal de número 1. Com a atuação do ponto, foi possível através do programa Ethereal verificar a transmissão do GOOSE, conforme figura 44. 


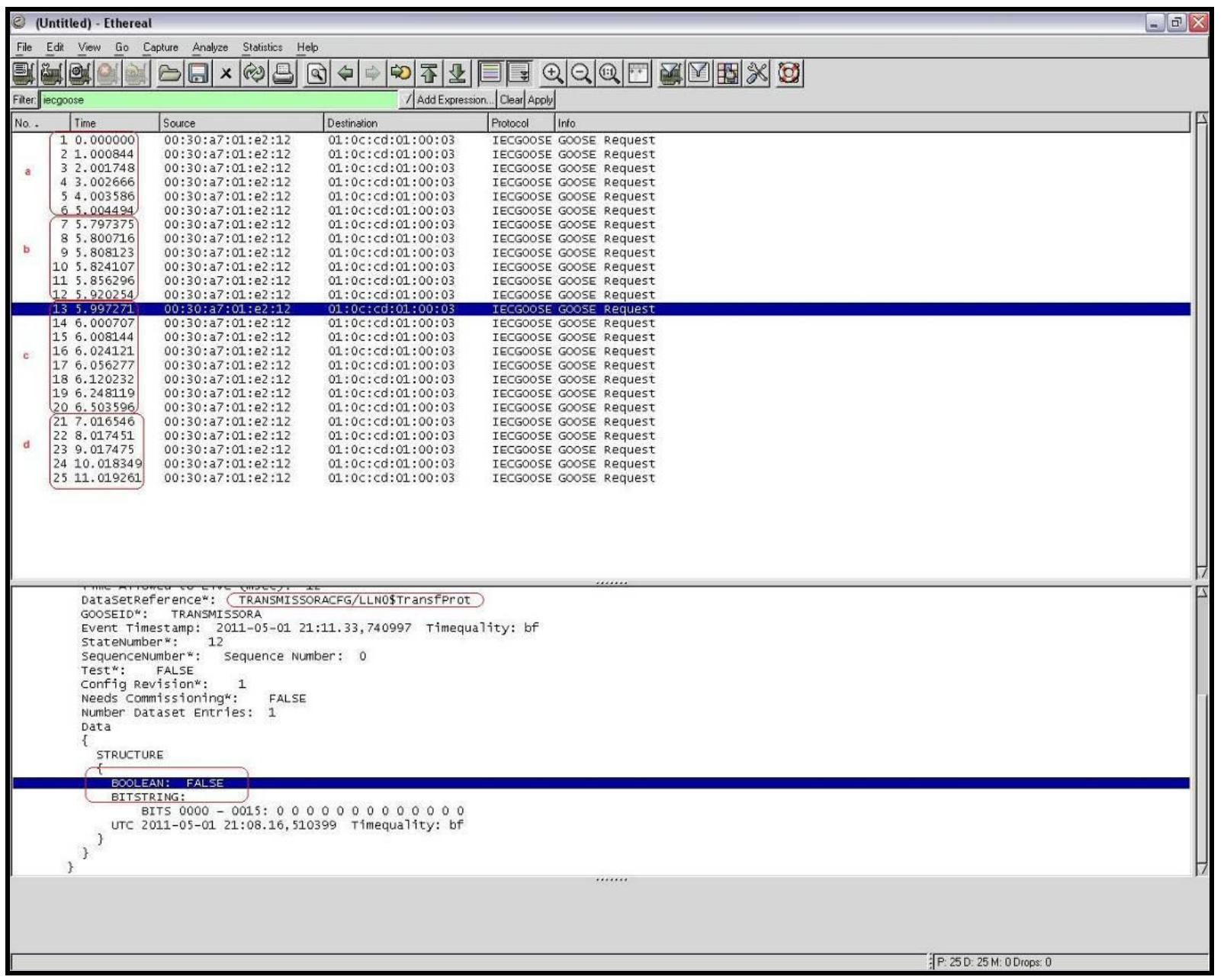

Figura 44 - Análise do comportamento do GOOSE com a atuação do trip no IED da transmissora

Nos itens assinalados de $a$ à $d$ na figura 44, são destacados:

a) publicação do GOOSE na rede a cada um segundo conforme definido pelo parâmetro Max. Time (ms) da janela de configuração; vide figura 40;

b) regime estável interrompido por atuação do GOOSE no tempo 5,797375 segundos. Conforme apresentado no capítulo 2, figura 5, houve seis atuações seguidas com o estado true para este GOOSE;

c) normalização do GOOSE no tempo 5,997271 segundos e retorno ao regime estável de publicação;

d) regime estável com publicação do GOOSE na rede a cada um segundo.

Observado que as mensagens GOOSE, por serem desenvolvidas na camada de enlace de dados do modelo OSI, podem ser enviadas do IED da transmissora para o IED da distribuidora mesmo estando em redes lógicas e VLANs diferentes. 


\subsubsection{Simulação das informações para operação em tempo real}

A troca de dados em MMS entre os IEDs e os sistemas supervisórios de cada agente é prevista para a operação local e remota da subestação.

Uma solução encontrada para evitar o acesso direto do computador com o sistema supervisório de uma empresa à rede da outra empresa, o que implicaria outras soluções de segurança, foi efetuar a troca dos dados necessários através de mensagens GOOSE de um IED para outro e na sequencia, mapeá-las através de um visualizador de MMS para o computador, conforme mostrado na figura 45 .

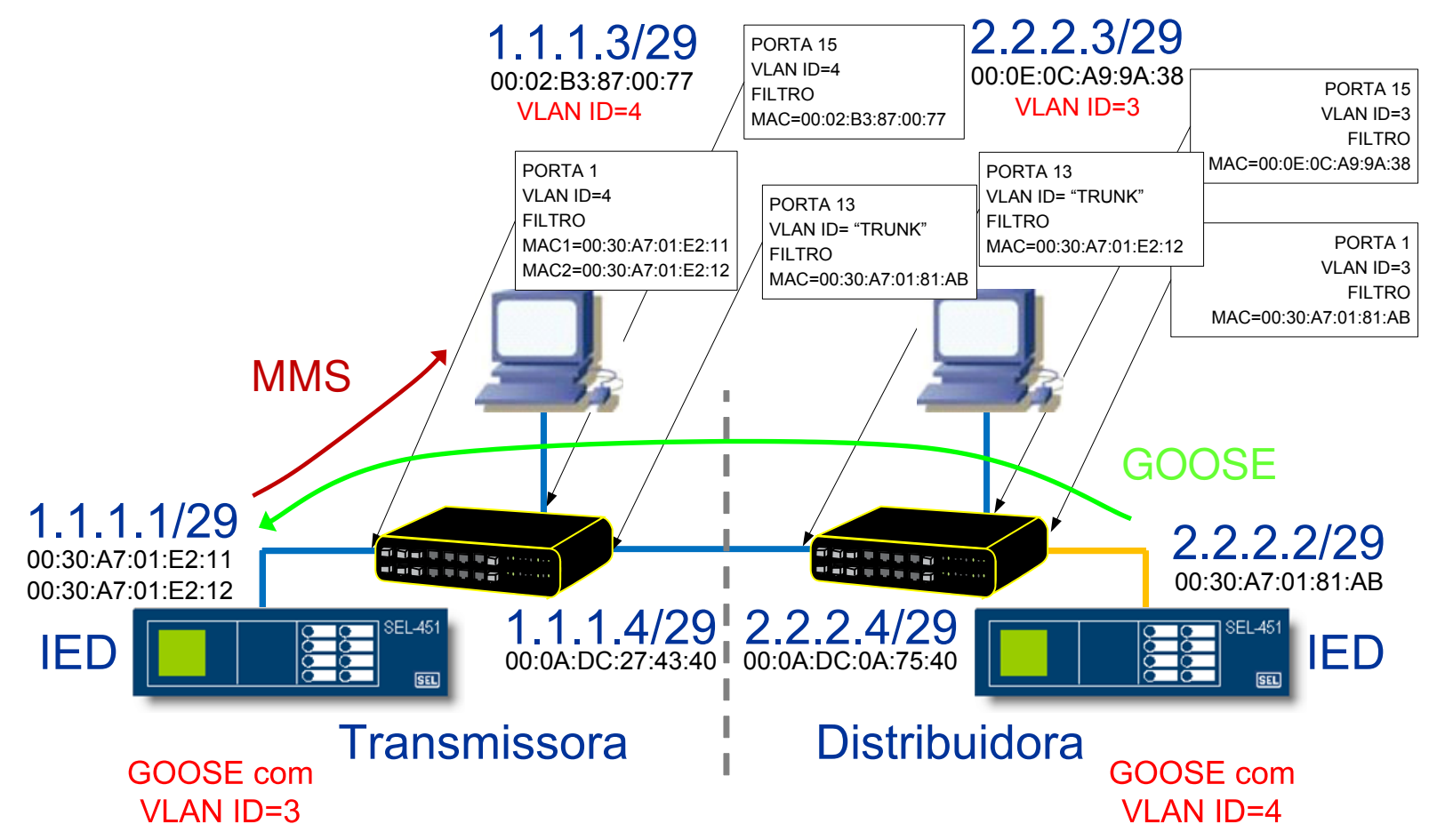

Figura 45 - Teste de troca de dados da distribuidora para a transmissora

O IED 451-5 utilizado, representando a transmissora, compartilha tanto mensagens GOOSE digitais como analógicas. Desta forma, todas as informações requeridas por este agente para o sistema de supervisão ficam disponíveis no IED, bastando para o sistema de supervisão mapear estes Logical Nodes diretamente via MMS.

Nos testes foi configurado para a transmissora apenas uma medida analógica requerida que foi a tensão das barras. Para simulação, a tensão disponibilizada na entrada VAY do IED 451-4, conforme verificado na figura 46, foi a tensão de 127 Volts em corrente alternada, disponível no laboratório. 


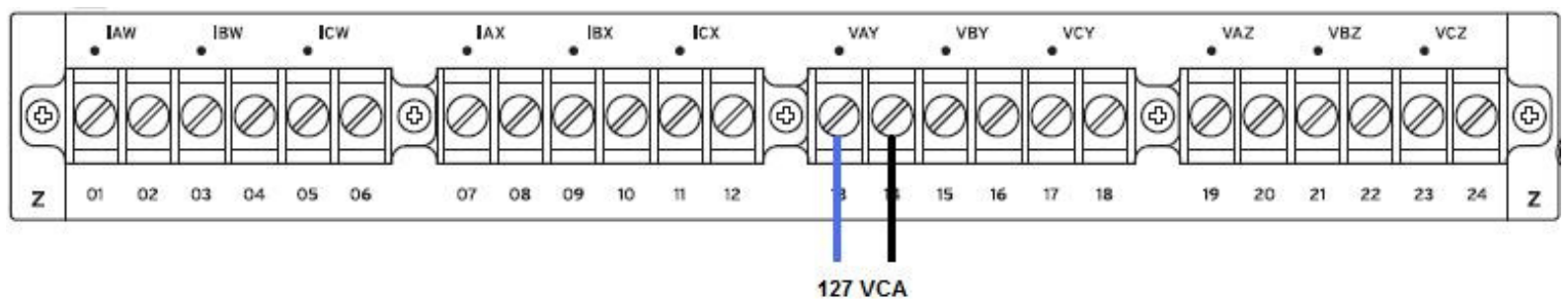

Figura 46 - Canal de entrada de tensão fase A e neutro no IED SEL 451-4

Definido um valor fictício de relação de transformação a fim de reproduzir na tela as faixas de tensão na classe de $138 \mathrm{kV}$. Na figura 47 é possível ver o campo para configuração no programa Acselerator Quickset.

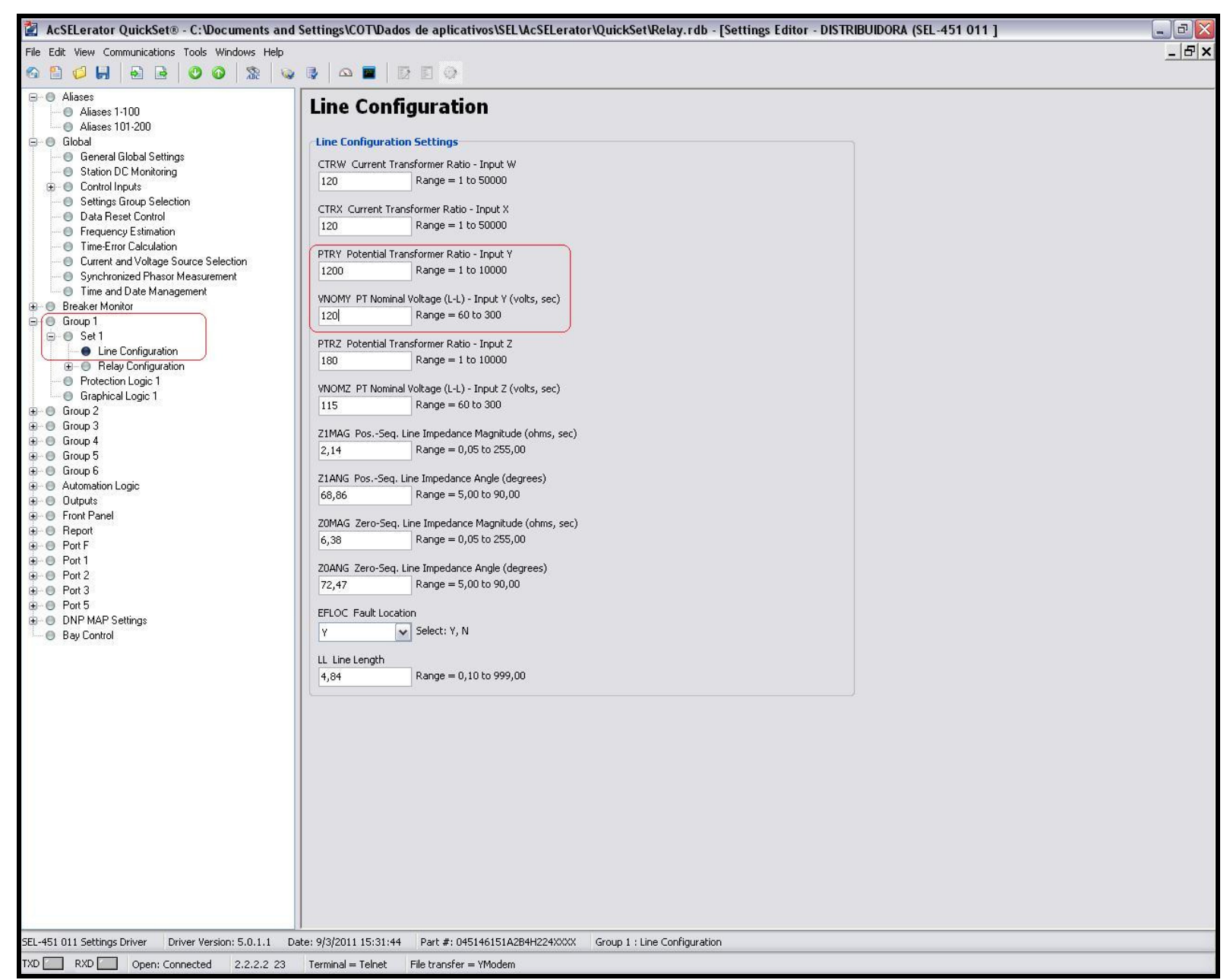

Figura 47 - Configurando a relação de transformação no IED SEL 451-4 da distribuidora

Após configurado e conectado à rede elétrica, foi possível visualizar a medida simulada de $\mathrm{kV}$ no display do IED da distribuidora, conforme figura 48 e no simulador de IHM do Acselerator Quickset, conforme figura 49. 


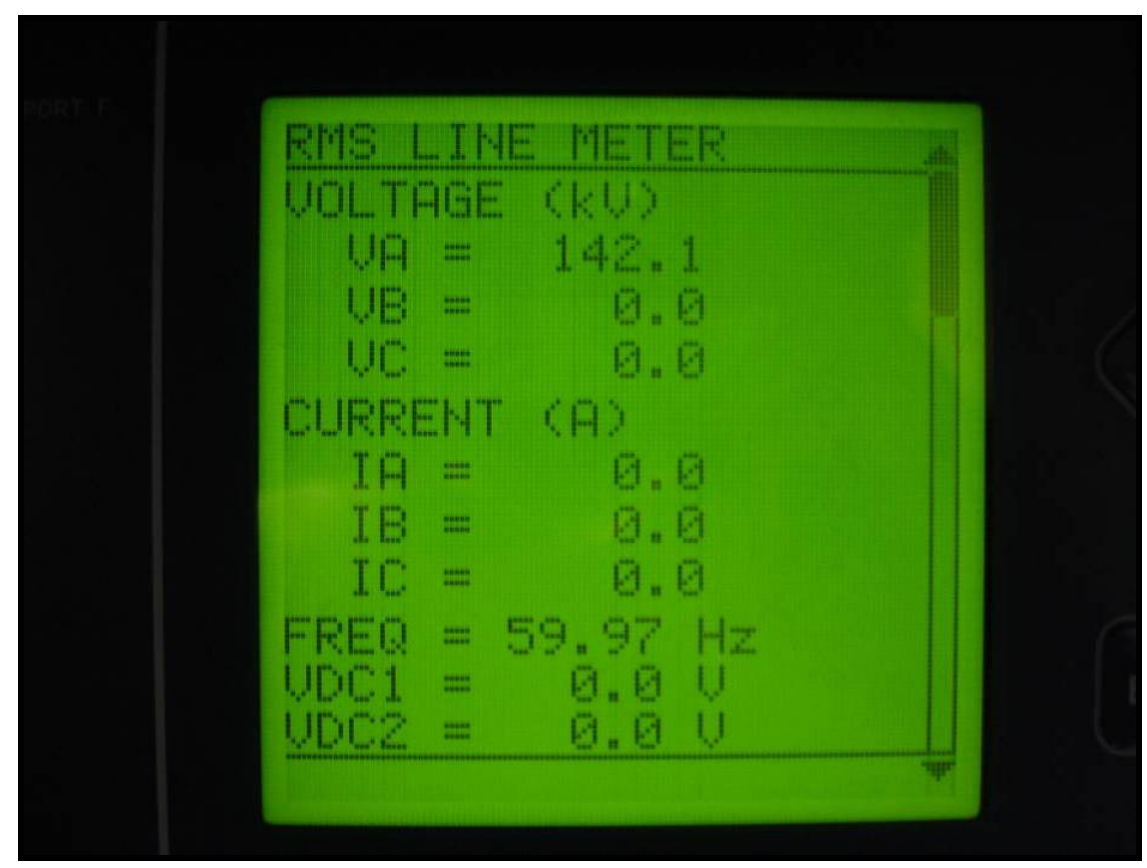

Figura 48 - Visualizando a tensão em kV no display do IED da distribuidora

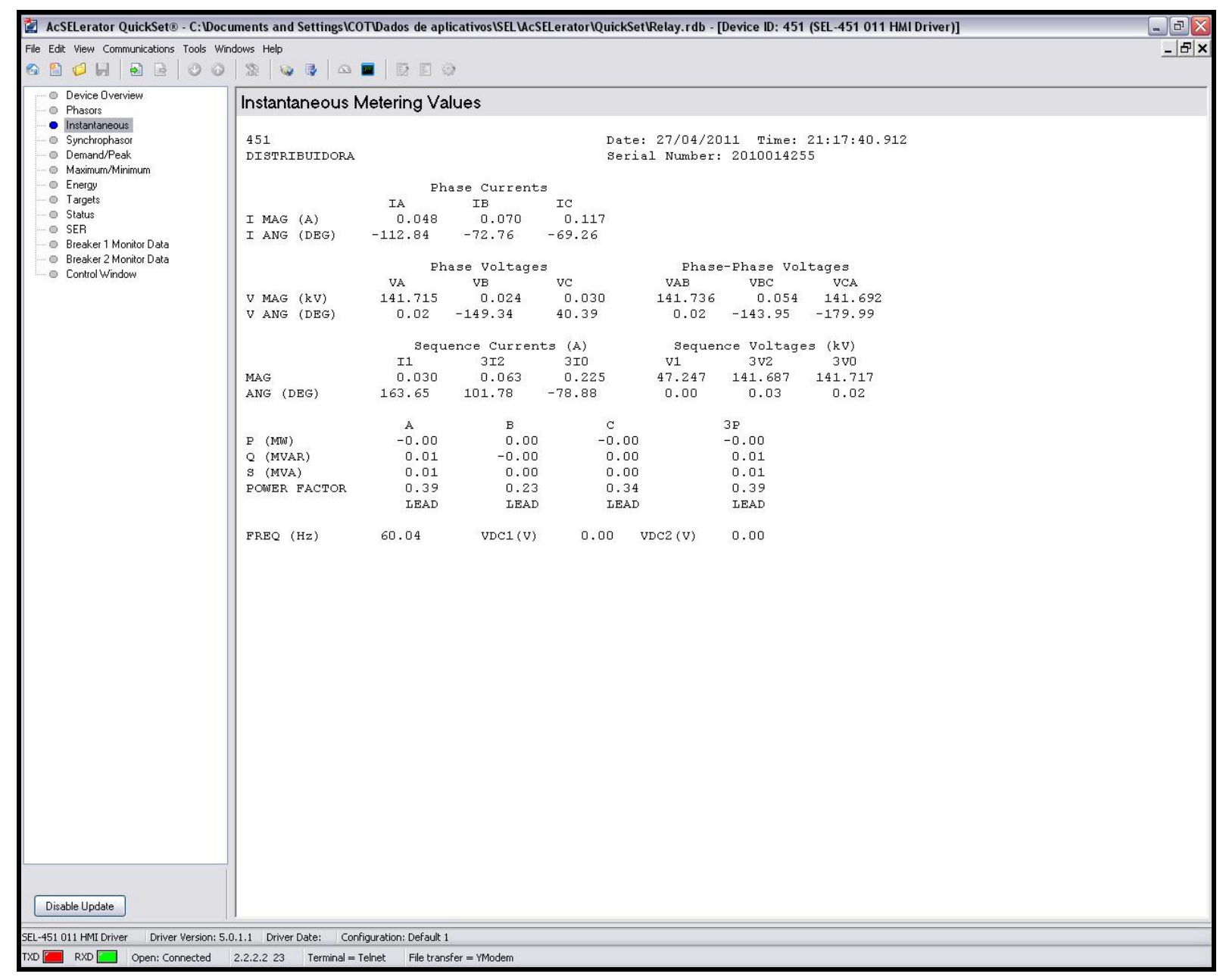

Figura 49 - Visualizando a tensão VA em kV do IED no programa Acselerator Quickset 
O próximo passo foi mapear esta medida como GOOSE para a transmissora. Inicialmente utilizando o programa Acselerator Architect foi mapeado dentro do Data set $\mathrm{kV}$ o logical node METMMXU1.PhV.phsA, conforme mostra a figura 50.

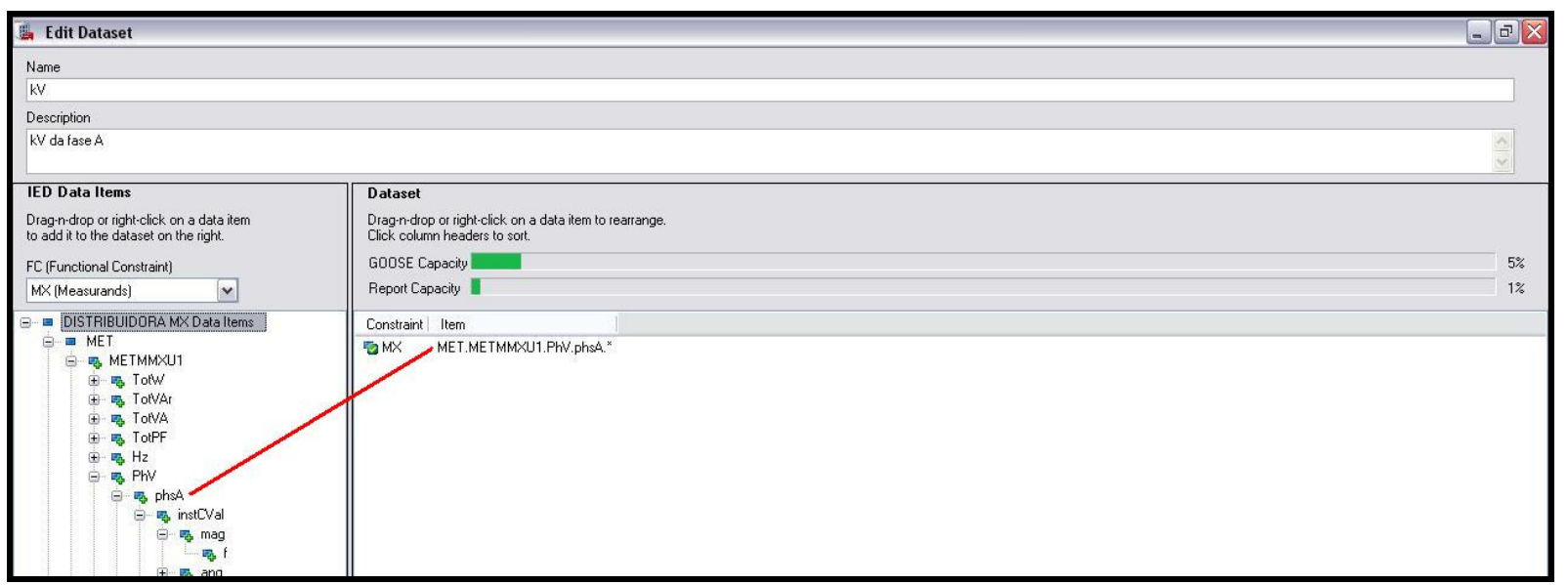

Figura 50 - Configurando o data set com o ponto de tensão da fase A do IED da distribuidora

$\mathrm{Na}$ aba GOOSE transmit este data set foi publicado com o endereço MAC multicast 01-0CCD-01-00-04, conforme pode ser visto na figura 51.

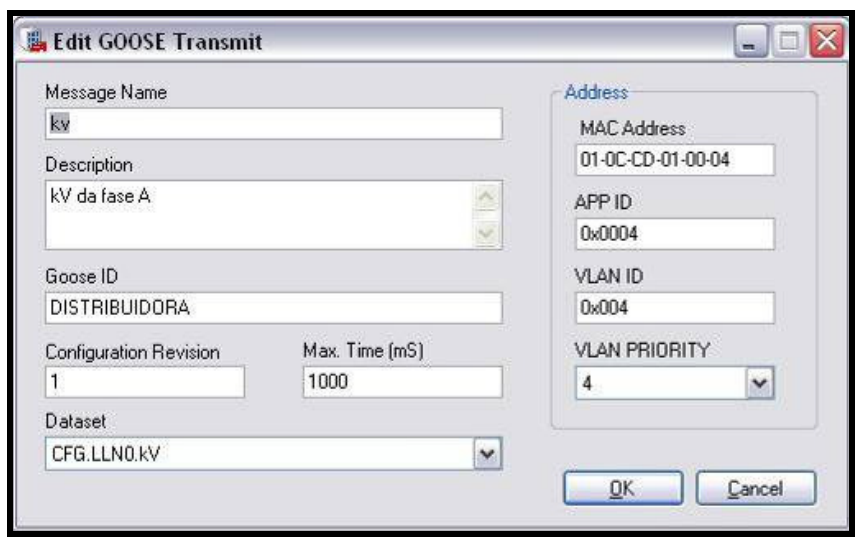

Figura 51 - Configurações para publicação do GOOSE com o data set da tensão da fase A

Dentro ainda do programa Acselerator Architect foi configurada a assinatura do GOOSE da distribuidora através do mapeamento na entrada RA001 do IED da transmissora, conforme figura 52. Utilizou-se o ponto METMMXU1.PhV.phsA.cVal ao invés do InstCVal pois no primeiro é aplicada a banda morta para controlar o limite de variações da medida analógica. Convém observar que esta aba RA somente está disponível no IED 451-5 utilizado, portanto somente este equipamento aceita a assinatura de mensagens GOOSE de dados analógicos. 


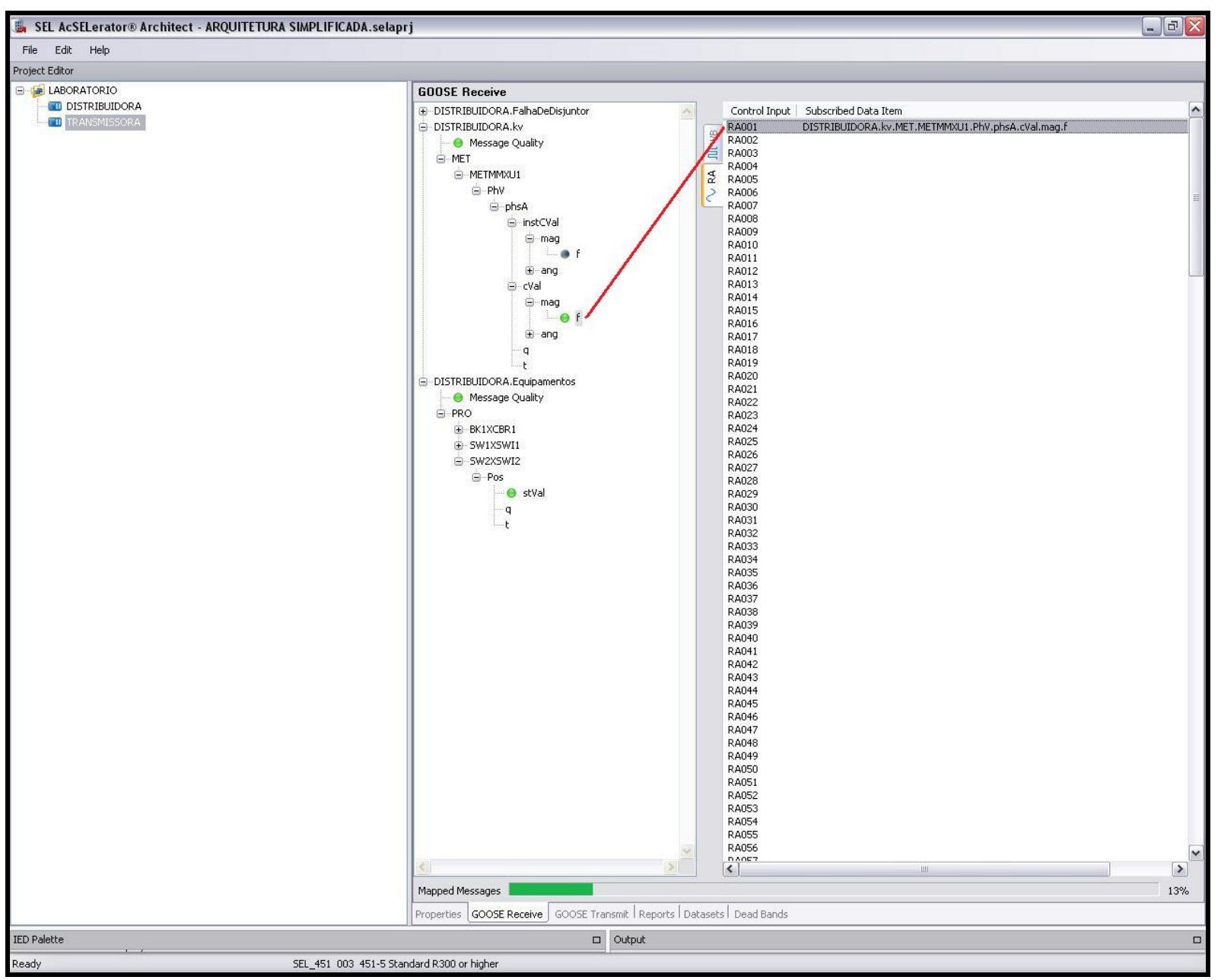

Figura 52 - Assinatura do GOOSE com o data set da medida analógica tensão

Para disponibilizar esta medida analógica para o sistema supervisório da transmissora foi necessário mapeá-la com o programa Acselerator Quickset em uma saída analógica virtual dentro do IED 451-5, denominada de RAO01, conforme visto na figura 53. 


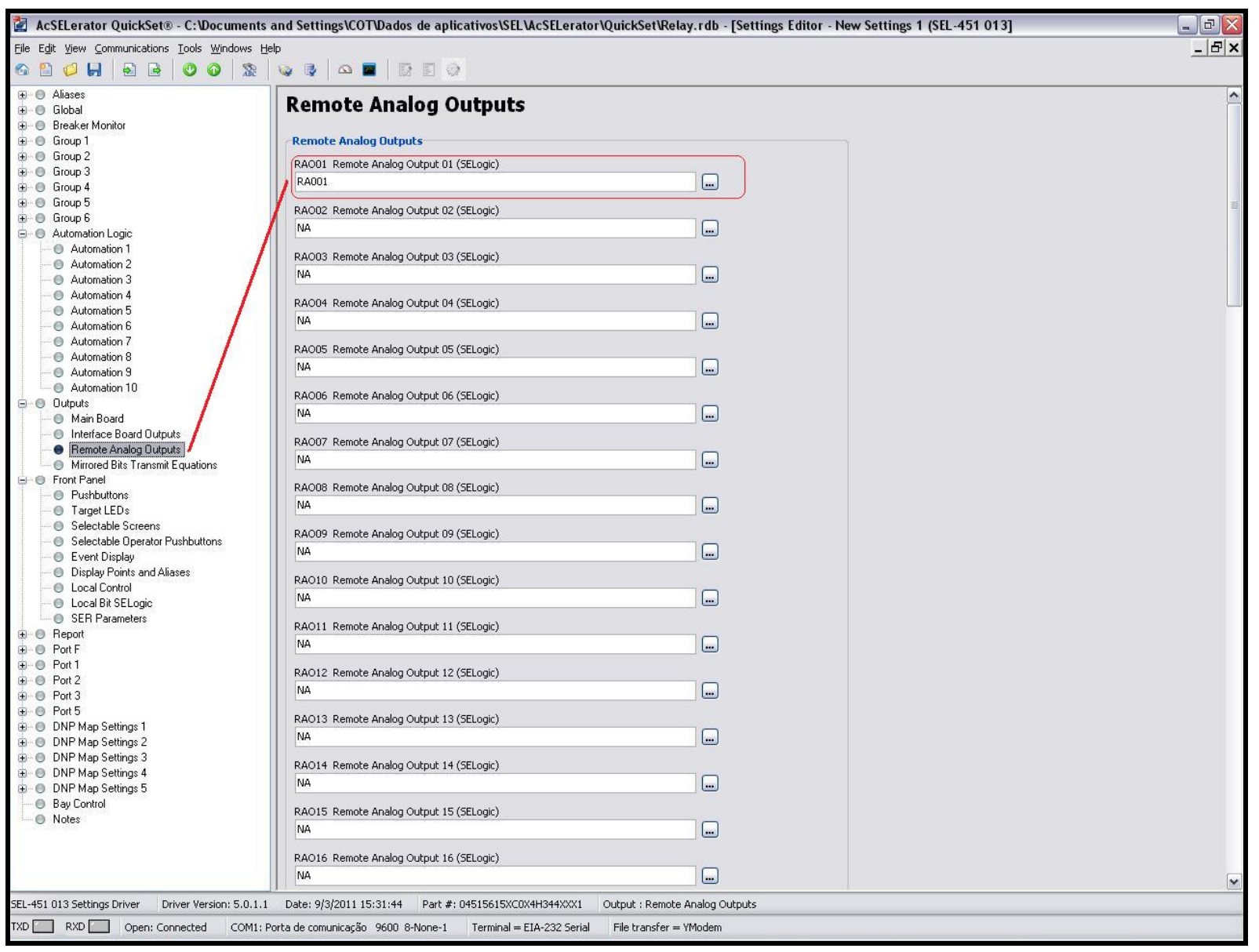

Figura 53 - Mapeando a medida analógica RA001 no IED da transmissora

Foram implementados também no IED da distribuidora, os estados dos equipamentos que compõe o bay do paralelo de barras. Para mudança de estado foram configurados os botões frontais do IED da distribuidora, onde o LED aceso indica o estado ligado do disjuntor ou fechado dos seccionadores, conforme figura 54.

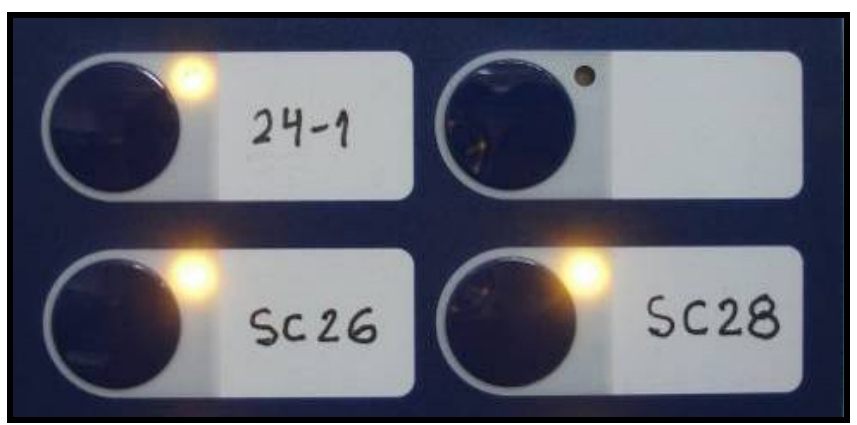

Figura 54 - Botões frontais configurados para mudar o estado dos equipamentos 
Configurado também o display frontal do IED para visualizar o diagrama do bay do paralelo, conforme visto na figura 55.

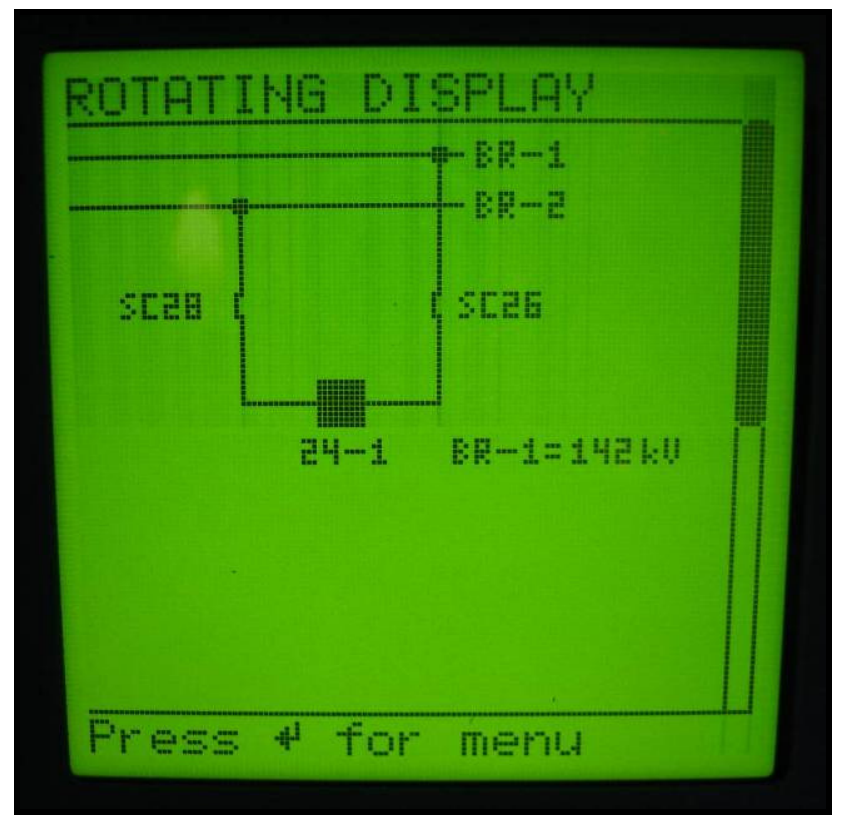

Figura 55 - Visualização dos equipamentos no IED da distribuidora

Utilizando o programa Acselerator Architect foi mapeado dentro do Data set "Equipamentos" os logical nodes BK1XCBR1.Pos, SW1XSWI1.Pos e SW2XSWI2.Pos, conforme mostra a figura 56. 


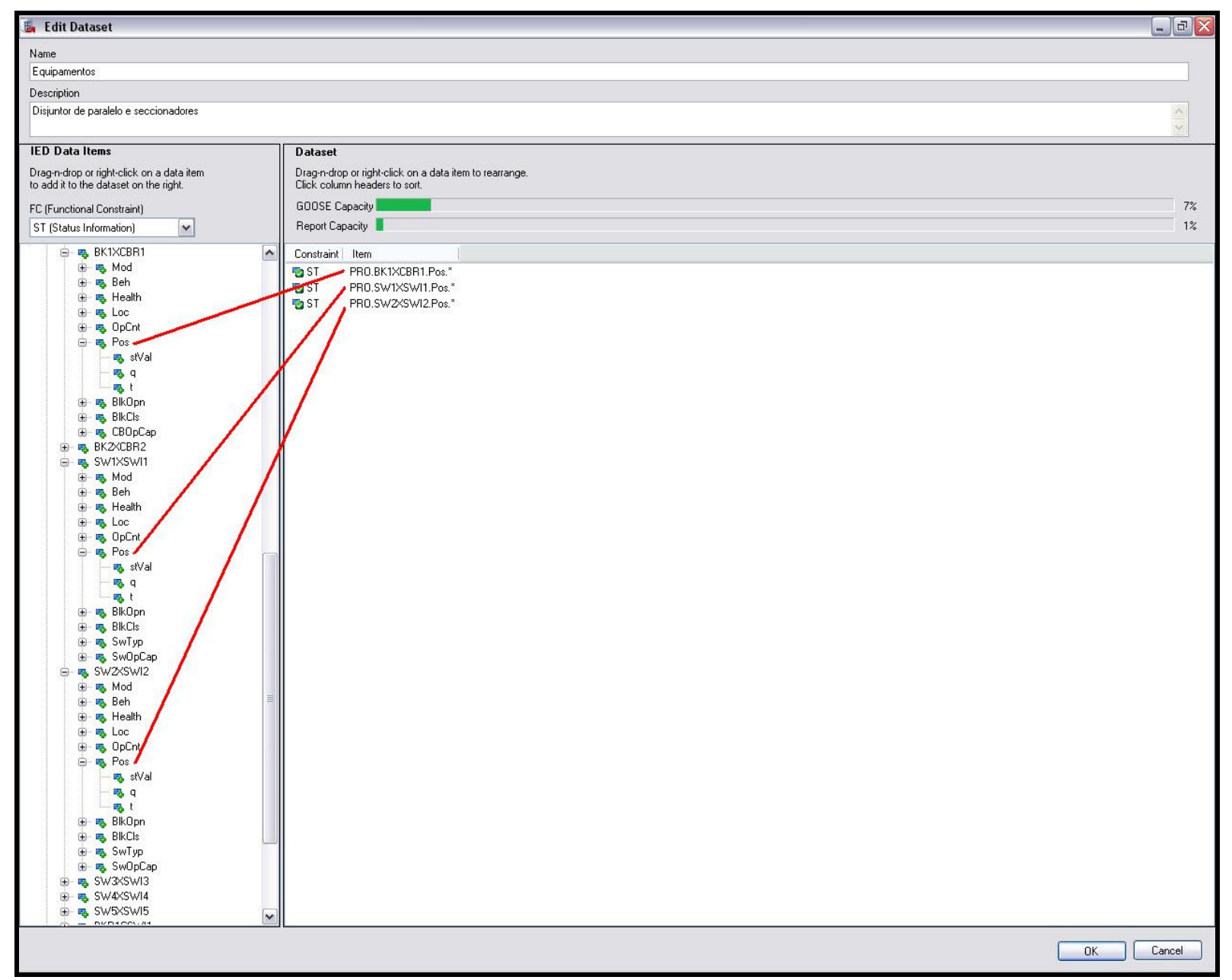

Figura 56 - Configurando o data set com os estados dos equipamentos

$\mathrm{Na}$ aba GOOSE transmit este data set foi configurado com o endereço MAC multicast 01-0CCD-01-00-04, conforme pode ser visto na figura 57.

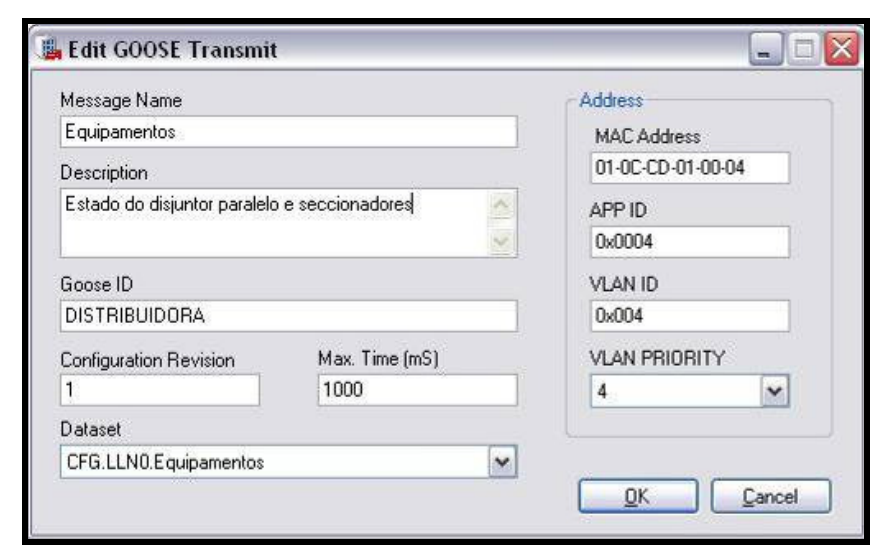

Figura 57 - Configurações para publicação do GOOSE com o data set dos estados dos equipamentos 
Dentro ainda do programa Acselerator Architect foi configurada a assinatura do GOOSE da distribuidora através do mapeamento das entradas virtuais do IED da transmissora VB002 e VB003 para o disjuntor, VB004 e VB005 para o seccionador 28 e as entradas VB006 e VB007 para o seccionador 26, conforme figura 58. Convém observar que estes equipamentos utilizam estados duplos para a indicação de estado, conforme tabela 6, por isso são alocadas duas entradas virtuais para cada equipamento.

Tabela 6 - Indicação de estado duplo

\begin{tabular}{lll}
\hline Estado & bit mais significativo & bit menos significativo \\
\hline Em trânsito & 0 & 0 \\
\hline Aberto ou desligado & 0 & 1 \\
\hline Fechado ou ligado & 1 & 0 \\
\hline Inconsistente & 1 & 1 \\
\hline
\end{tabular}




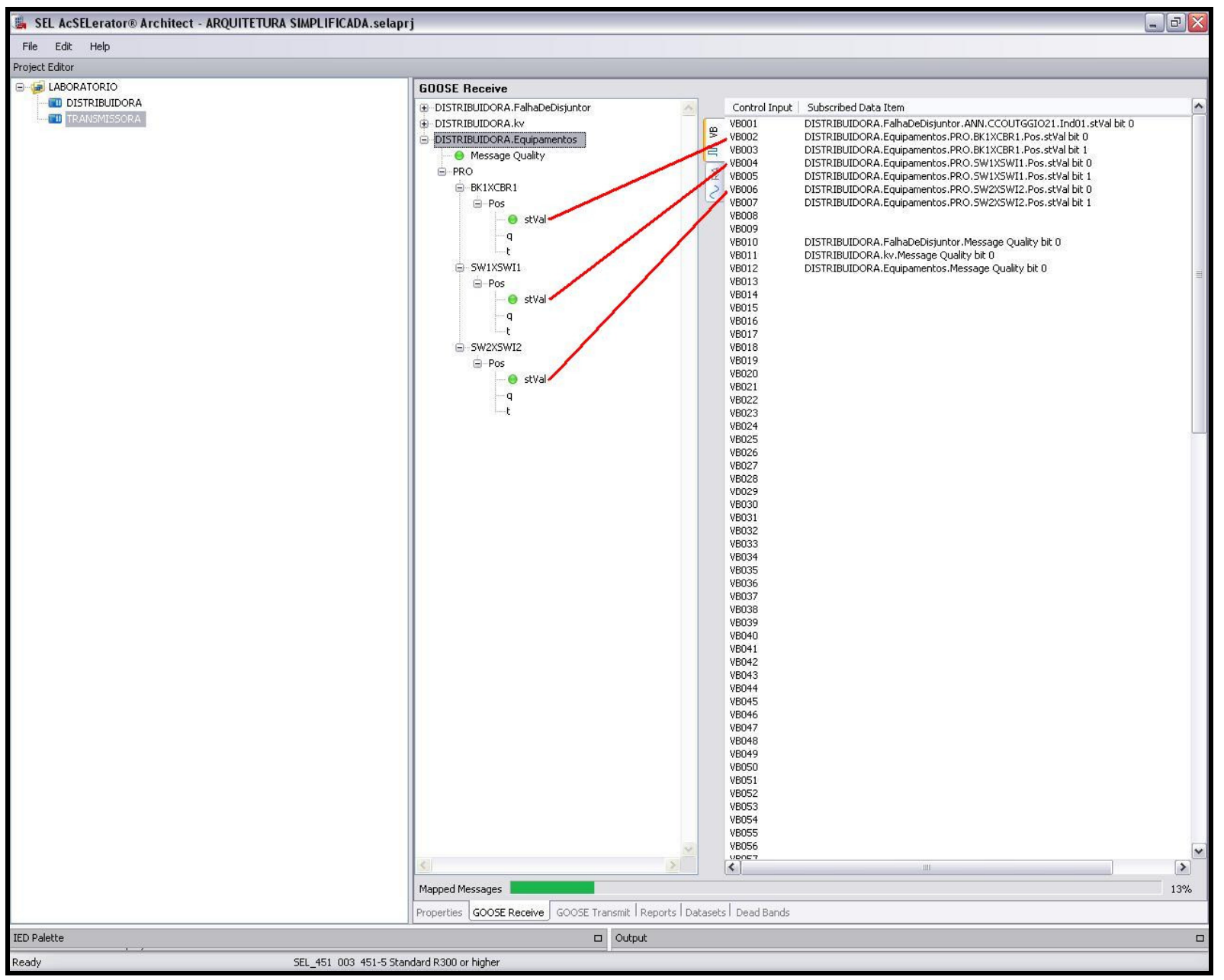

Figura 58 - Assinatura do GOOSE pelo IED da transmissora com os estados dos equipamentos

\subsubsection{Visualizando os dados compartilhados}

Através do programa ReLab OPC Console, conforme figura 59, foi possível visualizar todos os dados auto publicados do IED da transmissora, que foi mapeado através do endereço IP 1.1.1.1/29.

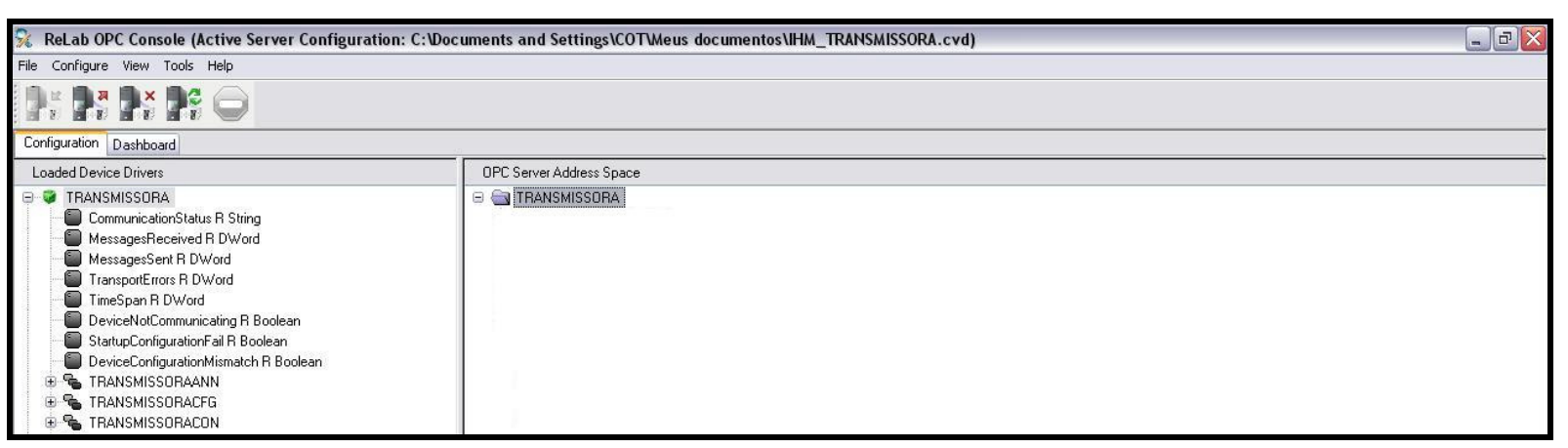

Figura 59 - Pontos auto publicados do IED da transmissora 
Através do aplicativo Ethereal foi possível verificar o envio do GOOSE da medida analógica do IED da distribuidora, com endereço MAC 00:30:A7:01:81:AB, para o IED da transmissora, conforme figura 60.

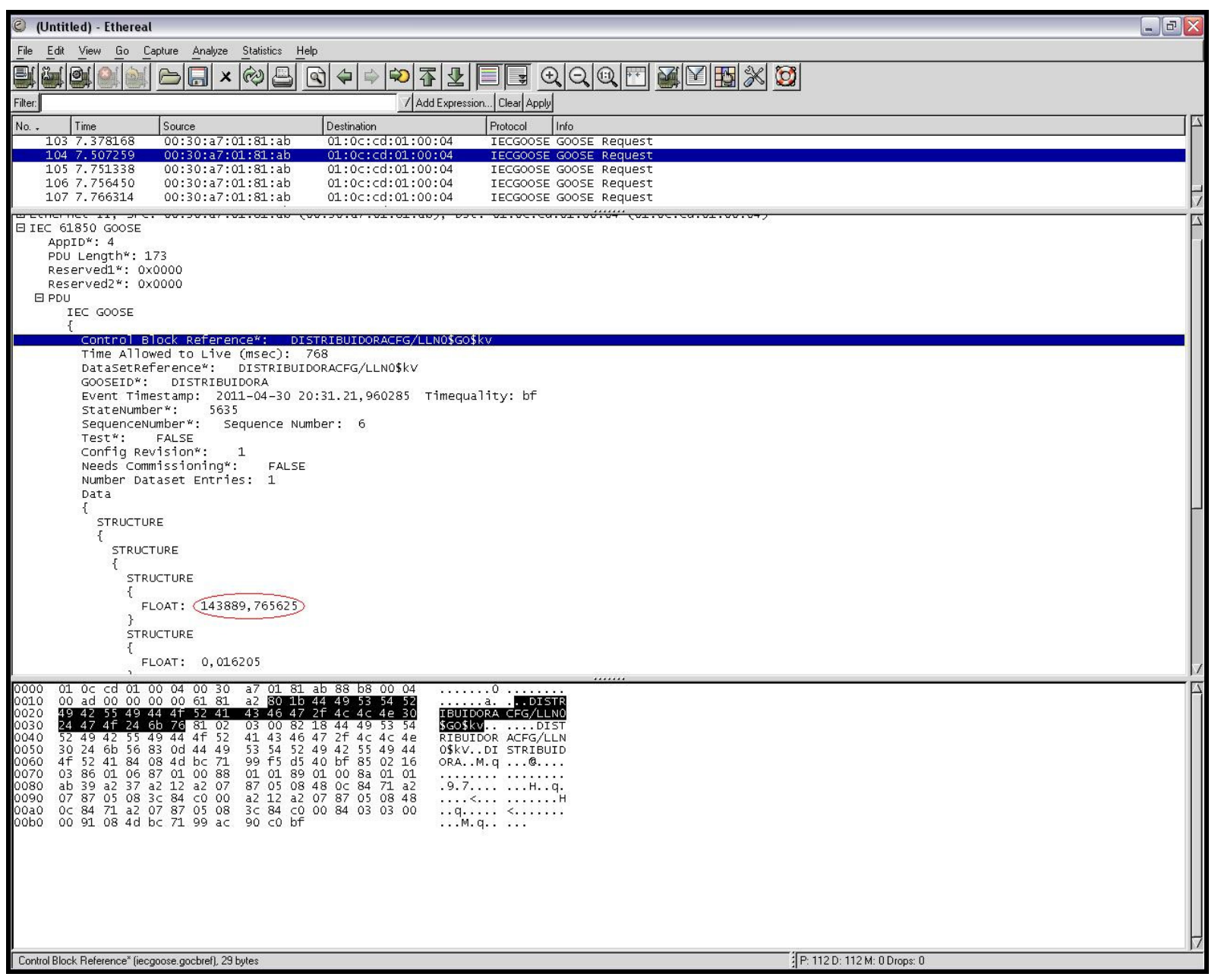

Figura 60 - Pacotes com o GOOSE da medida analógica capturados pelo programa Ethereal

Pelo programa Ethereal foi possível verificar também o estado ligado (1 0 ) dos três equipamentos, um disjuntor e dois seccionadores, conforme assinalado em vermelho na figura 61. 


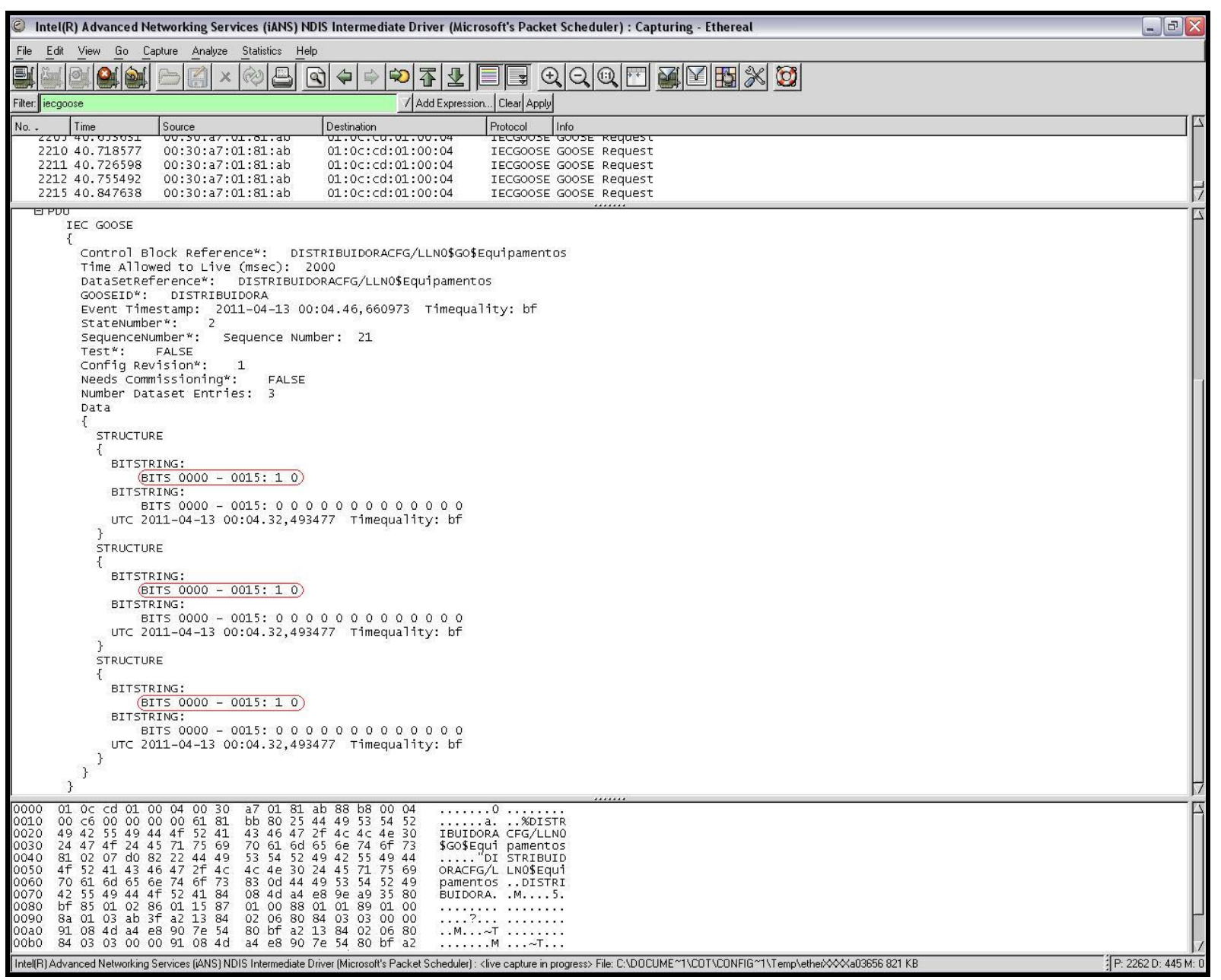

Figura 61 - Pacotes capturados pelo programa Ethereal contendo o GOOSE dos equipamentos

Através dos programas ReLab OPC Console e MMS Object Explorer, simulando os programas de SSC, foi possível mapear e visualizar com o computador da transmissora os pontos mapeados provenientes do IED da distribuidora, conforme mostrado na figura 62 onde está a medida de valor de tensão de 145,60kV e nas figuras 63, 64 e 65 os estados duplos dos equipamentos.

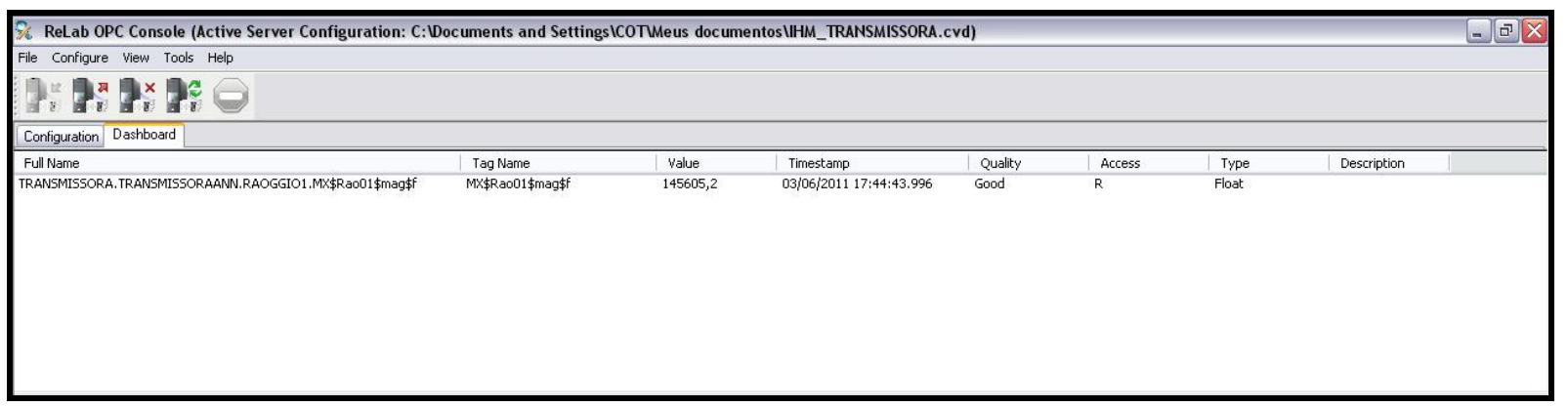

Figura 62 -Mapeando a medida analógica de tensão 


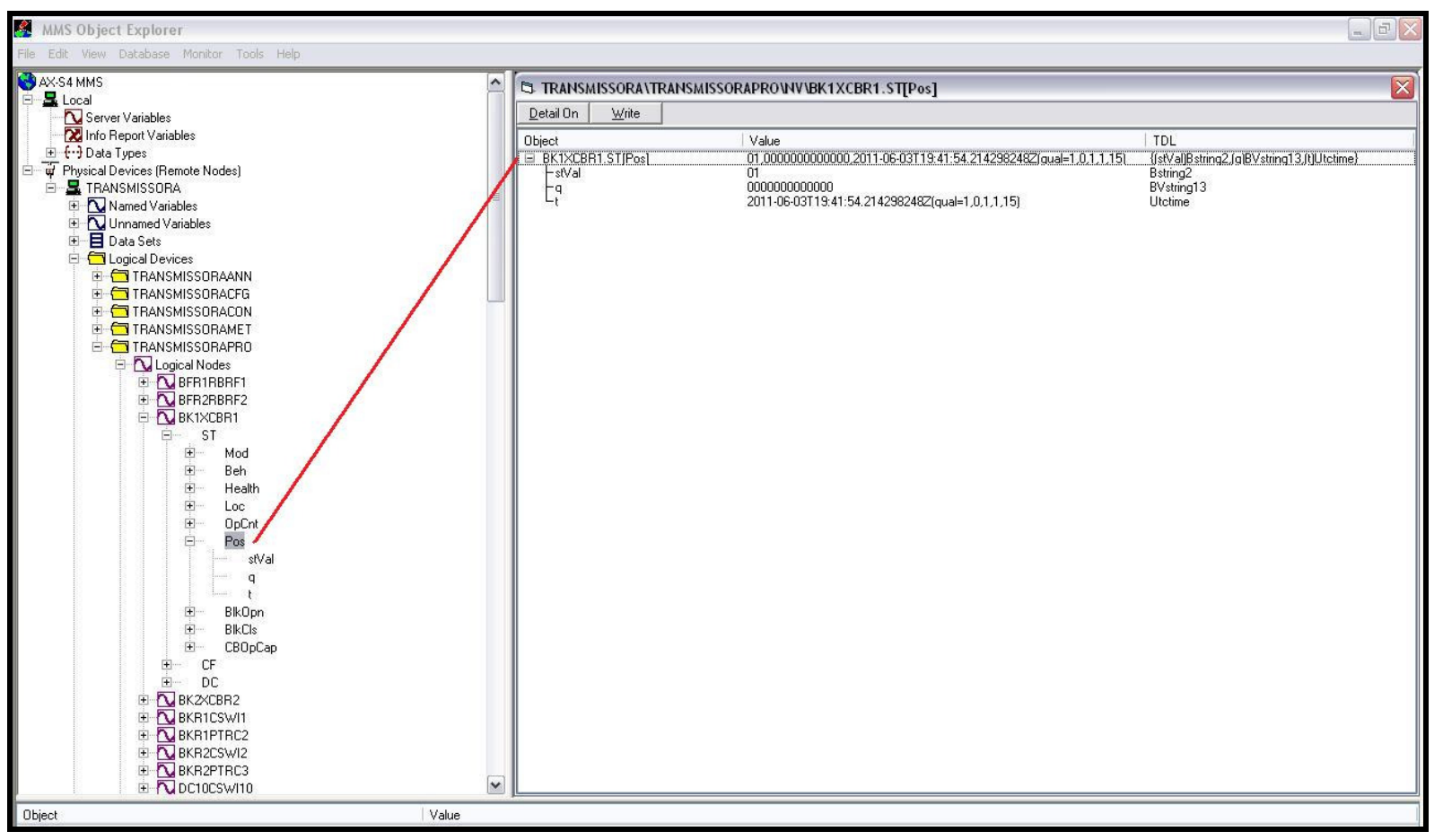

Figura 63 -Mapeando o estado desligado do disjuntor 24-1

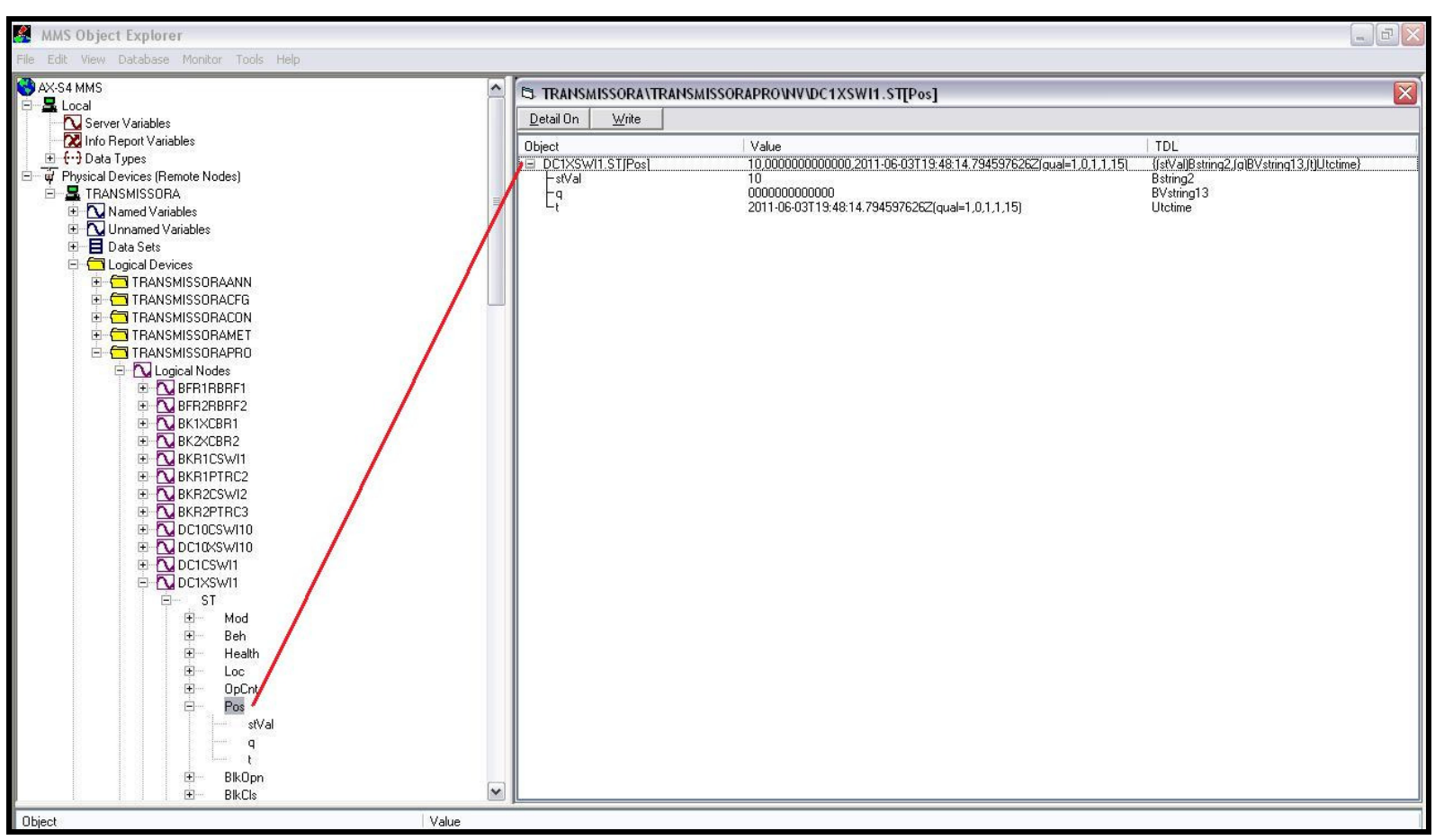

Figura 64 -Mapeando o estado fechado do seccionador 28 


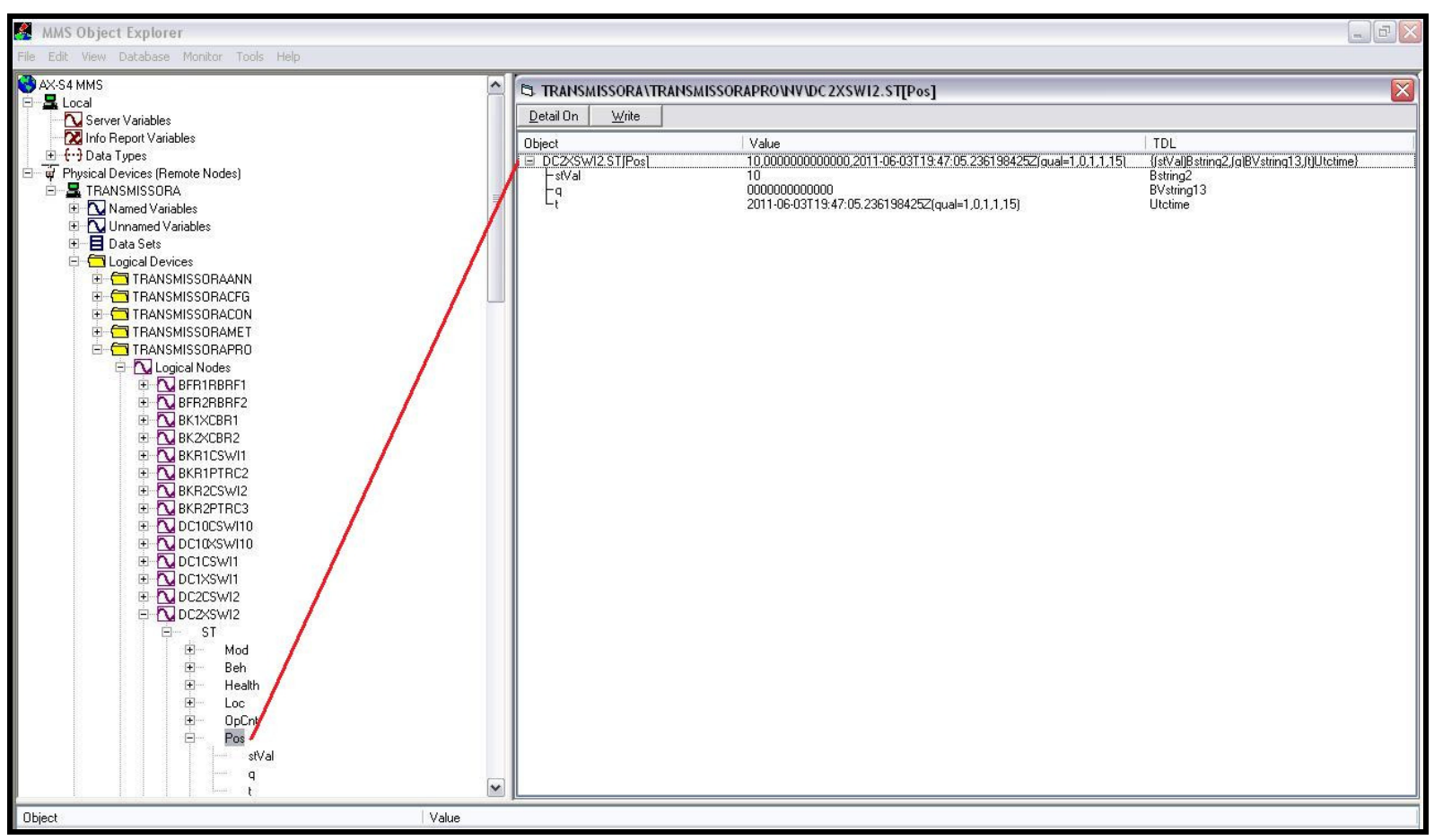

Figura 65 -Mapeando o estado fechado do seccionador 26

\subsubsection{Teste de intrusão}

Um teste simples de intrusão foi realizado através de uma nova configuração no computador da distribuidora deixando-o apto para se conectar a rede da transmissora. Foram realizados:

a) troca do endereço MAC 00:0E:0C:A9:9A:38 da interface de rede do computador da distribuidora para o endereço MAC 00:02:B3:87:00:77 da interface de rede da transmissora;

b) configuração do IP 1.1.1.5/29 válido para a rede da transmissora;

c) configuração da VLAN = 4, que pertence à transmissora.

Conforme a figura 66, é possível verificar que nas configurações avançadas da placa de rede Intel PRO/1000 MT, há a opção "Endereço administrado localmente”, onde é possível alterar o endereço MAC físico. 


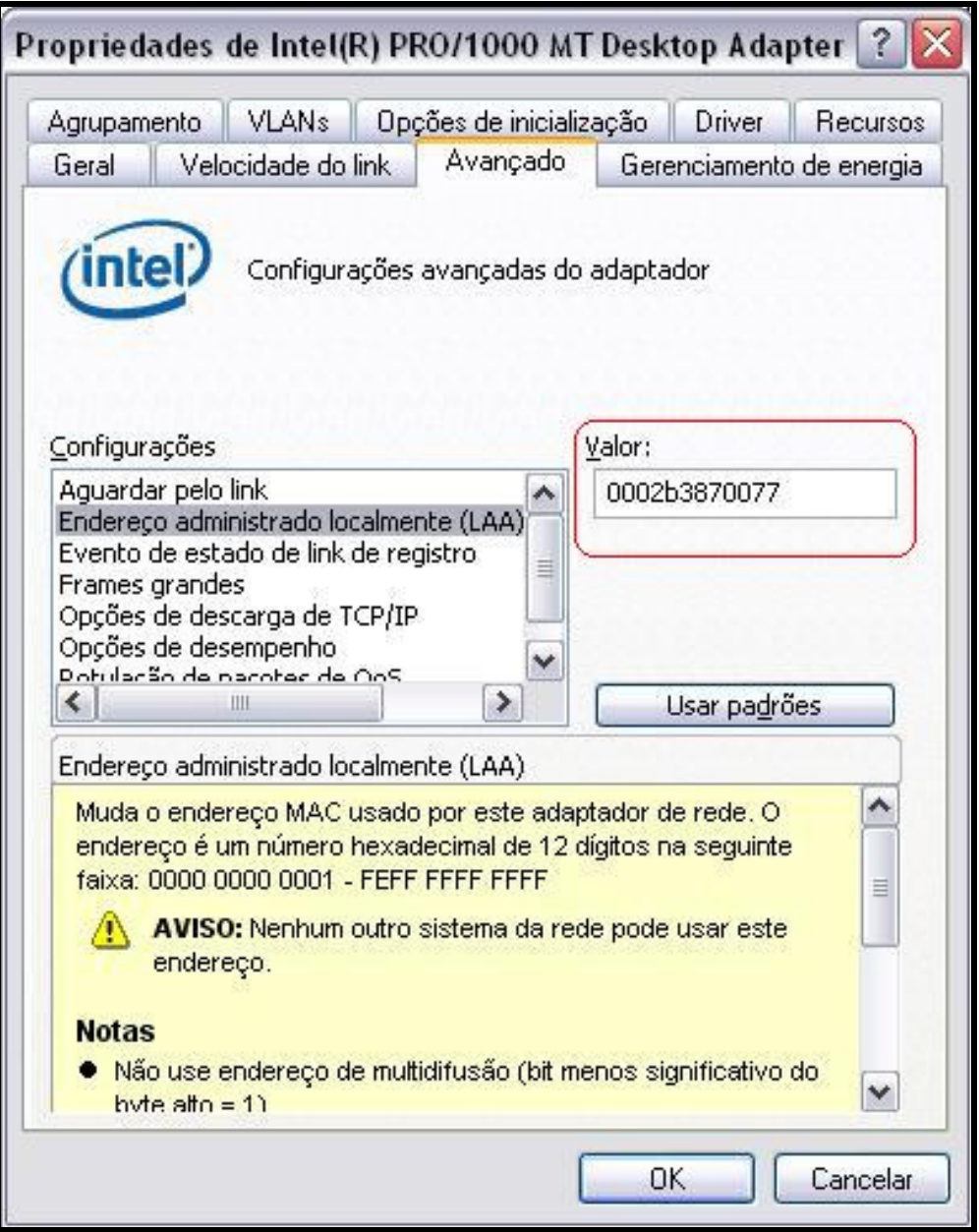

Figura 66 - Utilizando o endereço MAC da transmissora no computador da distribuidora

Mesmo depois de configurado o endereço MAC, atribuído o IP 1.1.1.5/29 e VLAN = 4 no computador da distribuidora, não foi possível, estando esse computador conectado ao switch da distribuidora, acessar a rede da transmissora. Isto se deu por dois motivos, a porta 15 do switch da distribuidora ainda estava com filtro apenas para o MAC 00:0E:0C:A9:9A:38 conforme figura 67.

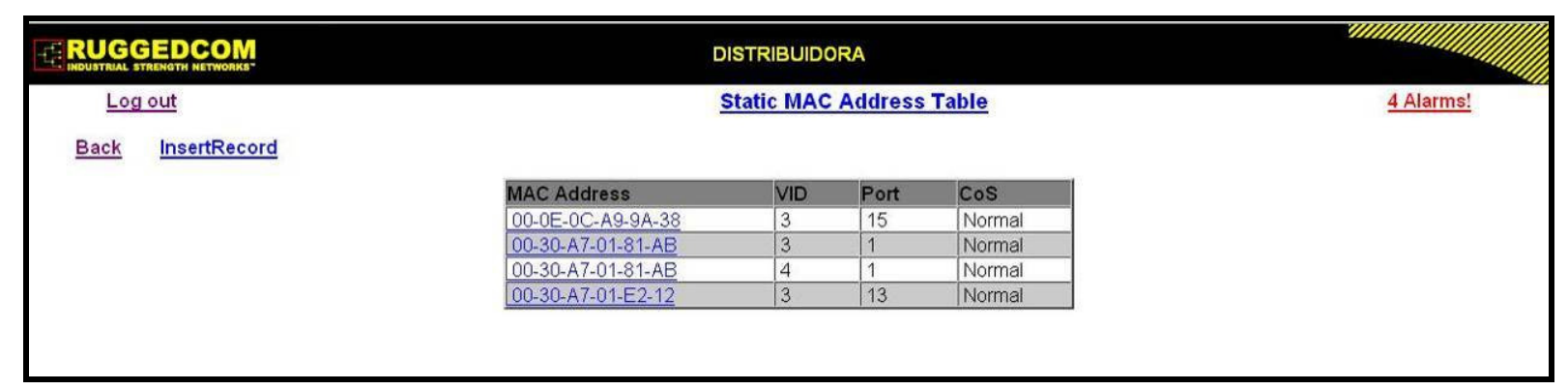

Figura 67 - Endereço MAC do computador configurado no switch da distribuidora 
Porém, mesmo configurando o MAC 00:02:B3:87:00:77 na porta do switch da distribuidora, a porta trunk de número 13 do switch da transmissora não tem o MAC 00:02:B3:87:00:77 declarado. Desta forma, o único jeito de algum computador se conectar a rede da transmissora, será acessando fisicamente o painel e utilizando a única porta configurada com o MAC 00:02:B3:87:00:77, que é a de número 15 do switch da transmissora, conforme figura 68.

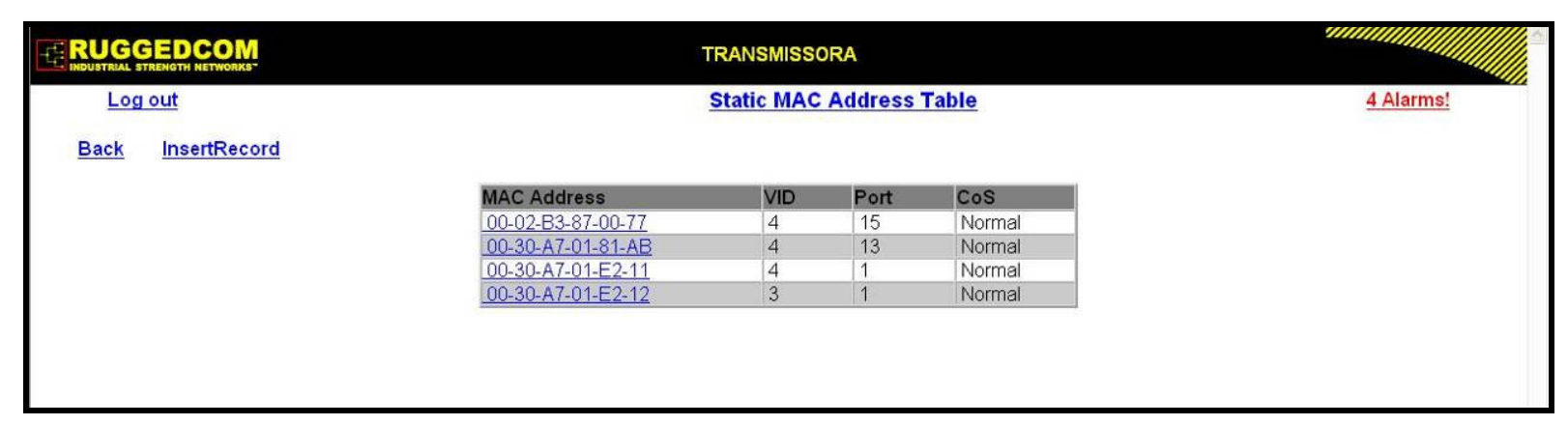

Figura 68 - Endereço MAC do computador configurado no switch da transmissora

Todas as tentativas indevidas de conexão nas portas dos switches foram registradas em seus $\log s$ de alarmes.

\subsection{Recomendações de segurança}

Alguns procedimentos são recomendados para prevenir acessos indevidos e aumentar a segurança e a disponibilidade dos sistemas digitais das subestações. Dentre eles podemos destacar:

a) limitar através da máscara de rede a faixa de IPs disponíveis para os IEDs e computadores da arquitetura;

b) utilizar firewalls nas conexões verticais com os centros de operações;

c) ativar log dos firewalls, dos switches e dos computadores;

d) verificar os $\log s$ dos dispositivos frequentemente;

e) simular testes de acesso indevidos em todos os sistemas a fim de detectar falhas na segurança;

f) desabilitar em todos os dispositivos, as portas físicas e virtuais que não serão utilizadas; 
g) desabilitar o acesso às configurações dos sistemas operacionais dos computadores utilizados como supervisório local;

h) desabilitar serviços de comunicação se não forem utilizados, como File Transfer Protocol (FTP) ou acesso via Web Browser;

i) não manter as senhas originais de fábrica dos equipamentos;

j) implantar senhas fortes para todos os acessos: computadores, switches e IEDs;

k) trocar as senhas com regularidade, principalmente quando um acesso indevido for detectado ou algum funcionário ligado a área técnica se desligar da empresa;

1) implantar segurança física de acesso à subestação e seus equipamentos.

\subsection{Implementação em arquitetura de redundância}

De forma a manter o sistema mais confiável, a arquitetura pode ser montada prevendo a redundância na interligação entre os switches dos agentes, conforme figura 69. É um modo também de se dividir a responsabilidade pela conexão de compartilhamento, designando que uma interligação em fibra óptica seja responsabilidade da transmissora e outra fibra seja de responsabilidade da distribuidora.

Outras configurações, como o RSTP, devem ser ativadas nos switches para este tipo de arquitetura.

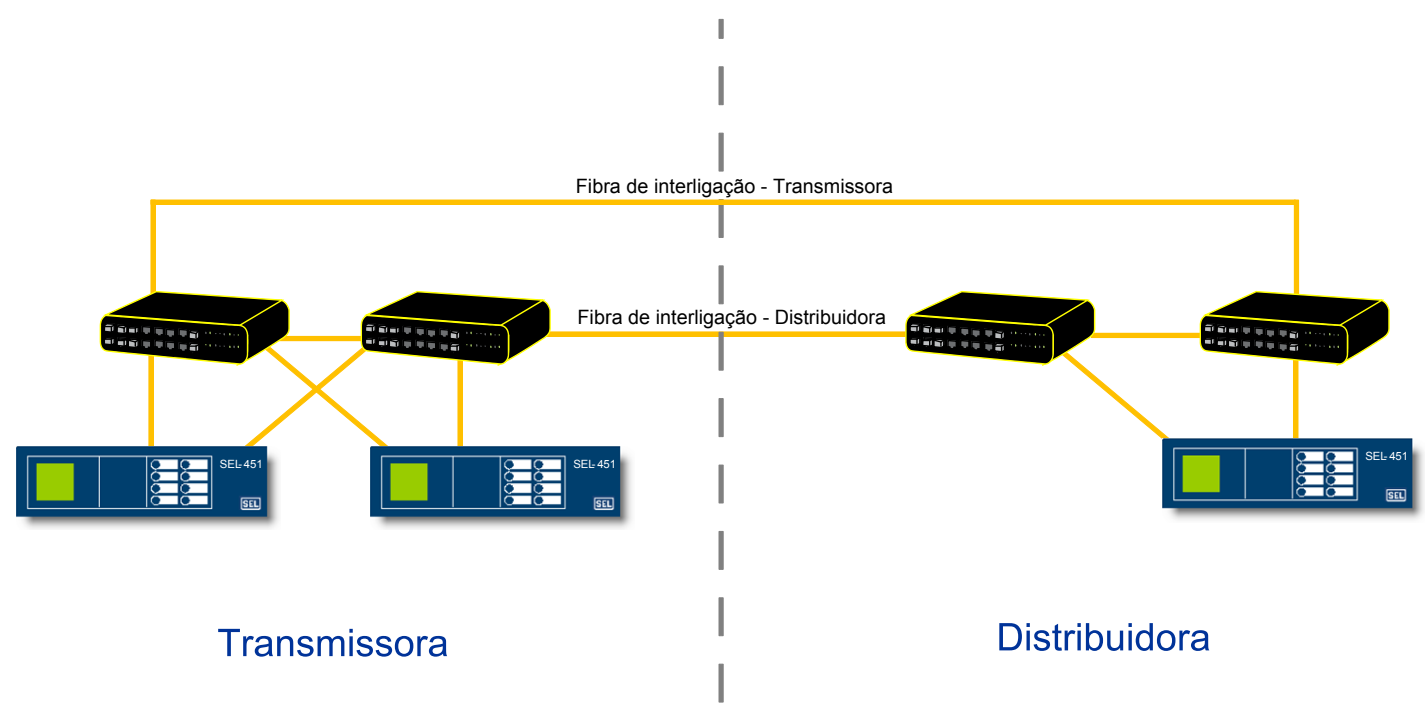

Figura 69 - Arquitetura em anel com redundância 


\section{Conclusão}

O trabalho abordou e discutiu os diversos aspectos referentes aos sistemas de proteção e automação em subestações compartilhadas de transmissão/distribuição de energia elétrica, com particular enfoque na questão da troca de informações entre os sistemas dos agentes envolvidos. Como a regulamentação que deu origem a este tipo de subestação é recente, as formas para compartilhamento da instalação, dos equipamentos e das informações entre os agentes de transmissão, distribuição e geração ainda não se encontram consolidadas e geram discussão com respeito à segurança desse compartilhamento e à divisão de responsabilidades técnicas.

Nesse cenário, o trabalho propôs uma solução, baseada na norma IEC 61850, para implementar o compartilhamento de informações entre os sistemas dos agentes, preservandose a confiabilidade e a segurança e procurando-se reduzir os custos de projeto, instalação, comissionamento e manutenção dessas instalações. Essa solução baseia-se na substituição da interface física utilizada atualmente por uma interface lógica, com significativa redução na quantidade de cabos metálicos, bornes e relés auxiliares utilizados.

Através dos testes de laboratório realizados com a interface lógica proposta foram verificadas e testadas as questões de segurança de acesso aos dados e equipamentos. Ficou demonstrado o funcionamento correto das funções requeridas e o isolamento virtual das redes dos agentes envolvidos.

O compartilhamento da mesma instalação entre duas empresas é algo não trivial e que deve ser efetuado com muito cuidado. Os planos de modernização de uma dessas empresas pode encontrar resistência por parte da outra, pois o conservadorismo das equipes de proteção dos sistemas elétricos de potência ainda é forte. Este lado conservador, mais presente nas empresas de transmissão de energia, pode ser explicado pelo número cada vez maior de linhas importantes de transmissão no SIN, pelas rigorosas fiscalizações e penalizações da ANEEL e pela dependência cada vez maior da sociedade no uso da energia elétrica. A fase de projeto portanto, deve ser muito bem trabalhada e discutida, pois é nesta etapa que todas as definições e exigências das empresas envolvidas devem ser consideradas.

Muito tem se falado em Cyber Security, porém há de se enfatizar que toda segurança seja ela virtual ou física, pode ser quebrada pela combinação de persistência, conhecimento técnico e pela utilização das ferramentas adequadas. Nesse cenário o objetivo de um sistema de 
segurança em redes de comunicação é o de minimizar a probabilidade dos ataques intencionais ou acidentais, aumentar o tempo necessário para intrusão e diminuir as áreas e redes afetadas.

O aprimoramento nas questões da segurança cibernética e o uso de Sampled Values para reduzir ainda mais o uso de cabos de cobre, minimizando também o risco de acidentes, são questões que devem ser melhor exploradas através de uma futura tese de doutorado, bem como em programas de Pesquisa e Desenvolvimento (P\&D).

A introdução da IEC 61850 é um processo que exige uma visão estratégica, plano de migração e seleção de soluções técnicas compatíveis com as metas que a empresa pretende atingir. Os processos identificados e padronizados pela norma IEC 61850 oferecem beneficio total somente quando são introduzidos como um conceito completo.

Fica claro que as empresas de energia, os fornecedores, integradores, centros de pesquisa e universidades precisam dispor de laboratórios equipados para realizar ensaios seguindo os padrões da norma IEC 61850 visando validar as possíveis soluções analisadas. Não é suficiente apenas o envio de suas equipes técnicas para seminários e treinamentos, mas necessária também a realização exaustiva de testes e simulações das situações reais de campo.

Como comprovado neste trabalho, a viabilidade da solução proposta, em seus aspectos de otimização de cabos, armários, esforços de instalação, de testes e documentação, assim como no cuidado a serem tomados quanto à segurança da informação, pode ser utilizada para a quebra de alguns paradigmas. A aplicação inicial em subestações como estas das usinas de biomassa, não pertencentes à rede básica e de configuração mais simples por envolverem poucos equipamentos, torna-se uma boa oportunidade para repensar as práticas de engenharia utilizadas e melhorar os processos internos das empresas. 


\section{REFERÊNCIAS}

(1) KEMA; COMPANHIA DE TRANSMISSÃO DE ENERGIA ELÉTRICA PAULISTA. Princípios Básicos para Automação de Grandes Subestações baseados na Norma IEC 61850. São Paulo: KEMA, 2010.

(2) ELETROPAUlO. Proteção de Sistemas Elétricos de Potência. São Paulo: Departamento de Treinamento e Desenvolvimento, Divisão de Treinamento Técnico e Comercial da Eletropaulo, 1990. Apostila de treinamento.

(3) PEREIRA, D. A. Proteções de linha de transmissão. Jundiaí: CTEEP, 2003. Apostila de treinamento.

(4) MIRANDA, J. C. IEC-61850: Interoperabilidade e Intercambialidade entre equipamentos de supervisão, controle e proteção através das redes de comunicação de dados. Dissertação (Mestrado) - Escola de Engenharia de São Carlos, Universidade de São Paulo, São Carlos, 2009.

(5) RESENDE, J. W. Proteção de Sistemas elétricos de Potência. Uberlândia: CONPROVE Engenharia, 2004. Apostila de treinamento.

(6) COURY, D.V.; OLESKOVICZ, M.; GIOVANINI, R. Proteção Digital de Sistemas elétricos de Potência: dos relés eletromecânicos aos microprocessados inteligentes. São Carlos: EESC-USP, 2007. ISBN 978-85-85205-78-2.

(7) MORAES, C. C.; CASTRUCCI, P. L. Engenharia de automação industrial. 2. ed. Rio de Janeiro: LTC, 2007. ISBN 85-216-1532-9.

(8) INTERNATIONAL ELECTROTECHNICAL COMISSION. IEC TR 61850-1 Communication networks and systems in substations. Part 1: introdution and overview. Suíça, 2003. IEC/TR 61850-1:2003(E).

(9) INTERNATIONAL ELECTROTECHNICAL COMISSION. IEC 61850-3 Communication networks and systems in substations. Part 3: general requirements. Suíça, 2002. CEI/IEC 61850-3:2002.

(10) INTERNATIONAL ELECTROTECHNICAL COMISSION. IEC 61850-8-1 Communication networks and systems in substations. Part 8-1: specific communication service mapping (SCSM) - Mappings to MMS (ISO 9506-1 and ISO 9506-2) and to ISO/IEC 8802-3. Suíça, 2004. IEC:2004(E). 
(11) INTERNATIONAL ELECTROTECHNICAL COMISSION. IEC 61850-7-1 Communication networks and systems in substations. Part 7-1: basic communication structure - Principles and models. 2.ed. Suíça, 2011. IEC:2004(E).

(12) AGÊNCIA NACIONAL DE ENERGIA ELÉTRICA. Pesquisa Resolução Normativa. Disponível em: http://www.aneel.gov.br/biblioteca/pesquisadigitres.cfm. Acesso em: 03 de mar. 2011.

(13) AGÊNCIA NACIONAL DE ENERGIA ELÉTRICA. Resolução Normativa ANEEL n ${ }^{\circ}$ 68. Estabelece os procedimentos para acesso e implementação de reforços nas Demais Instalações de Transmissão, não integrantes da Rede Básica, e para a expansão das instalações de transmissão de âmbito próprio, de interesse sistêmico, das concessionárias ou permissionárias de distribuição, e dá outras providências. 2004.

(14) AGÊNCIA NACIONAL DE ENERGIA ELÉTRICA. Resolução Normativa ANEEL $\mathbf{n}^{\circ}$ 312. Altera a Resolução Normativa $n^{\circ} 68$, de 8 de junho de 2004, que estabelece os procedimentos para implementação de reforços nas Demais Instalações de Transmissão, e dá outras providências. 2008.

(15) MINISTÉRIO DE MINAS E ENERGIA. Dados do PROINFA. Disponível em: http://www.mme.gov.br/programas/proinfa/. Acesso em: 07 de ago. de 2010.

(16) BRIGHENTI, C. R. F. Integração do cogerador de energia do setor Sucroalcooleiro com o Sistema Elétrico. Dissertação (Mestrado) - Programa Interunidades de Pós-Graduação em Energia da Universidade de São Paulo - PIPGE. São Paulo, 2003.

(17) BANCO NACIONAL DE DESENVOLVIMENTO ECONÔMICO E SOCIAL. Bioetanol de Cana-de-açúcar: Energia para o Desenvolvimento Sustentável. BNDES/CGEE. Rio de Janeiro: BNDES, 2008. ISBN: 978-85-87545-24-4

(18) UNIÃO DA INDÚSTRIA DE CANA-DE-AÇÚCAR. Etanol e bioeletricidade: a canade-açúcar no futuro da matriz energética. São Paulo: Luc Projetos de Comunicação, 2010.

(19) UNIÃO DA INDÚSTRIA DE CANA-DE-AÇÚCAR. Usina Virtual - Disponível em http://www.unica.com.br/usina-virtual/video-new/usina-virtual.htm. Acesso em: 03 de mar. de 2011. 
(20) AGÊNCIA NACIONAL DE ENERGIA ELÉTRICA. Banco de Informações de Geração. Disponível em

http://www.aneel.gov.br/aplicacoes/capacidadebrasil/CombustivelPorClasse.asp?Classe=Bio massa. Acesso em: 23 de jun. de 2011.

(21) MINISTÉRIO DA AGRICULTURA. Cana-de-açúcar. Disponível em http://www.agricultura.gov.br/portal/page/portal/Internet-MAPA/paginainicial/vegetal/culturas/cana-de-acucar/saiba-mais. Acesso em: 03 de mar. de 2011.

(22) COMPANHIA DE TRANSMISSÃO DE ENERGIA ELÉTRICA PAULISTA; SENDI; COCAL. Projeto SE COCAL II. São Paulo, 2009.

(23) APOSTOLOV, A.; DOCARMO, H.; PAULINO, M. Aplicações IEC 61850 de proteção de barramento. In: SEMINÁRIO TÉCNICO DE PROTEÇÃO E CONTROLE, 10, 2010, Recife. Resumos... Recife, 2010. p. 9.

(24) FINDER S.p.A. Gama 2009-2010. ZGR0208BR. Catálogo. VII. Brasil. 2009.

(25) CIGRE. The Impact of Implementing Cyber Security Requirements using IEC 61850. Work Group B5.38. França, 2009.

(26) RUGGEDCOM. Rugged Operating System v3.8.0 User Guide. For use with: RSG2100, M2100. Canadá, 2010.

(27) RUGGEDCOM. NERC Cyber Security.

http://www.ruggedcom.com/applications/electric-utilities/nerc/. Acesso em: 02 de mai. de 2011.

(28) SCHWEITZER ENGINEERING LABORATORIES. SEL-451 Relay: Protection, Automation, and Control System Instruction Manual. 20101109. Pullman, 2010. 


\section{ANEXO A - Usinas conectadas em seccionamento}

a) Usina Quatá

Potência: $65 \mathrm{MW}$

Tensão: $88 \mathrm{kV}$

Cidade: Quatá-SP

Proprietário: Açucareira Quatá S/A

Concessionária de distribuição: ELEKTRO

Concessionária de transmissão: Companhia de Transmissão de Energia Elétrica Paulista

Resolução ANEEL: № 360, de 27 de agosto de 2001

Linha de transmissão seccionada: Assis - Presidente Prudente circuito 2

Entrada em operação: 26 de abril de 2009

b) Usina Ferrari

Potência: 69,5 MW

Tensão: $138 \mathrm{kV}$

Cidade: Pirassununga-SP

Proprietário: Ferrari Termoelétrica S/A.

Concessionária de distribuição: ELEKTRO

Concessionária de transmissão: Companhia de Transmissão de Energia Elétrica Paulista

Resolução Autorizativa ANEEL: Nº 1.116, de 20 de novembro de 2007

Linha de transmissão seccionada: Porto Ferreira - Limoeiro circuito 2

Entrada em operação: 22 de junho de 2009 
c) Usina Da Mata

Potência: 40 MW

Tensão: $138 \mathrm{kV}$

Cidade: Valparaíso-SP

Proprietário: Da Mata S.A.

Concessionária de distribuição: CPFL Energia

Concessionária de transmissão: Companhia de Transmissão de Energia Elétrica Paulista

Resolução Autorizativa ANEEL: No 1.577 , de 23 de setembro de 2008

Linha de transmissão seccionada: Valparaíso - Três Irmãos

Entrada em operação: 30 de agosto de 2009

d) Usina Cocal II

Potência: 80 MW

Tensão: $138 \mathrm{kV}$

Cidade: Narandiba-SP

Proprietário: Cocal Comércio Indústria Canaã Açúcar e Álcool Ltda

Concessionária de distribuição: ELEKTRO

Concessionária de transmissão: Companhia de Transmissão de Energia Elétrica Paulista

Resolução Autorizativa ANEEL: Nº 1.404, de 10 de junho 2008

Linha de transmissão seccionada: Capivara - Presidente Prudente circuito 1

Entrada em operação: 25 de outubro de 2009

e) Usina Cerradinho

Potência: 40,2 MW

Tensão: $138 \mathrm{kV}$ 
Cidade: Potirendaba-SP

Proprietário: Usina Cerradinho Açúcar e Álcool S/A.

Concessionária de distribuição: CPFL Energia

Concessionária de transmissão: Companhia de Transmissão de Energia Elétrica Paulista

Resolução Autorizativa ANEEL: No 1.882 , de 14 de abril de 2009

Linha de transmissão seccionada: Promissão - Catanduva circuito 1

Entrada em operação: 21 de dezembro de 2009

\section{f) Usina BIOPAV}

Potência: 65 MW

Tensão: $138 \mathrm{kV}$

Cidade: Brejo Alegre-SP

Proprietário: BIOPAV S.A. Açúcar e Álcool

Concessionária de distribuição: CPFL Energia

Concessionária de transmissão: Companhia de Transmissão de Energia Elétrica Paulista

Resolução Autorizativa ANEEL: No 1.575 , de 23 de setembro de 2008

Linha de transmissão seccionada: Promissão - Nova Avanhandava circuito 2

Entrada em operação: 17 de janeiro de 2010

\section{g) Usina Baldin}

Potência: 45 MW

Tensão: $138 \mathrm{kV}$

Cidade: Pirassununga-SP

Proprietário: CPFL Bioenergia S/A

Concessionária de distribuição: CPFL 
Concessionária de transmissão: Companhia de Transmissão de Energia Elétrica Paulista

Resolução Autorizativa ANEEL: No 2.106, de 22 de setembro de 2009

Linha de transmissão seccionada: Porto Ferreira - Rio Claro I circuito 1

Entrada em operação: 22 de agosto de 2010

h) Usina São João

Potência: 77 MW

Tensão: $138 \mathrm{kV}$

Cidade: São João da Boa Vista-SP

Proprietário: Abengoa Bioenergia Agroindústria Ltda.

Concessionária de distribuição: ELEKTRO

Concessionária de transmissão: Companhia de Transmissão de Energia Elétrica Paulista

Resolução Autorizativa ANEEL: No 2.433, de 1 de junho de 2010

Linha de transmissão seccionada: Euclides da Cunha - São João da Boa Vista II circuito 1

Entrada em operação: 22 de agosto de 2010

i) Usina São Luiz

Potência: 70,4 MW

Tensão: $138 \mathrm{kV}$

Cidade: Pirassununga-SP

Proprietário: Abengoa Bioenergia Agroindústria Ltda.

Concessionária de distribuição: ELEKTRO

Concessionária de transmissão: Companhia de Transmissão de Energia Elétrica Paulista 
Resolução Autorizativa ANEEL: No 2.431, de 1 de junho de 2010

Linha de transmissão seccionada: Porto Ferreira - Limoeiro circuito 1

Entrada em operação: 19 de setembro de 2010

\section{j) Usina Alcídia}

Potência: 38,1 MW

Tensão: $138 \mathrm{kV}$

Cidade: Teodoro Sampaio-SP

Proprietário: Destilaria Alcídia S/A.

Concessionária de distribuição: ELEKTRO

Concessionária de transmissão: Companhia de Transmissão de Energia Elétrica Paulista

Resolução Autorizativa ANEEL: No 2.179, de 17 de novembro de 2009

Linha de transmissão seccionada: Rosana - Presidente Prudente circuito 2

Entrada em operação: 12 de dezembro de 2010 